\title{
Recent Advances in Copper-Based Solid Heterogeneous Catalysts for Azide-Alkyne Cycloaddition Reactions
}

\author{
Noura Aflak $^{1}$ (D) Hicham Ben El Ayouchia ${ }^{1}\left(\mathbb{D}\right.$, Lahoucine Bahsis ${ }^{1,2}\left(\mathbb{D}\right.$, Hafid Anane ${ }^{1}\left(\mathbb{D}\right.$, Miguel Julve $^{3}$ \\ and Salah-Eddine Stiriba ${ }^{3, *(D)}$
}

1 Laboratoire de Chimie Analytique et Moléculaire/LCAM, Faculté Polydisciplinaire de Safi, Université Cadi Ayyad, Safi 46030, Morocco; noura.aflak@gmail.com (N.A.); belayou@gmail.com (H.B.E.A.); bahsis.lahoucine@gmail.com (L.B.); ananehafid@gmail.com (H.A.)

2 Laboratoire de Chimie de Coordination et d'Analytique/LCCA, Département de Chimie, Faculté des Sciences d'El Jadida, Université Chouaïb Doukkali, El Jadida 24000, Morocco

3 Instituto de Ciencia Molecular/ICMol, Universidad de Valencia, C/Catedrático José Beltrán 2, 46980 Valencia, Spain; miguel.julve@uv.es

* Correspondence: stiriba@uv.es

check for updates

Citation: Aflak, N.; Ben El Ayouchia, H.; Bahsis, L.; Anane, H.; Julve, M.; Stiriba, S.-E. Recent Advances in Copper-Based Solid Heterogeneous Catalysts for Azide-Alkyne

Cycloaddition Reactions. Int. J. Mol. Sci. 2022, 23, 2383. https://doi.org/ $10.3390 /$ ijms 23042383

Academic Editor: Rajender S.

Varma

Received: 26 January 2022

Accepted: 15 February 2022

Published: 21 February 2022

Publisher's Note: MDPI stays neutral with regard to jurisdictional claims in published maps and institutional affiliations.

Copyright: (C) 2022 by the authors. Licensee MDPI, Basel, Switzerland. This article is an open access article distributed under the terms and conditions of the Creative Commons Attribution (CC BY) license (https:// creativecommons.org/licenses/by/ $4.0 /)$.

\begin{abstract}
The copper(I)-catalyzed azide-alkyne cycloaddition (CuAAC) reaction is considered to be the most representative ligation process within the context of the "click chemistry" concept. This $\mathrm{CuAAC}$ reaction, which yields compounds containing a 1,2,3-triazole core, has become relevant in the construction of biologically complex systems, bioconjugation strategies, and supramolecular and material sciences. Although many $\mathrm{CuAAC}$ reactions are performed under homogenous conditions, heterogenous copper-based catalytic systems are gaining exponential interest, relying on the easy removal, recovery, and reusability of catalytically copper species. The present review covers the most recently developed copper-containing heterogenous solid catalytic systems that use solid inorganic/organic hybrid supports, and which have been used in promoting CuAAC reactions. Due to the demand for 1,2,3-triazoles as non-classical bioisosteres and as framework-based drugs, the $\mathrm{CuAAC}$ reaction promoted by solid heterogenous catalysts has greatly improved the recovery and removal of copper species, usually by simple filtration. In so doing, the solving of the toxicity issue regarding copper particles in compounds of biological interest has been achieved. This protocol is also expected to produce a practical chemical process for accessing such compounds on an industrial scale.
\end{abstract}

Keywords: copper; solid inorganic support; heterogeneous catalyst; click chemistry; cycloaddition reaction; 1,2,3-triazoles

\section{Introduction}

"Click chemistry" is a concept that uses the most convenient and practical chemical transformations for clicking available reagents or building blocks into final products with high yield and in a selective manner [1]. In 2001, Sharpless listed the criteria of a click chemistry reaction as wide in scope, very high in yield, and stereospecific [1] Among these "clickable" reactions, the copper-catalyzed [3+2] cycloaddition between azides and alkynes ( $\mathrm{CuAAC})$, which is the uncatalyzed version of the known Huisgen reaction usually performed at higher temperatures for longer times, yields a mixture of 1,4- and 1,5-disubstituted 1,2,3-triazoles [2]. Since the independent discovery of CuAAC by Sharpless et al. [3] and Meldal et al. [4], several other research groups have reported an improved version of the Huisgen [3+2] cycloaddition by using a copper(I) catalyst to exclusively produce the corresponding 1,4-disubstituted 1,2,3-triazoles in very high yields with few or no side products. Due to these characteristics, copper-catalyzed azide-alkyne [3+2] cycloaddition (CuAAC) has become a leading method for the covalent assembly of large and small molecules by using 1,2,3-triazole as a bridging block unit $[5,6]$. Furthermore, transition metals, such as silver [7,8], ruthenium [9], iridium [10], and zinc [11], have also 
been used to catalyze azide-alkyne cycloaddition reactions for the regioselective synthesis of 1,4- or 1,5-disubstituted or 1,4,5-trisubstituted triazoles (Scheme 1).

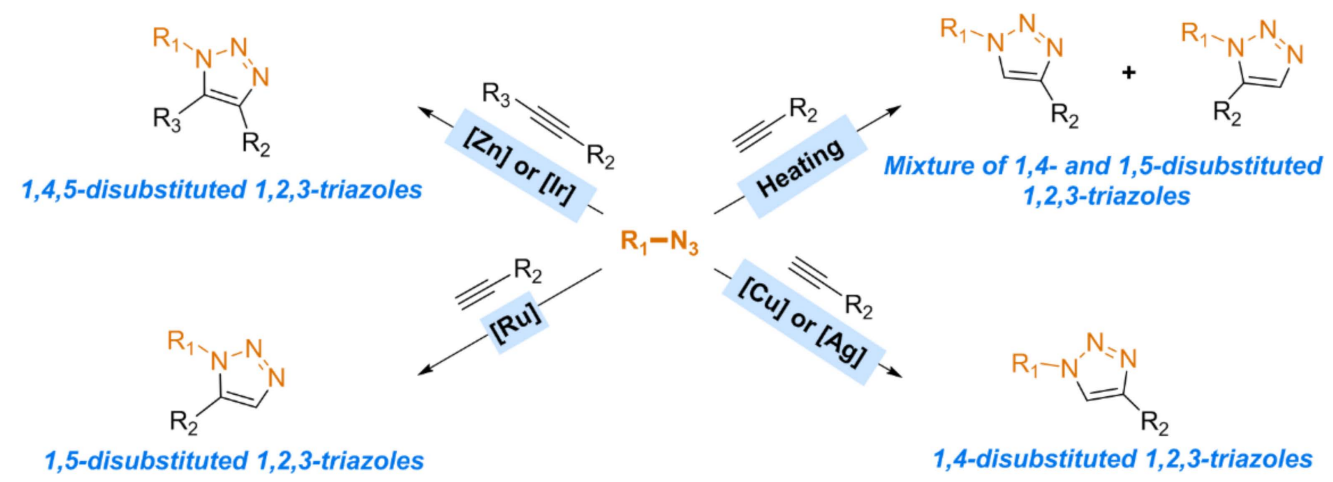

Scheme 1. Huisgen uncatalyzed cycloaddition and metal-catalyzed azide-alkyne [3+2] cycloaddition reactions.

These five-membered nitrogen heterocyclic scaffolds, especially 1,4-disubstituted 1,2,3triazoles, are involved in various research areas, including the agrochemical [12], pharmaceutical [13], medicinal [14], and industrial fields [15-18]. Moreover, 1,4-disubstituted 1,2,3triazoles have also shown excellent biological properties; for example, as anticancer [19], antiviral [20], and anti-HIV agents [21]. In general, these compounds are prepared through a cycloaddition reaction between alkynes and azides, which depends on reagents (e.g., aliphatic or aromatic) and the selected conditions for a CuAAC reaction, as summarized in Scheme 2.

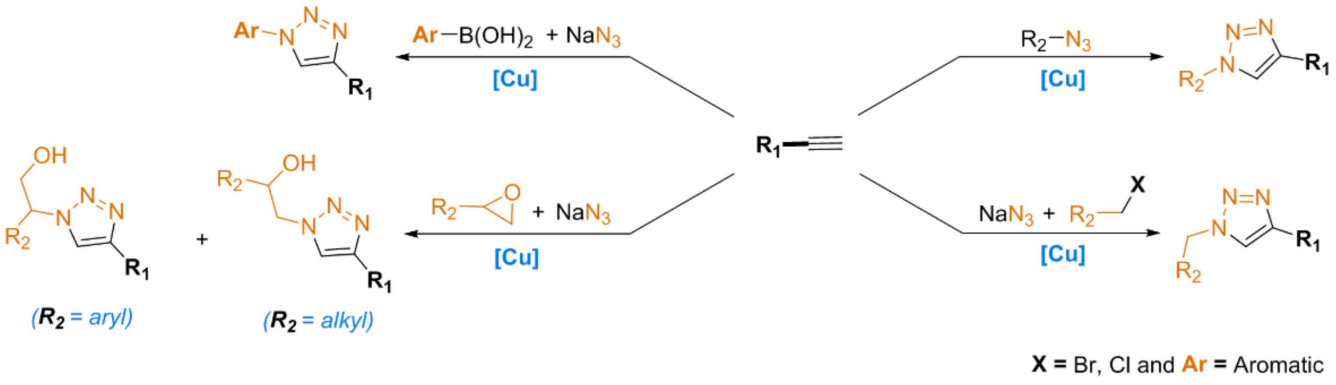

Scheme 2. Examples of synthetic routes to 1,2,3-triazoles using copper as a catalyst.

Furthermore, copper(I) species are thermodynamically unstable, and $\mathrm{Cu}(\mathrm{I})$ can be easily oxidized to $\mathrm{Cu}(\mathrm{II})$ under aerobic conditions. $\mathrm{Cu}(\mathrm{II})$ leads to the oxidation of the homocoupling of alkynes in the absence of any reducing agent or ligand [22]. Therefore, the active copper(I) catalysts can be easily obtained by reducing copper(II) precursors with a reducing agent, oxidizing copper metal with copper(II) (comproportionation reaction), or by using a combination of copper salts with a suitable ligand and/or a base [23]. However, the removal of the copper catalyst from the reaction mixture remains a challenge due to its toxicity, which causes serious problems in the synthesis of bioactive molecules [24]. In this regard, great emphasis has been placed on the use of heterogeneous catalysts instead of copper(I)-based homogeneous catalysts in order to facilitate the recovery and recycling of the catalysts, whilst keeping the inherent activity of the catalytic metal center [25].

In recent years, several comprehensive, as well as tutorial, reviews have covered the development of heterogeneous $\mathrm{CuAAC}$ methods, mainly based on the immobilization of the copper catalysts as molecular complexes or copper nanoparticles on a variety of supports, including polymers, biopolymers, silica, zeolites, and carbon-based materials [25-38]. The last five-year period has witnessed an increase in the development of such heterogeneous CuAAC methods, taking into account environmental concerns by using water as the reaction medium and avoiding the use of reducing additives, as well as the issue of the 
recovery of the copper species. The present review provides an up-to-date overview of the covalent and non-covalent immobilization methods of copper salts on inorganic solid supports as well as carbon and magnetic materials applied in azide-alkyne [3+2] cycloaddition reactions, covering the last five years.

\section{Inorganic Solid-Supported Catalysts for CuAAC}

\subsection{Silica Supports}

Silica-supported copper salts play a significant role in heterogeneous catalysis because of their low cost, accessibility, high stability, and large surface area with excellent porosity. They provide the advantage of reaction pathways under mild reaction conditions and comprise environmentally friendly processes toward sustainable chemistry [39]. In this context, Ben El Ayouchia et al. investigated a copper catalyst on silica gel for click chemistry [40]. The $\mathrm{Cu}(\mathrm{I})-\mathrm{SiO}_{2}$ catalyst was prepared by impregnating dinuclear copper(I) acetate on silica gel in acetone as a solvent. The resulting copper-silica catalyst was found to mediate [3+2] azide-alkyne cycloaddition in 1:1 (v/v) water/ethanol as a mixed solvent, giving rise to a variety of 1,4-disubstituted 1,2,3-triazoles in excellent yields (85-95\%) at room temperature. In addition, the immobilized catalyst could be reused up to five times.

The encapsulation of copper by direct interaction with the silica sol-gel matrix loading 9.4 wt.\% of copper was also reported by Gil and Coelho et al. in a click reaction [41]. The $\mathrm{SiO}_{2}-\mathrm{Cu}$ composite was prepared using a one-pot sol-gel procedure with the addition of copper iodide during a hydrolysis/condensation reaction of nanofunctionalized tetra-silicon alkylalkoxide. The resulting catalyst was shown to exhibit excellent catalytic activity in the synthesis of 1,4-disubstituted 1,2,3-triazoles under mild conditions using $N, N$-diisopropylethylamine (DIPEA) through azide-alkyne cycloaddition reactions in $3: 1(\mathrm{v} / \mathrm{v})$ tert-BuOH$-\mathrm{H}_{2} \mathrm{O}(90-98 \%$ in $3-4 \mathrm{~h})$ or dimethylformamide (DMF) (83-90\% in 4-5 h), and through the one-pot three components reactions of halides, sodium azide, and alkynes in 3:1 (v/v) tert- $\mathrm{BuOH}-\mathrm{H}_{2} \mathrm{O}(80-98 \%$ in 3-6 h) using $0.05 \mathrm{~mol} \%$ of catalyst. The recyclability tests showed that this catalyst could be reused for 10 cycles in both click reactions. Hayton et al. [42] reported the synthesis of an organometallic $\mathrm{Cu}_{20}$ nanocluster immobilized on silica to catalyze CuAAC reactions. The nanocluster was prepared through the reduction of $\mathrm{Cu}(\mathrm{OAc})_{2}$ in the presence of $\mathrm{Ph}_{2} \mathrm{SiH}_{2}$ and phenylacetylene to produce $\left.\left[\mathrm{Cu}_{20}(\mathrm{CCPh})_{12}(\mathrm{OAc})_{6}\right)\right]$. They used $0.5 \mathrm{~mol} \%$ of catalyst in the click reaction between benzyl azide and phenylacetylene in the $\mathrm{CD}_{2} \mathrm{Cl}_{2}$ as a solvent at room temperature, a process that produced the corresponding compounds in high yield (95\%) within $7 \mathrm{~h}$. In a similar approach, Zarenezhad et al. [43] immobilized copper(II) complexes, named [Cu(cdsalMeen)], containing the methyl-2-(1-((2-hydroxybenzylidene)amino)propan-2yl)amino-1-cyclopentenedithiocarboxylate ligand (cdsalMeen) on silica gel to catalyze the $[3+2]$ cycloaddition reaction between alkynes and $\beta$-azido alcohols using ascorbic acid as a reducing agent and $\mathrm{THF} / \mathrm{H}_{2} \mathrm{O}(2: 1 \mathrm{v} / \mathrm{v})$ as solvent mixture at room temperature. The $\beta$-hydroxy-1,2,3-triazolylalkyl products were obtained in good to excellent yields using $0.05 \mathrm{~mol} \%$ of $[\mathrm{Cu}$ (cdsalMeen) $]-\mathrm{SiO}_{2}$ catalyst (81-94\% in $\left.0.5-1 \mathrm{~h}\right)$. In addition, the catalyst was recycled for five further runs without losing its activity (94-80\% within $0.5-1.5 \mathrm{~h}$ ).

Many studies have focused on the immobilization of copper complexes on inorganic silica supports to improve the stability and selectivity of the copper catalyst on silica gel support. Rhee et al. [44] immobilized $\mathrm{Cu}(\mathrm{I})$ and $\mathrm{Cu}(\mathrm{II})$ species onto functionalized silica gel (Figure 1). Catalysts 1 and $\mathbf{2}$ were synthesized via the functionalization of reversedphase 3-aminopropyl functionalized silica gel by a 2-pyridinecarboxaldehyde ligand in dichloromethane as solvent. The complexation reaction of the resulting Schiff base, named iminopropyl-functionalized silica gel (IPSi), with $\left[\mathrm{Cu}\left(\mathrm{CH}_{3} \mathrm{CN}\right)_{4}\right] \mathrm{PF}_{6}$ and $\mathrm{CuSO}_{4}$ produced $\mathrm{Cu}(\mathrm{I}) @ I P S i$ and $\mathrm{Cu}(\mathrm{II}) @ \mathrm{IPSi}$, respectively. The catalytic activity of the Cu(I)@IPSi and $\mathrm{Cu}(\mathrm{II}) @ I P S i$ composites was investigated in the one-pot three-component condensation reaction of benzyl bromides, phenylacetylenes, and sodium azide, which afforded good to excellent yields (76-97 and 74-96\%, respectively) of 1,4-triazoles using 2.5 and 5 mol\% of catalyst in water at $60{ }^{\circ} \mathrm{C}$, respectively. Interestingly, the catalysts could be reused for seven 
consecutive runs with almost equivalent performances. In a similar approach, Bakherad et al. [45] prepared a heterogeneous catalyst by anchoring the $\mathrm{Cu}(\mathrm{I})$ aminothiophenol (AT) complex on silica $\mathrm{SiO}_{2}-\mathrm{AT}-\mathrm{Cu}(\mathrm{I})$ (3) for the synthesis of triazole compounds (Scheme 3). The use of $0.2 \mathrm{~mol} \%$ of $\mathrm{SiO}_{2}$-AT-Cu(I) (3) catalyst was shown to exhibit a high catalytic activity in one-pot click reactions of aryl bromides, sodium azide, and terminal alkynes in water as solvent at $80^{\circ} \mathrm{C}$ within 2-4 h (96-98\%). The recovery/recycling tests showed that this catalyst could still be active and reused for at least five repeated cycles (96-89\%).

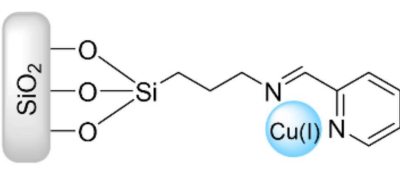

1

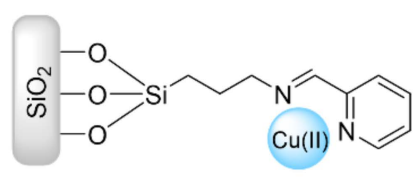

2

Figure 1. Chemical structure of the catalysts 1 and 2.

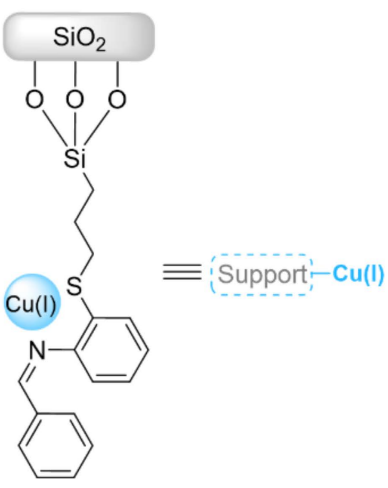

3

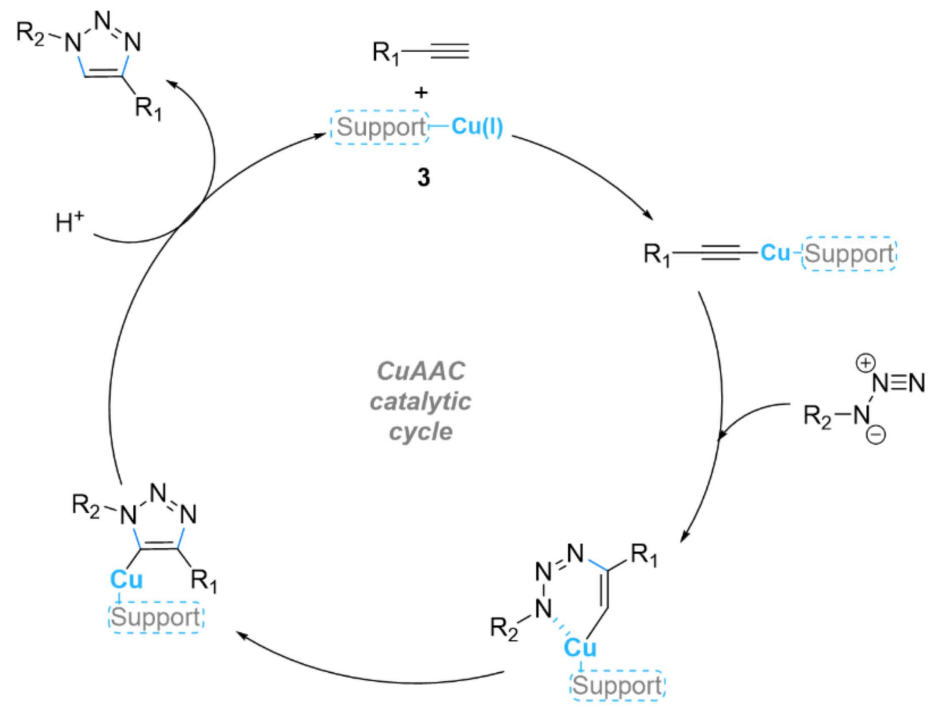

Scheme 3. Chemical structure of the catalyst 3 and its catalytic activity in the copper(I)-catalyzed azide-alkyne cycloaddition (CuAAC) reaction.

More recently, Bikas et al. reported the functionalization of silica gel with the $\mathrm{Cu}(\mathrm{II})$ hydrazide complex, followed by its use for the construction of $\beta$-hydroxy-1,2,3-triazoles from the multicomponent $\mathrm{CuAAC}$ reaction of alkyl or aryl epoxides, sodium azide, and terminal alkynes (Scheme 4) [46]. The catalyst showed high catalytic activity in water at different temperatures, but two products resulted at a temperature higher than $50{ }^{\circ} \mathrm{C}$ due to their type of epoxide ring-opening reaction. In addition, the nature of the epoxide reagent was found to have an impressive effect on the resulting products.

In 2017, a copper(II) bis-triazole complex immobilized on silica nanoparticles was prepared by Moghadam et al. via the immobilization of the copper(II)-3,5-bis(2-benzothiazolyl) pyridine $\left(\mathrm{Cu}(\mathrm{II}) \mathrm{Br}_{2}-\mathrm{BTP}\right)$ complex on nano-silica functionalized with trimethoxysilylpropylchloride $\left(\mathrm{Cu}(\mathrm{II}) \mathrm{Br}_{2}-\mathrm{BTP} @ \mathrm{TMSP}-\mathrm{nSiO}_{2}\right)$ (5) (Scheme 5) [47]. This heterogeneous catalyst was found to exhibit excellent catalytic activity within short times for the synthesis of 1,4-triazoles regioisomers through one-pot three-component reactions of benzyl halides or $\alpha$-bromoketones, sodium azide, and alkynes, using a solvent mixture of ethanol/water (3:1 $\mathrm{v} / \mathrm{v})$ at $85{ }^{\circ} \mathrm{C}$ in the presence of sodium ascorbate. Moreover, the $\mathrm{Cu}(\mathrm{II}) \mathrm{Br}_{2}-\mathrm{BTP} @ \mathrm{TMSP}-$ $\mathrm{nSiO}_{2}$ catalyst could be reused five consecutive times. 


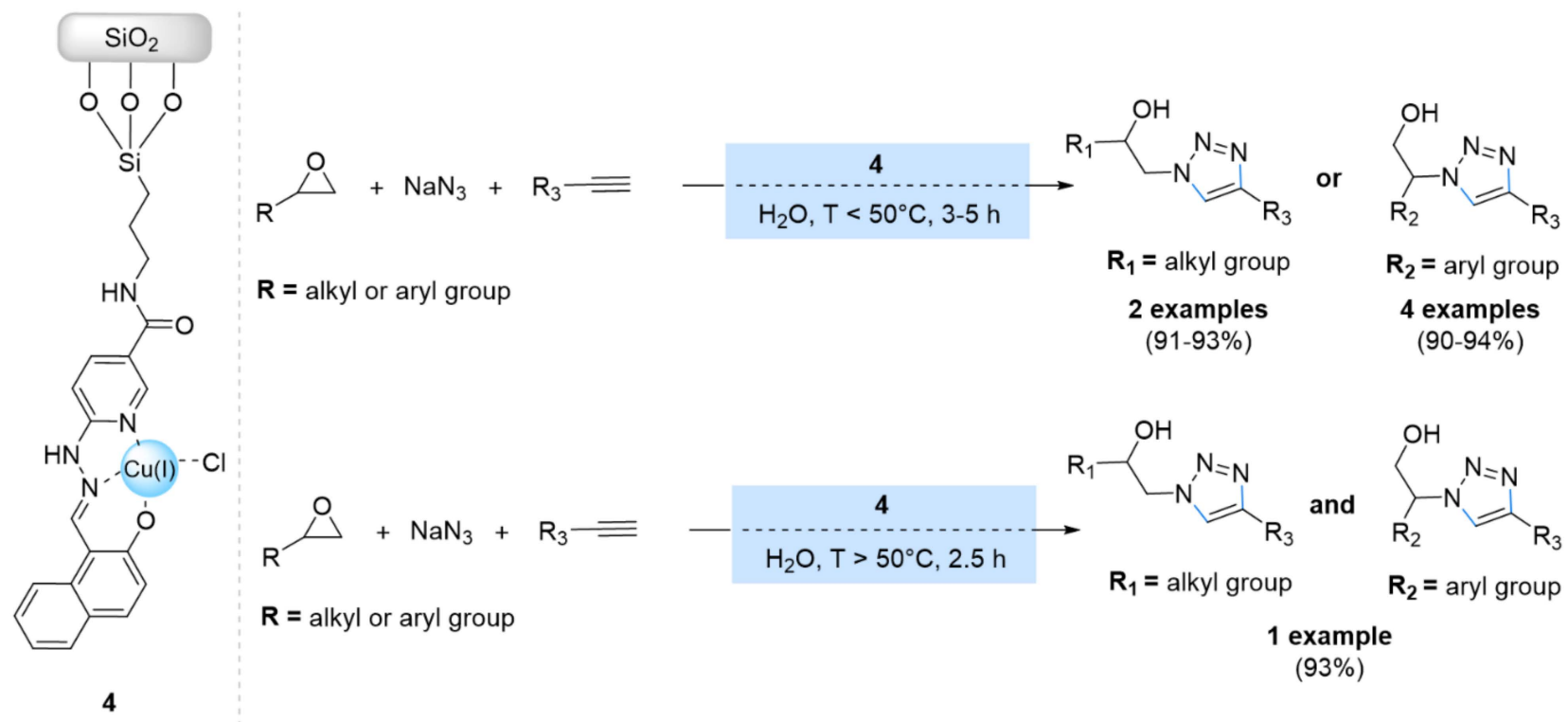

Scheme 4. Chemical structure and catalytic applications of the catalyst 4 in multicomponent CuAAC reactions.
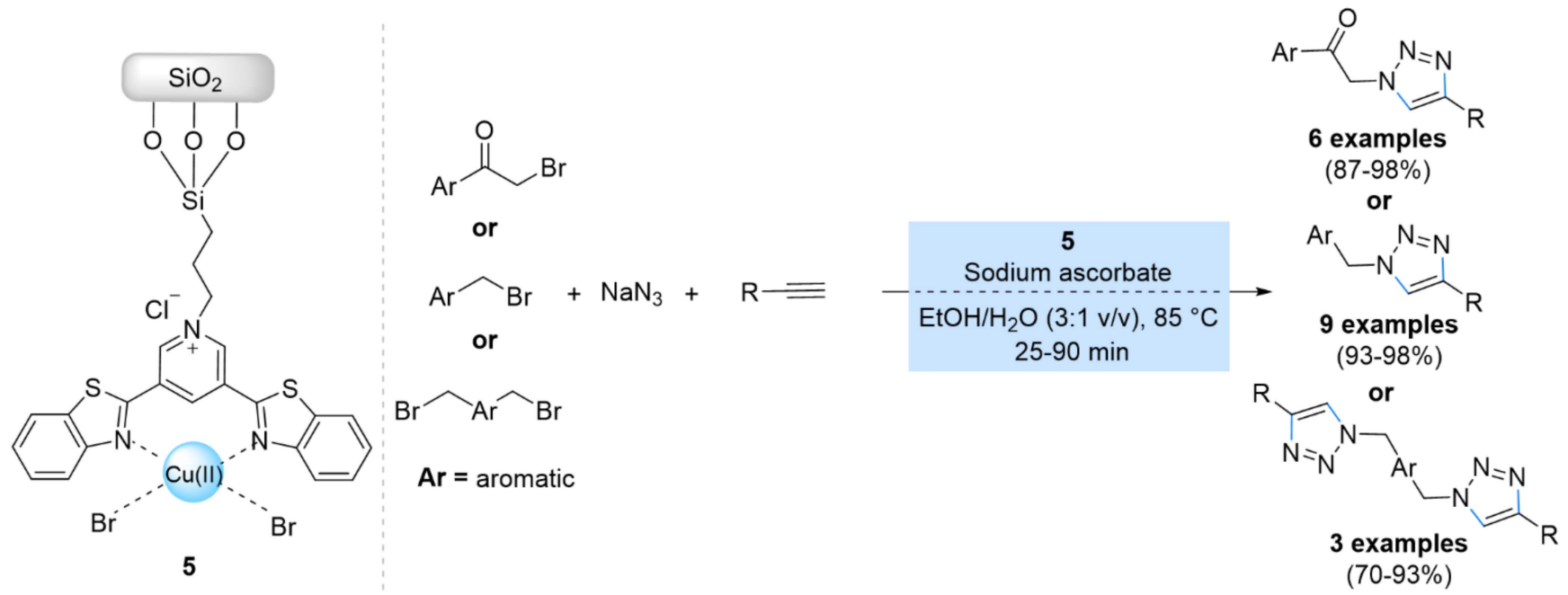

Scheme 5. Chemical structure and catalytic activity of the catalyst 5 in multicomponent CuAAC reactions.

Soltani Rad et al. also reported a new thioamide-based ligand designed for the modification of traditional $\mathrm{SiO}_{2}$ to prepare the silica-tethered cuprous acetophenone thiosemicarbazone (STCATSC) (6) as a nanocatalyst (Figure 2) [48]. The prepared catalyst 6 was used to synthesize the 1,2,3-triazolyl-based metronidazole hybrid analogues from 2-methyl-5nitro-1-prop-2-ynyl- $1 H$-imidazole with diverse $\beta$-azidoalcohols in a THF-water medium at room temperature, which provided the products in good to excellent yields (76-92\%) within $2 \mathrm{~h}$. Moreover, no significant loss of catalyst activity was noted after five sequential runs. Bai et al. anchored a copper acetylacetonate complex onto an hexagonal mesoporous silica (HMS) solid using 2-butoxy-3,4-dihydropyrans (DP) (Figure 2) [49]. The obtained HMS-DP-Cu(II) (7) composite exhibited excellent catalytic activity in the click reaction of sodium azide, organic halides, and alkynes in ethanol medium at $80^{\circ} \mathrm{C}$ within $8 \mathrm{~h}$ (70-99\%).

A supported copper catalyst on 3D-silica functionalized by amino groups was also reported by Gil et al. (Figure 2) [50]. The 3D-SiO ${ }_{2}-\mathrm{APTS}-\mathrm{Cu}$ composite (8) was prepared via the surface functionalization of a 3D-printing silica support using (3-aminopropyl) 
trimethoxysilane (APTS). The obtained $3 \mathrm{D}-\mathrm{SiO}_{2}-\mathrm{APTS}-\mathrm{Cu}$ catalyst showed high activity for the regioselective synthesis of 1-(2-iodobenzyl)-4-phenyl-1,2,3-triazole from a threecomponent click reaction involving phenylacetylene, sodium azide, and 2-iodobenzyl bromide in a tert- $\mathrm{BuOH} / \mathrm{H}_{2} \mathrm{O}(3: 1 \mathrm{v} / \mathrm{v})$ solvent mixture. Further, it was reused for 10 sequential cycles aimed at investigating its recyclability, and the results revealed that no significant loss of catalytic activity occurred.

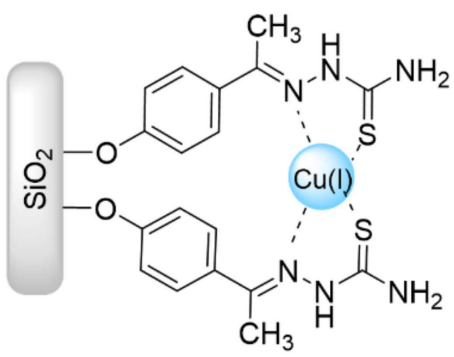

6

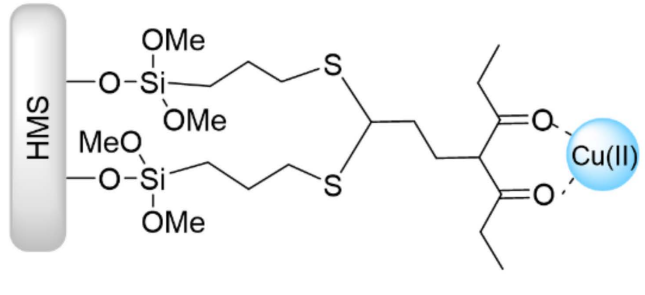

7

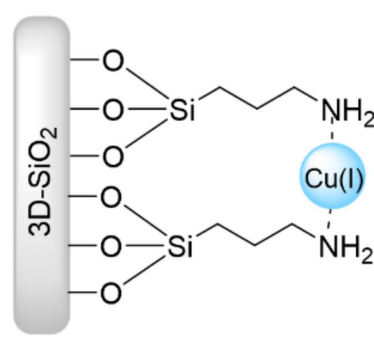

8

Figure 2. Chemical structure of the catalysts 6-8.

Recently, heterogeneous immobilized ionic liquids (ILs) have attracted considerable interest due to their many advantages, such as easy recovery and reusability, low cost, and operational simplicity [51-54]. In this regard, Moghadam et al. reported silica nanoparticles supporting copper(II)-containing ionic liquid (SNIL-Cu(II)) (9) as a new catalyst for click reactions between azides and alkynes (Scheme 6) [55]. The SNIL-Cu(II) composite was obtained via the functionalization of silica nanoparticles by 3-chloropropyltrimethoxysilane followed by their complexation with $\mathrm{Cu}(\mathrm{OTf})_{2}$, which resulted into composite-loaded $0.21 \mathrm{mmol} / \mathrm{g}$ of copper, as measured by ICP analysis. The catalytic activity of catalyst 9 showed high efficiency in a one-pot synthesis of mono- and multi-fold 1,4-disubstituted 1,2,3-triazoles via three-component reactions of alkynes, organic halides, and sodium azide at room temperature in aqueous polyethylene glycol. Moreover, the catalyst 9 was reused six consecutive times.

Similarly, Skoda-Földes et al. [56] supported the copper catalyst on an ionic liquid polymer/silica hybrid composite via the deposition of $\mathrm{Cu}(\mathrm{I})$ on an inorganic/organic hybrid material consisting of silica and a polymer of 1-methyl-3-(4-vinylbenzyl)imidazolium chloride (Figure 3). The application of the resulting heterogeneous catalyst (10) in CuAAC reactions of alkynes and azides showed moderate to excellent yields (26-99\%) in a less polar solvent (dichloromethane) at room temperature within $24 \mathrm{~h}$, using $10 \mathrm{~mol} \%$ of catalyst. Moreover, the catalyst $\mathbf{1 0}$ was able to be used in at least three further cycles. Moghadam et al. [57] attached a poly ( $\mathrm{N}$-heterocyclic carbine copper complex) onto nano-silica ((Cu(II)$\mathrm{NHCs}) \mathrm{n} @ \mathrm{nSiO}_{2}$ ) (11) (Figure 3). The catalytic activity of the prepared catalyst (11) was investigated in the synthesis of 1,2,3-triazoles by the reaction of benzyl halide derivatives, sodium azide, and phenylacetylene. The resulting products were obtained in excellent yields (85-96\% in 15-30 $\mathrm{min}$ ), using $0.02 \mathrm{~mol} \%$ of the catalyst with sodium ascorbate in an $\mathrm{H}_{2} \mathrm{O} / \mathrm{EtOH}(2: 1 \mathrm{v} / \mathrm{v})$ solvent mixture at room temperature. Moreover, the catalyst 11 was reused up to seven runs, with its activity being sustained (96-79\%). 


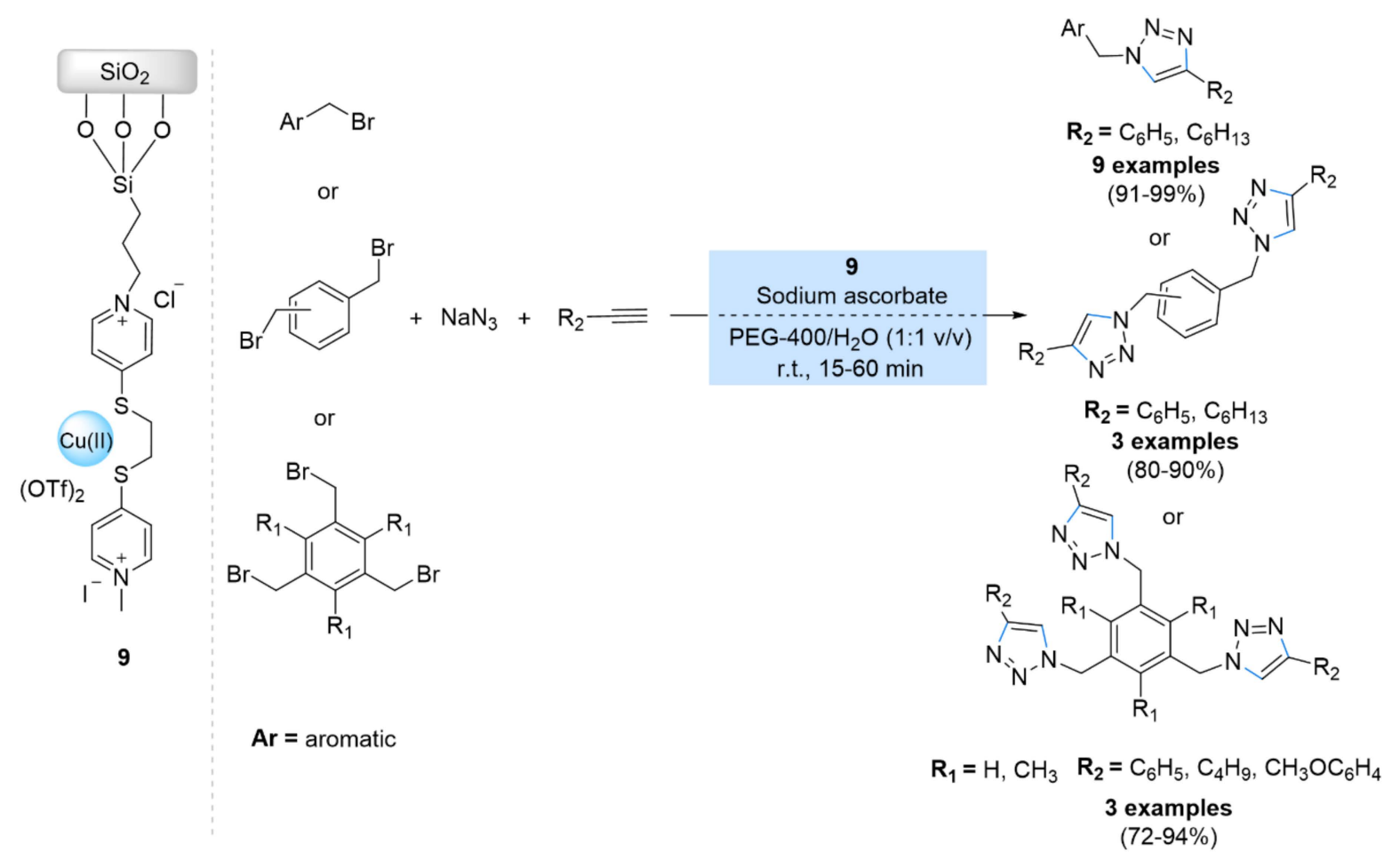

Scheme 6. Chemical structure and catalytic applications of the catalyst SNIL-Cu(II) (9) in multicomponent $\mathrm{CuAAC}$ reactions.

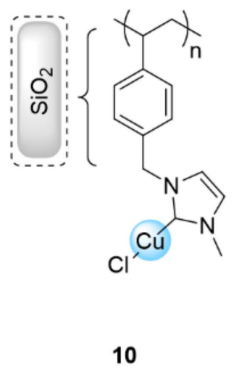

10

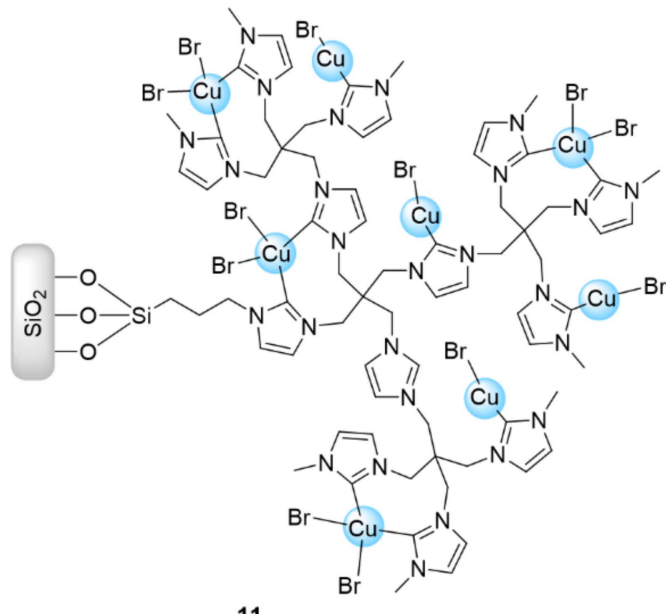

11

Figure 3. Chemical structure of the catalysts $\mathbf{1 0}$ and $\mathbf{1 1 .}$

More recently, Berlier et al. [58] prepared novel catalysts based on the organic/inorganic hybrid concept (Figure 4). Six different systems (12-17) were synthesized, including the $\mathrm{Cu}(\mathrm{II})$ catalyst in silica functionalized by $\beta$-cyclodextrins $(\beta-\mathrm{CD})$ using diamino (DiAm) and triamino (TriAm) alkoxy silyl spacers, and only two organic-inorganic silica-supported $\beta$-CD-Cu(II) catalysts were applied in the click azide-alkyne cycloaddition at $85^{\circ} \mathrm{C}$ in a tert-BuOH$/ \mathrm{H}_{2} \mathrm{O}(1: 1 \mathrm{v} / \mathrm{v})$ solvent mixture. These two Si-TriAm-CD-Cu and Si-DiAm-CD$\mathrm{Cu}$ catalysts exhibited high catalytic activity under greener conditions with short reaction times. The reusability investigation of these catalysts showed that they could be reused up to five and three runs, respectively. 


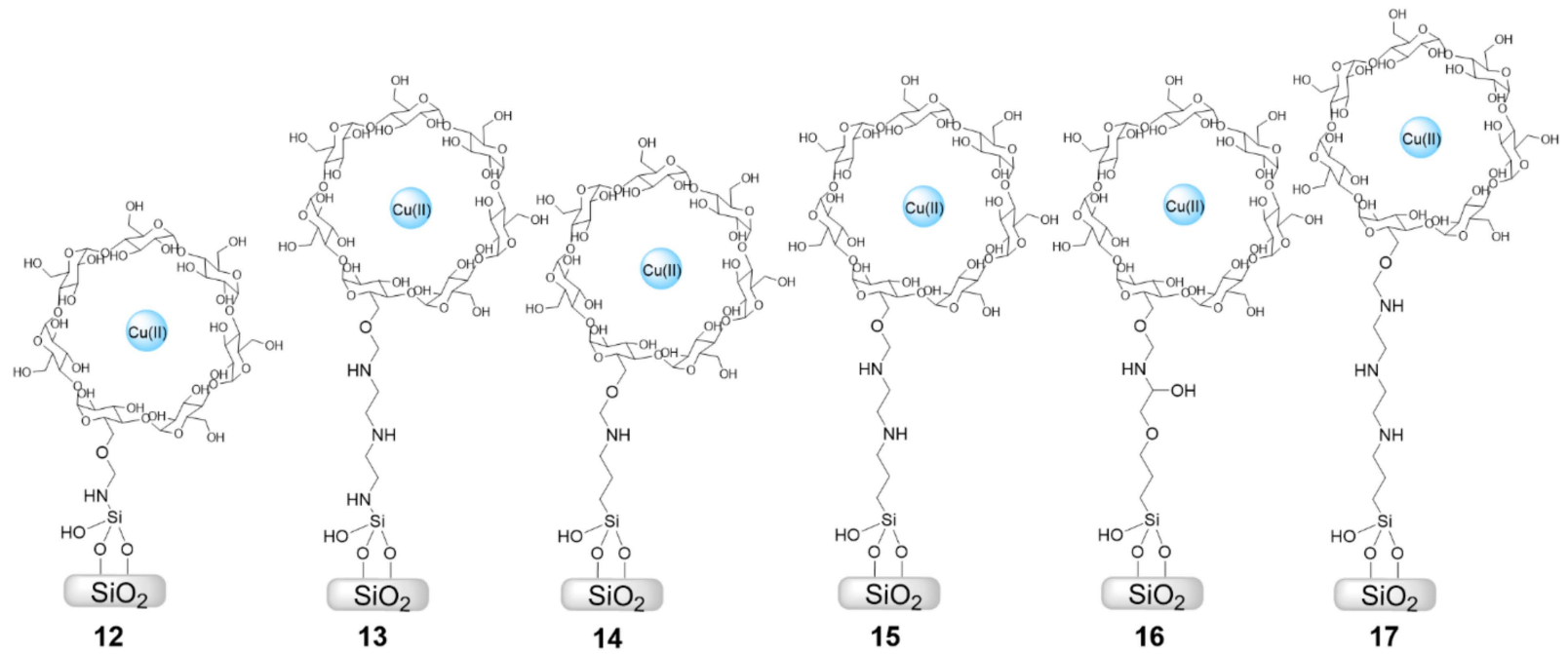

Figure 4. Chemical structure of the catalysts 12-17.

Mesoporous silica, either as Mobil Composition of Matter (MCM-41), Santa Barbara Amorphous (SBA-15), or mesoporous silica materials (KIT-5), are solid supports that provide vast surface areas, making immobilized active species more accessible for substrates during catalytic reactions [59-61]. Pourhassan et al. [62] functionalized mesoporous SBA-15 silica by thioamide groups to be applied as a recyclable catalyst for the CuAAC reaction (Figure 5). In this context, the channels of SBA-15 were modified with tris(2-aminoethyl)amine (TAEA) groups and then reacted with $\mathrm{S}_{8}$ and phenylacetylene to form thioamide groups. Next, the acquired solid was immersed in a solution of copper(II) chloride to produce the final SBA-15/thioamide-Cu(I) catalyst. The use of this so-formed catalyst (18) afforded excellent yields (85-95\% in 90-250 min, $1 \mathrm{~mol} \%$ of catalyst) in synthesizing the desired triazoles from sodium azide, phenylacetylene, and alkyl/benzyl halides or alkyl epoxides in water at room temperature. Furthermore, this catalytic system was able to be used for nine consecutive runs. Banan et al. [63] supported a Cu(II)/Schiff-base complex on SBA-15 to catalyze a one-pot azide-alkyne cycloaddition reaction (Figure 5). The organic-inorganic material was prepared via the immobilization of the complex between 4-[((2-hydroxyethyl)imino)methyl] phenol and $\mathrm{CuCl}_{2} \cdot 2 \mathrm{H}_{2} \mathrm{O}$ on a SBA-15 support. The catalyst 19 showed excellent activity in converting organic halides, alkynes, and sodium azide into the corresponding triazole compounds via one-pot azide-alkyne cycloadditions in water within $12 \mathrm{~h}$, and it was also able to be reused for five runs.

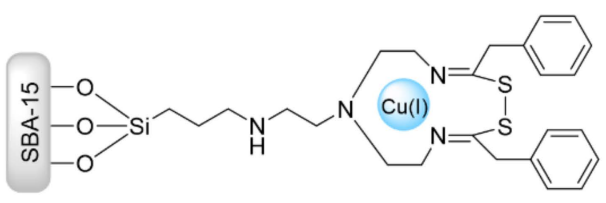

18

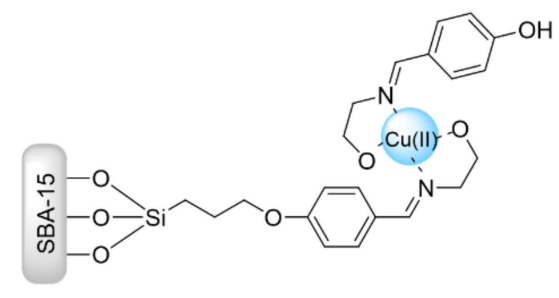

19

Figure 5. Chemical structure of the catalysts 18 and 19.

Bakherad et al. [64] supported dithizone(dtz)-copper(I) on a SBA-15 support (Scheme 7). The obtained SBA-15-dtz-Cu(I) (20) material was investigated as a new catalyst in the click reaction between benzyl chloride derivatives, terminal alkynes, and sodium azide in water at $60{ }^{\circ} \mathrm{C}$, affording the corresponding products in good to excellent yields (78-98\% in $1-3 \mathrm{~h}$ ) by using $0.2 \mathrm{~mol} \%$ of catalyst. In addition, the catalyst 20 was able to be reused over five 
recycling cycles with yields from $98 \%$ to $89 \%$ [64]. Sun et al. anchored $\mathrm{Cu}(\mathrm{OAc})_{2}$ on a SBA-15 organic/inorganic support via the proton exchange of a carboxyl functionalized SBA-15 silica with copper(II) acetate (Scheme 8) [65]. The resulting Cu@SBA-15-PTAA catalyst (21) exhibited high catalytic activity for azide-alkyne cycloaddition reactions in water at $50{ }^{\circ} \mathrm{C}(91-98 \%$ in $6-12 \mathrm{~h})$, and it was also able to be reused at least five times.

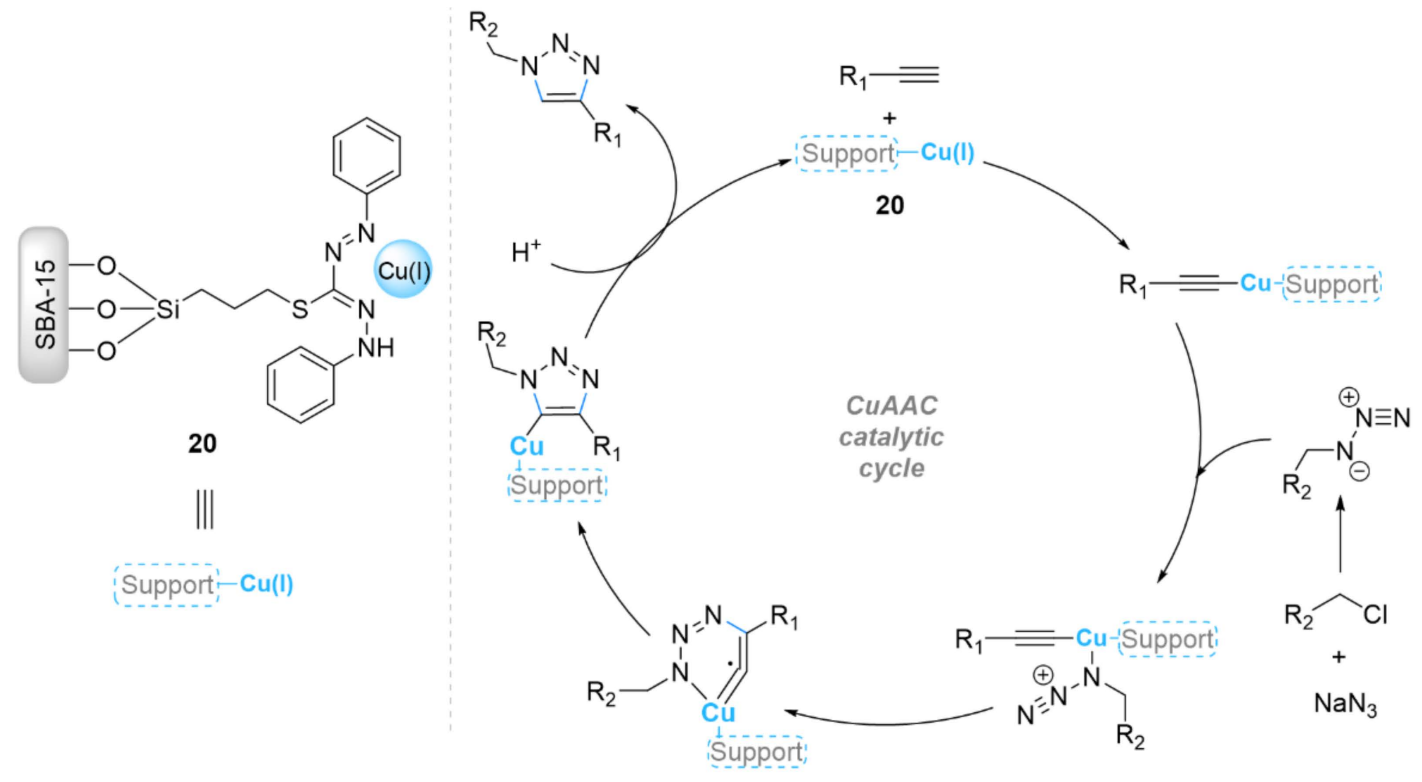

Scheme 7. Chemical structure of the catalyst 20 and its catalytic mechanism in the CuAAC reaction.

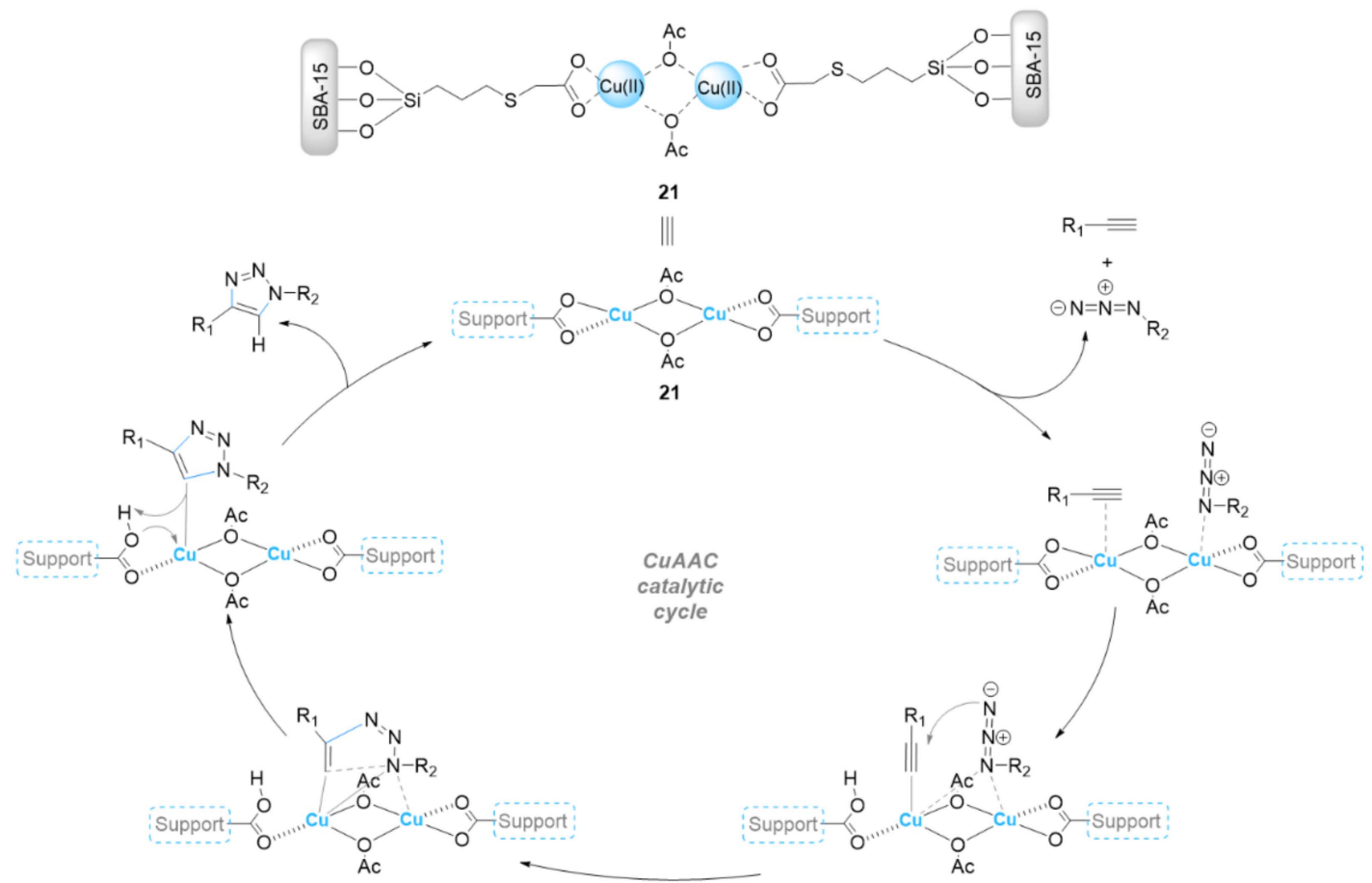

Scheme 8. Chemical structure of the catalyst 21 and its catalytic mechanism in the CuAAC reaction. 
Rostamnia et al. supported a $\mathrm{Cu}(\mathrm{I})$ catalyst on SBA-15 that additionally contained an ethylene diamine (PrEn) and ionic liquid $\left(\mathrm{ImPF}_{6}\right)$ functionalities (Scheme 9) [66]. The CuI@SBA-15/PrEn/ImPF 6 catalyst (22) was investigated in the synthesis of 1,4-disubstituted 1,2,3-triazoles from phenylacetylene, sodium azide, and the in situ preparation of azides using two different methods [iodobenzene (method A) and phenylbronic acid (method B)], resulting in excellent yields. Furthermore, the catalyst was able to be recycled for several consecutive runs (7-14). Pzsyan et al. [67] anchored the Cu-Koc acid complex (KA) on functionalized silica-MCM-41 by 3-chloropropyltrimethoxysilane (CPTMS) (MCM41CPTMS-Kojic acid-Cu) (23) (Scheme 9). The copper(II) complex on Kojic acid-functionalized nano silica-MCM-41 (23) was investigated in the synthesis of 1,2,3-triazoles through the click reaction of 2-(azidomethyl)-5-benzyloxy-4-pyrone and azido Kojic acid with terminal alkynes in ethanol/water (1:1 v/v) and ethylene glycol (EG) as solvents at $100{ }^{\circ} \mathrm{C}$ within 5 to $30 \mathrm{~min}$. In addition, this catalyst was able to be recycled up to six times.

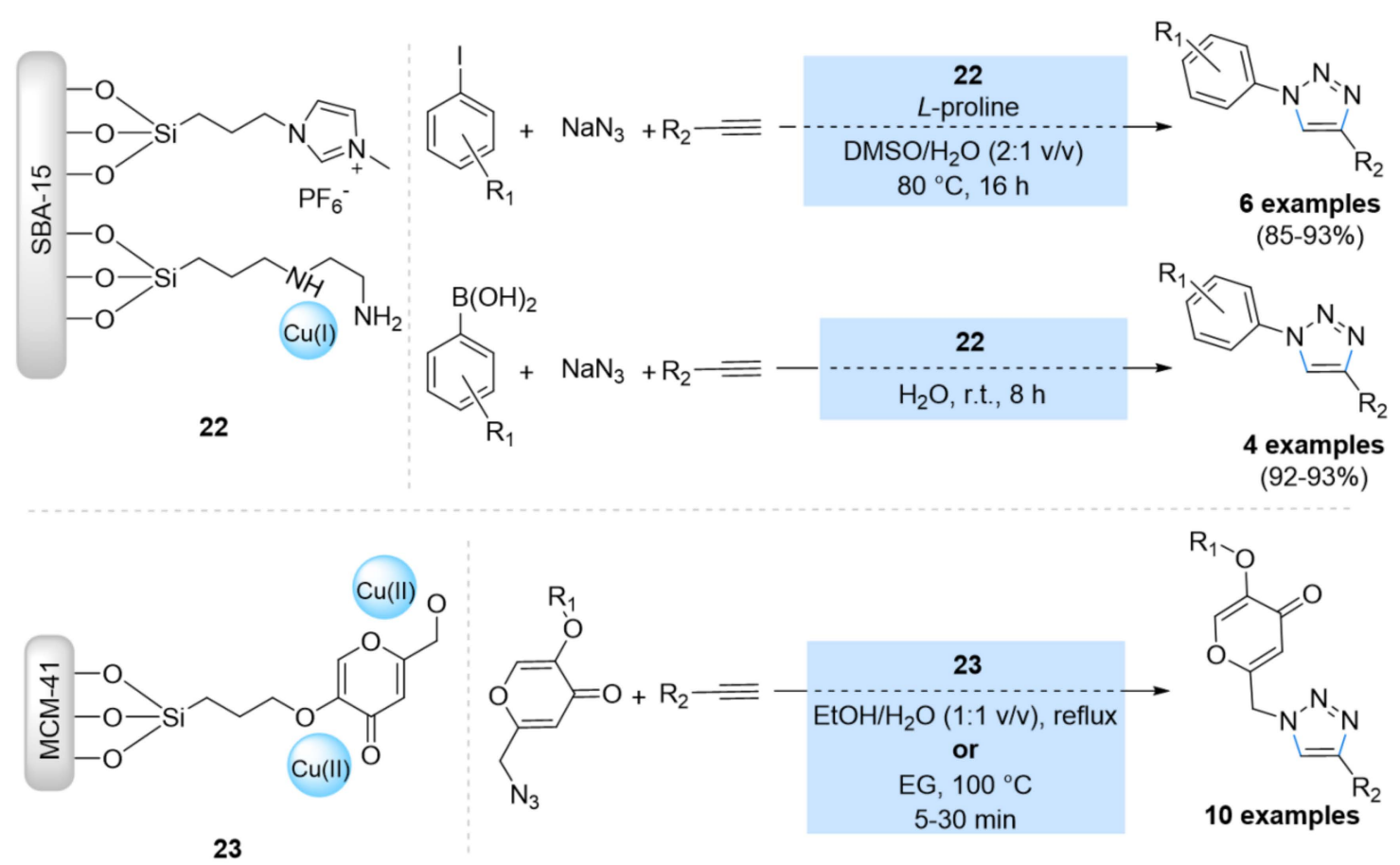

Scheme 9. Chemical structure of the catalysts CuI@SBA-15/PrEn/ImPF 6 (22) and MCM41-CPTMSKojic acid-Cu (23), and their application in CuAAC reactions.

Naeimi et al. [68,69] reported a nanocomposite acetylide for click reaction using copperimprinted periodic mesoporous organosilica ( $\mathrm{Cu} @ \mathrm{PMO} \mathrm{NC}$ ) (Figure 6). This Cu@PMO NC catalyst (24) showed excellent results up to $99 \%$ for the microwave-assisted synthesis of $\beta$-hydroxy-1,2,3-triazoles at room temperature in water within $7 \mathrm{~min}$, and was also able to be reused up to six other cycles. M. Heravi et al. [70] supported copper(I) iodide catalyst on modified mesoporous KIT-5 silica via the coordination of 3-aminopropyltriethoxysilane (APTES) on KIT-5 with copper(I) (Figure 6). This catalyst (25) exhibited an excellent catalytic performance for the regioselective synthesis of 1,4-disubstituted 1,2,3-triazoles via a one-pot reaction between terminal alkynes, $\alpha$-halo ketones or alkyl halide, and sodium azide in boiling water (69-88\% in 15-150 min). Moreover, the catalyst 25 was reused for six further runs. 

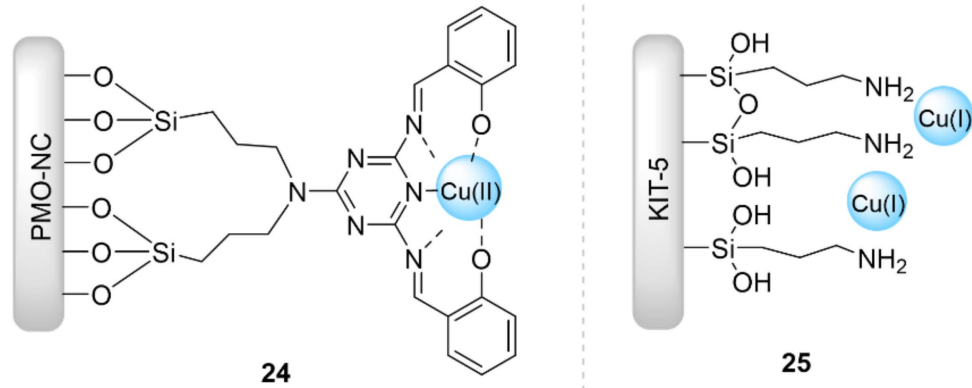

Figure 6. Chemical structure of the catalysts 24 and 25 .

\subsection{Anionic Clay-Supported Catalysts for CuAAC}

Hydrocalcites (HTs) are other inorganic heterogeneous catalytic systems that have been described for azide-alkyne click chemistry. Layered double hydroxides or hydrotalcites are one class of anionic clay containing di- $\mathrm{M}(\mathrm{II})$ and trivalent $\mathrm{M}(\mathrm{III})$ cations, represented by the general formula $\left[\mathrm{M}(\mathrm{II})_{1-\mathrm{x}} \mathrm{M}(\mathrm{III})_{\mathrm{x}}(\mathrm{OH})_{2}\right]\left(\mathrm{A}^{\mathrm{n}-}\right)_{\mathrm{x} / \mathrm{n} \cdot \mathrm{yH}} \mathrm{O}$, where $\mathrm{A}^{\mathrm{n}-}$ is an exchangeable anion in the interlayer usually with water (Figure 7). Layered double hydroxides (LDH) are reported to have attractive properties, such as a simple work-up synthesis, surface hydroxyl groups, a distribution of different metal cations in the brucite layer, intercalated anions with interlayer spaces, biocompatibles, and high chemical and thermal stability. All these properties make them excellent candidates for metal immobilization and catalytic activity [71].
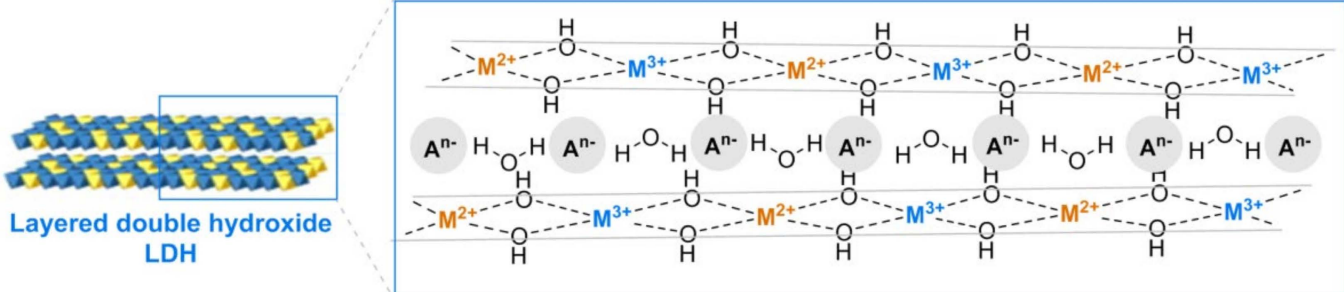

Figure 7. Idealized structure of layered double hydroxides (LDH).

Fülöp et al. [72] reported the $\mathrm{Cu}(\mathrm{II}) \mathrm{Fe}(\mathrm{III})$-layered double hydroxide catalyst for [3+2] azide-alkyne cycloaddition reactions as a heterogeneous catalyst in a continuous-flow reactor. The catalytic activity of the as-prepared material that was generated from in situ reductions of copper(II) to copper(I) by the oxidative homocoupling of the alkyne (Glaser reaction) exhibited good to high activity (77-98\%) in the synthesis of 1,4-disubstituted 1,2,3-triazoles at high pressure/temperature conditions. In 2016, González-Olvera et al. [73] investigated the as-synthesized and calcined (mixed oxide) $\mathrm{Cu}-\mathrm{Al} \mathrm{LDH}$. Both catalysts exhibited excellent yields in azide-alkyne cycloadditions in EtOH- $\mathrm{H}_{2} \mathrm{O}$ solvent mixtures under microwave heating. The outcome of the reaction resulted from both hetero- and homogeneous catalytic processes capturing copper(II) from the material by sodium ascorbate. In addition, this study demonstrated that the reconstruction of Cu-Al LDH from $\mathrm{Cu}(\mathrm{Al}) \mathrm{O}$ mixed oxides via the so-called memory effect was not possible, despite the use of severe reaction conditions $\left(\mathrm{EtOH} / \mathrm{H}_{2} \mathrm{O}, 80^{\circ} \mathrm{C}, \mathrm{MW}, 10 \mathrm{~min}\right)$. More recently, $\mathrm{Cu}-\mathrm{Al}$ mixed oxide was also employed for the synthesis of new 1,2,3-triazole derivatives, such as glucoand allofuranose-linked 1,2,3-triazole derivatives, using glucofuranose and allofuranose diacetonides in the same reaction conditions $\left(\mathrm{EtOH} / \mathrm{H}_{2} \mathrm{O}, 80{ }^{\circ} \mathrm{C}, \mathrm{MW}\right)$, affording one regioisomer as a product in moderate to good yields (53-89\%) within $10 \mathrm{~min}$ [74].

Recently, Amini et al. [75] synthesized an LDH-supported copper(0) catalyst via an exchange of $\left[\mathrm{CuCl}_{4}\right]^{2-}$ followed by a reduction with hydrazine hydrate. On exposure to air, $\mathrm{LDH}-\mathrm{Cu}(0)$ is again oxidized to the $\mathrm{LDH}-\mathrm{Cu}(\mathrm{II})$ form as a green powder. The prepared $\mathrm{LDH}-\left[\mathrm{CuCl}_{4}\right]^{2-}$ catalyst was used in water at $70{ }^{\circ} \mathrm{C}$ for the click reaction of terminal 
alkynes with benzyl azides generated in situ from sodium azide and benzyl halides. Under these conditions, the desired products were obtained in excellent yields (62-96\%), and the catalyst was reused for four cycles with relatively high catalytic activity. Bakherad et al. [76] immobilized $\mathrm{CuI}$ on $\mathrm{Mg}$-Al-LDH to produce the $\mathrm{CuI} / \mathrm{Mg}$-Al-LDH material as a heterogeneous catalyst for $\mathrm{CuAAC}$ reactions. Its catalytic activity was investigated in the synthesis of pyrimidine-1,2,3-triazole derivatives in an ethanol medium at room temperature, the desired products being obtained in excellent yields (88-97\%) within short reaction times (15-25 $\mathrm{min})$.

\subsection{Other Inorganic Solid Supports}

As shown above, the development of heterogeneous copper catalysts immobilized by solid inorganic supports has attracted attention due to its merger advantages. In the last few years, different approaches have been established to immobilize copper salts onto various solid supports effectively. Table 1 summarizes the catalytic performances of different heterogeneous inorganic solid-supported copper salts in [3+2] cycloaddition reactions by copper salts immobilized onto new alternative inorganic supports.

Table 1. Different heterogeneous inorganic solid-supported copper salts for CuAAC.

\begin{tabular}{|c|c|c|c|c|c|c|c|c|}
\hline Entry & Support & Catalyst * & Substrats & Conditions & Time & Yield (\%) & $\mathbf{N}^{\circ}$ Run & Ref. \\
\hline 1 & \multirow{3}{*}{ Cationic clay } & $\mathrm{Cu}^{\mathrm{I}}-\mathrm{MMT}$ & Alkyl azide, alkyne & $\begin{array}{c}5 \text { mg of catalyst; } \\
\mathrm{H}_{2} \mathrm{O} ; \text { r.t. }\end{array}$ & $2 \mathrm{~h}$ & $\begin{array}{c}88-98 \% \\
\text { (9 examples) }\end{array}$ & 5 & [77] \\
\hline 2 & & $\begin{array}{c}\text { Claycop } \\
(\text { Clay Cu(II)) }\end{array}$ & $\begin{array}{l}\text { Organic azide, } \\
\text { alkyne }\end{array}$ & $\begin{array}{c}20 \mathrm{mg} \text { of catalyst; } \\
\text { Solvent free; r.t.; } \\
\mathrm{NH}_{2} \mathrm{NH}_{2}, \mathrm{H}_{2} \mathrm{O} \text { as } \\
\text { additive }\end{array}$ & $5-50 \mathrm{~min}$ & $\begin{array}{c}81-98 \% \\
\text { (13 examples) }\end{array}$ & 4 & [78] \\
\hline 3 & & Clay-Cu(II) & $\begin{array}{c}\text { Azide, } \\
\text { propargylated } \\
\text { alloxan }\end{array}$ & $\begin{array}{c}5 \text { mol\% of catalyst; } \\
\mathrm{H}_{2} \mathrm{O} / \mathrm{MeOH} \\
(1: 10 \mathrm{v} / \mathrm{v}) ; \text { r.t. }\end{array}$ & $4 \mathrm{~h}$ & $\begin{array}{c}92-96 \% \\
\text { (14 examples) }\end{array}$ & 5 & [79] \\
\hline 4 & \multirow{3}{*}{ Alumina } & $\mathrm{CuI} / \mathrm{Al}_{2} \mathrm{O}_{3}$ & $\begin{array}{l}\text { Organic halide, } \\
\mathrm{NaN}_{3} \text {, alkyne }\end{array}$ & $\begin{array}{c}3 \mathrm{~mol} \% \text { of catalyst; } \\
\mathrm{H}_{2} \mathrm{O} ; \mathrm{MW}(100 \mathrm{~W}) \\
70{ }^{\circ} \mathrm{C}\end{array}$ & $6-13 \mathrm{~min}$ & $\begin{array}{c}70-98 \% \\
\text { (16 examples) }\end{array}$ & 8 & [80] \\
\hline 5 & & $\mathrm{Cu}-\mathrm{Co} / \mathrm{ZSM}-5$ & $\begin{array}{l}\text { Organic halide, } \\
\mathrm{NaN}_{3} \text {, propargyl } \\
\text { alcohol }\end{array}$ & Catalyst; $\mathrm{H}_{2} \mathrm{O} ; 70^{\circ} \mathrm{C}$ & $2 \mathrm{~h}$ & $\begin{array}{c}86-93 \% \\
\text { (7 examples) }\end{array}$ & 8 & [81] \\
\hline 6 & & $\mathrm{Cu}-\mathrm{Co} / \mathrm{ZSM}-5$ & $\begin{array}{l}\text { Organic halide, } \\
\mathrm{NaN}_{3} \text {, propargyl } \\
\text { alcohol }\end{array}$ & $\begin{array}{c}\text { Catalyst; } \mathrm{H}_{2} \mathrm{O} ; \mathrm{MW} \text {, } \\
\text { r.t. }\end{array}$ & $5 \mathrm{~min}$ & $\begin{array}{c}83-99 \% \\
\text { (7 examples) }\end{array}$ & 8 & [81] \\
\hline 7 & Titane & $\mathrm{Cu} / 6 \mathrm{~b} / \mathrm{SM} / \mathrm{A}$ & $\begin{array}{l}\text { Organic azide, } \\
\text { alkyne }\end{array}$ & $\begin{array}{c}1 \mathrm{~mol} \% \text { of catalyst; } \\
\mathrm{THF} ; 60{ }^{\circ} \mathrm{C} ; \mathrm{NEt}_{3} \text { as } \\
\text { additive }\end{array}$ & $3 \mathrm{~h}$ & $\begin{array}{c}92-99 \% \\
\text { (8 examples) }\end{array}$ & 10 & [82] \\
\hline 8 & \multirow{2}{*}{$\begin{array}{c}\text { Natural } \\
\text { phosphate }\end{array}$} & $\mathrm{Cu}(\mathrm{II}) / \mathrm{NP}$ & $\begin{array}{l}\text { Organic halide, } \\
\mathrm{NaN}_{3} \text {, aromatic } \\
\text { alkyne }\end{array}$ & $\begin{array}{l}50 \text { mg of catalyst; } \\
\text { MeOH; r.t. }\end{array}$ & $1-25 \min$ & $\begin{array}{c}95-99 \% \\
\text { (15 examples) }\end{array}$ & 6 & [83] \\
\hline 9 & & FBPs-CuBr & $\begin{array}{c}\text { Azide, amine, } \\
\text { propargyl bromide }\end{array}$ & $\begin{array}{c}5.5 \mathrm{mg} \text { of catalyst; } \\
\mathrm{H}_{2} \mathrm{O} ; \mathrm{MW}(400 \mathrm{~W}) \\
80^{\circ} \mathrm{C}\end{array}$ & $30 \mathrm{~min}$ & $\begin{array}{c}70-98 \% \\
\text { (9 examples) }\end{array}$ & 7 & [84] \\
\hline
\end{tabular}

* Abbreviations: $\mathrm{MMT}=$ montmorillonite, $\mathrm{NP}=$ natural phosphate, $\mathrm{ZSM}=$ zeolite socony mobil, FBPs = fish bone powders.

\section{Carbon Material-Supported Catalysts for CuAAC}

Carbon-based materials are characterized as having good stability, high electrical and thermal conductivities, low production cost, oxidation stability, and low density [85-88]. In addition to the generally required simple and highly efficient separation issue, these beneficial properties led to their use as support materials in heterogeneous CuAAC. Recently, our group reported the immobilization of copper(I) iodide on activated carbon materials from vegetable biomass through Argan nut shells (Cu-CANS), and the commercially available activated carbon material ( $\mathrm{Cu}-\mathrm{C})$ was also used for comparative purposes [89]. The $\mathrm{Cu}-\mathrm{CANS}$ and $\mathrm{Cu}-\mathrm{C}$ materials were prepared by impregnating the corresponding carbon materials with copper(I) iodide in acetonitrile. The presence of $\mathrm{CuI}$ on the carbon surface 
of the resulting materials was revealed using XRD patterns. The determination of copper loading in the prepared $\mathrm{Cu}$-carbon materials was investigated by using AAS analysis. In this way, 3.82 (Cu-CC) and $1.38 \mathrm{wt} \%$ of $\mathrm{Cu}(\mathrm{Cu}-\mathrm{CANS})$ were found. The Cu-CANS and $\mathrm{Cu}-\mathrm{C}$ catalysts exhibited moderate to excellent yields $(60-95 \%)$ in synthesizing the corresponding 1,4-disubstituted 1,2,3-triazoles via [2+3] azide-alkyne cycloaddition in water at room temperature within $6 \mathrm{~h}$ using $0.5 \mathrm{~mol} \%$ of catalyst. Furthermore, these Cu-carbon catalysts were reused ten successive times without any significant loss of activity.

Recently, Devi et al. prepared a $\mathrm{SO}_{3} \mathrm{Cu}$-carbon catalyst via the immobilization of $\mathrm{CuCl}_{2}$ on a glycerol-based $\mathrm{SO}_{3} \mathrm{H}$-carbon support. Mixed-valence $\mathrm{Cu}(\mathrm{I}) / \mathrm{Cu}(\mathrm{II})$ occurs in this catalyst with a copper loading of $3.32 \%$ being determined by $\mathrm{X}$-ray photoelectron spectroscopy (XPS) and industrial plasma optical emission (ICP-OES) analysis, respectively [90]. The obtained catalyst was used in a one-pot $\mathrm{CuAAC}$ reaction for the synthesis of $\beta$-hydroxy-1,2,3-triazoles in excellent yields (89-94\% in 2.5-4 h) using epoxide, sodium azide, and terminal alkyne in water at $60{ }^{\circ} \mathrm{C}$. Moreover, this catalyst was recycled for at least five cycles.

The use of carbon quantum dots (CQDs) as photoinitiators was also investigated in click chemistry through zigzag-structured $\mathrm{Cu}(\mathrm{I})$-doped CQDs for [3+2] cycloaddition between azides and alkynes by Zou et al. [91]. This $\mathrm{Cu}(\mathrm{I})-\mathrm{CQD}$ catalyst showed excellent activity in an $\mathrm{H}_{2} \mathrm{O} / \mathrm{EtOH}(1: 1 \mathrm{v} / \mathrm{v})$ solvent mixture under $11 \mathrm{~h}$ of irradiation with $365 \mathrm{~nm}$ of UV light in the absence of any reducing agent. Furthermore, the obtained results pointed to the fact that the prepared CQDs catalyst support may provide a new opportunity permitting copper(I) to exist in the stable $\mathrm{Cu}(\mathrm{I})$-CQDs catalyst, without decreasing the catalytic activity.

Graphene oxide (GO), a single two-dimensional (2D) layer of carbon atoms, has also been extensively tested in the heterogeneous catalysis of transition metals due to its high surface area and efficient adsorption capacity [92-96]. However, only a limited number of reports are known because of the metal-leaching problems resulting from its weak chelation capacity toward metals. To overcome these problems, research attempts were carried out on GO functionalization. Two strategies were used: (i) the covalent functionalization of the intercalant via coupling on the terminal acid moieties or the opening of epoxides or chemical conjugation on the secondary $\mathrm{OH}$ moieties [97-100]; and (ii) noncovalent interactions on the surface of GO via van der Waals interactions using aromatic substrates [101-104]. Pourjavadi et al. [105] reported a cross-linked poly(vinyl imidazole) matrix (Pim) on GO as a support for copper(II) salts by complexation with the imidazole rings in the chains. The loading amount of copper ions in the resulting GO/Pim/Cu material was $2.10 \mathrm{mmol} / \mathrm{g}$, calculated by atomic absorption spectroscopy (AAS). This catalyst was used for the regioselective synthesis of 1,2,3-triazole derivatives through a one-pot cycloaddition of halides, terminal alkynes, and sodium azide in a water medium. Good to excellent yields of the products $(80-96 \%$ in $0.5-3.5 \mathrm{~h})$ were obtained using $1 \mathrm{~mol} \%$ of catalyst at $50{ }^{\circ} \mathrm{C}$ in the presence of sodium ascorbate as a reducing agent. Further, the GO/Pim/Cu catalyst was recovered in up to eight runs without any significant loss of activity. Naeimi et al. functionalized GO via different copper complexes for click chemistry (Scheme 10) [106-110]. In 2016, GO was functionalized by 1,7-heptandiamine and isotonic anhydride through a reaction of carboxylic groups on the GO surface with amino groups, and the obtained catalyst (26) was treated with CuI (Scheme 10) [106-108]. Catalyst 26 was investigated in a one-pot cycloaddition reaction of alkyl halides and sodium azide with terminal alkynes in $\mathrm{H}_{2} \mathrm{O} / \mathrm{EtOH}(1: 1 \mathrm{v} / \mathrm{v})$ under different environmental conditions. The desired products were achieved in all cases with good to excellent yields. Furthermore, the recyclability of the catalyst $\mathbf{2 6}$ was tested and the results indicate that it can be reused several times without any significant deactivation. In 2017, the same group reported a preparation of GO-supported copper catalyst, containing poly-1,2,3-triazoles (PTA) as $\mathrm{Cu}$ (I)-stabilizing ligands for the construction of $\beta$-hydroxy-1,2,3-triazoles (Scheme 10) $[109,110]$. The prepared GO@PTA-Cu catalyst (27) was investigated in one-pot three-component reactions between epoxides, terminal alkynes, and sodium azide in water using $0.017 \mathrm{~mol} \%$ of the catalyst under microwave and thermal conditions, affording the triazole products in excellent 
yields. Moreover, the catalyst 27 was able to be reused five times without any loss of its catalytic activity.

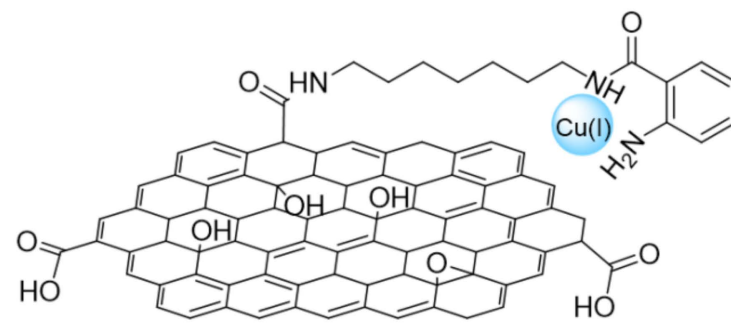

26
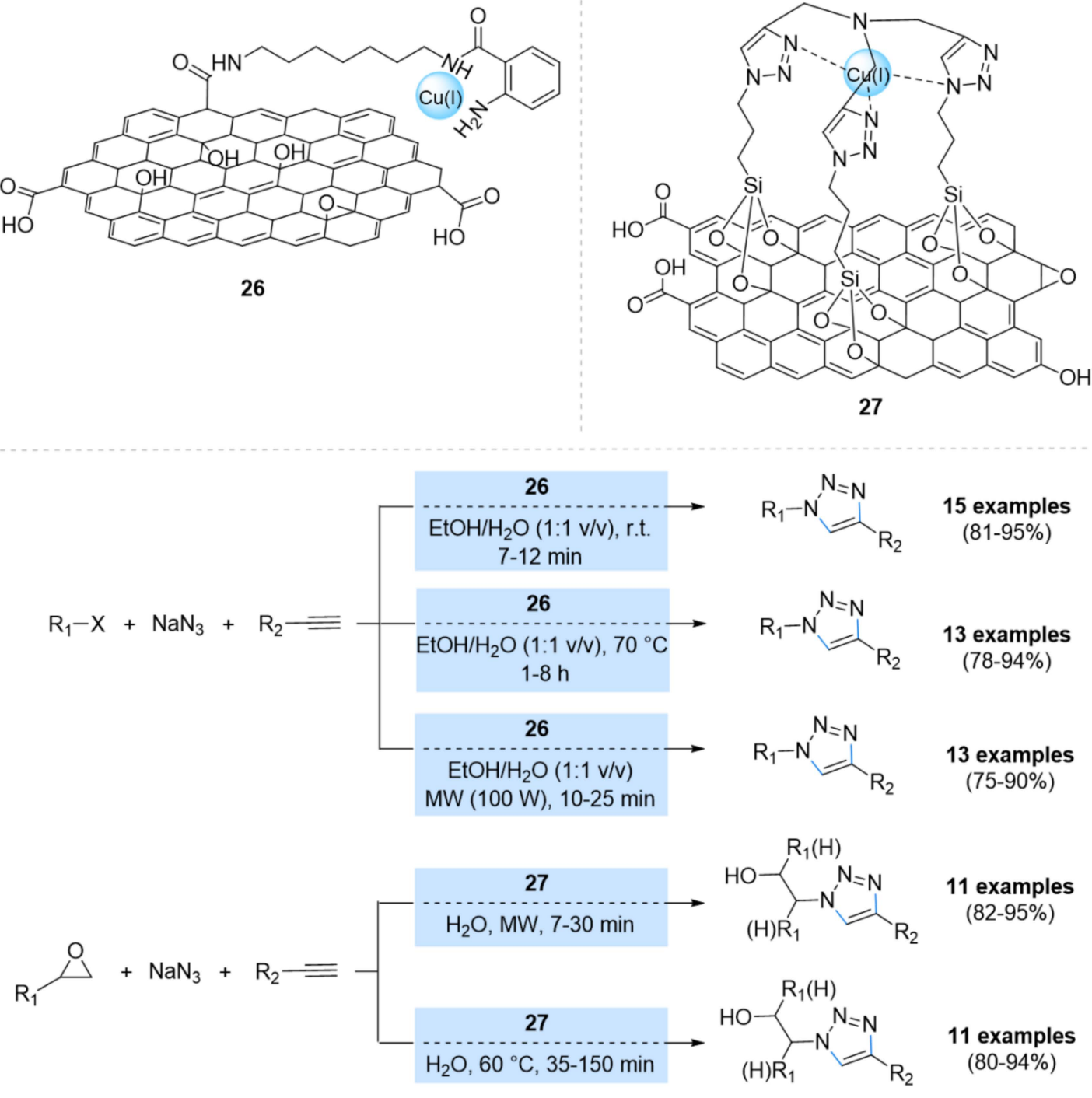

Scheme 10. Chemical structure of the catalysts 26 and 27 and their catalytic applications in multicomponent $\mathrm{CuAAC}$ reactions.

Recently, a new covalently cross-linked graphene oxide material (GO-CuPPh) was prepared via a cross-linking process using carboxyl groups at the surface of GO with the nucleophilic reaction of copper(II) coordinated by 5,10,15,20-tetrakis(aminophenyl)porphyrin (CuPPh) (Khojastehnezhad et al. [111] (28), Scheme 11). FT-IR analysis successfully confirmed the covalent linkage of the porphyrin on GO. The amount of copper in the final catalyst was studied using the inductively coupled plasma (ICP) technique, ensuring the successful insertion of copper into the PPh ring with $6.012 \mathrm{wt} \%$ of $\mathrm{Cu}$. The catalyst 28 was then tested for the synthesis of 1,4-disubstituted 1,2,3-triazole derivatives via the reaction of aryl azides and terminal alkynes in a $\mathrm{H}_{2} \mathrm{O} / \mathrm{EtOH}$ solvent mixture under ultrasonic irradiation at $60{ }^{\circ} \mathrm{C}$ with good to excellent yield (88-96\% in 5-30 min). In addition, the GO-CuPPh catalyst was able to be reused five times. In a similar approach, Dabiri et al. [112] performed the synthesis of a supported $\mathrm{N}$-heterocyclic carbene-copper complex covalently anchored onto graphene oxide (NHC-Cu/GO-IL) through the silylation of GO with the ionic liquid (IL) and, subsequently, the formation of NHC-Cu across the reaction of GO-IL with copper iodide in the presence of tert-BuONa as a base. The as-prepared NHC-Cu/GO-IL com- 
posite showed excellent results for the synthesis of triazoles (89-99\% yields) via reacting terminal alkynes and aryl azides in $\mathrm{a} \mathrm{H}_{2} \mathrm{O} / \mathrm{EtOH}(1: 1 \mathrm{v} / \mathrm{v})$ solvent mixture at $70{ }^{\circ} \mathrm{C}$, using $1 \mathrm{~mol} \%$ of catalyst, within one hour. In addition, no significant reduction in the catalytic activity of this catalyst was observed after ten successive reaction runs. Similarly, Binder et al. [113] immobilized $\mathrm{N}$-heterocyclic carbene (NHC)-Cu(I) complexes, prepared from an imidazolium(Ima)-based carbine, on a graphene nanoconjugate (CRGO-Ima-Cu(I)) (29) (Figure 8). The catalyst 29 showed excellent catalytic activity in CuAAC reactions (85-99\% yields) at $2 \mathrm{~mol} \%$ catalyst loading within $72 \mathrm{~h}$ at $40{ }^{\circ} \mathrm{C}$. It was also able to be reused for up to 10 cycles of click reactions without its decomposition.
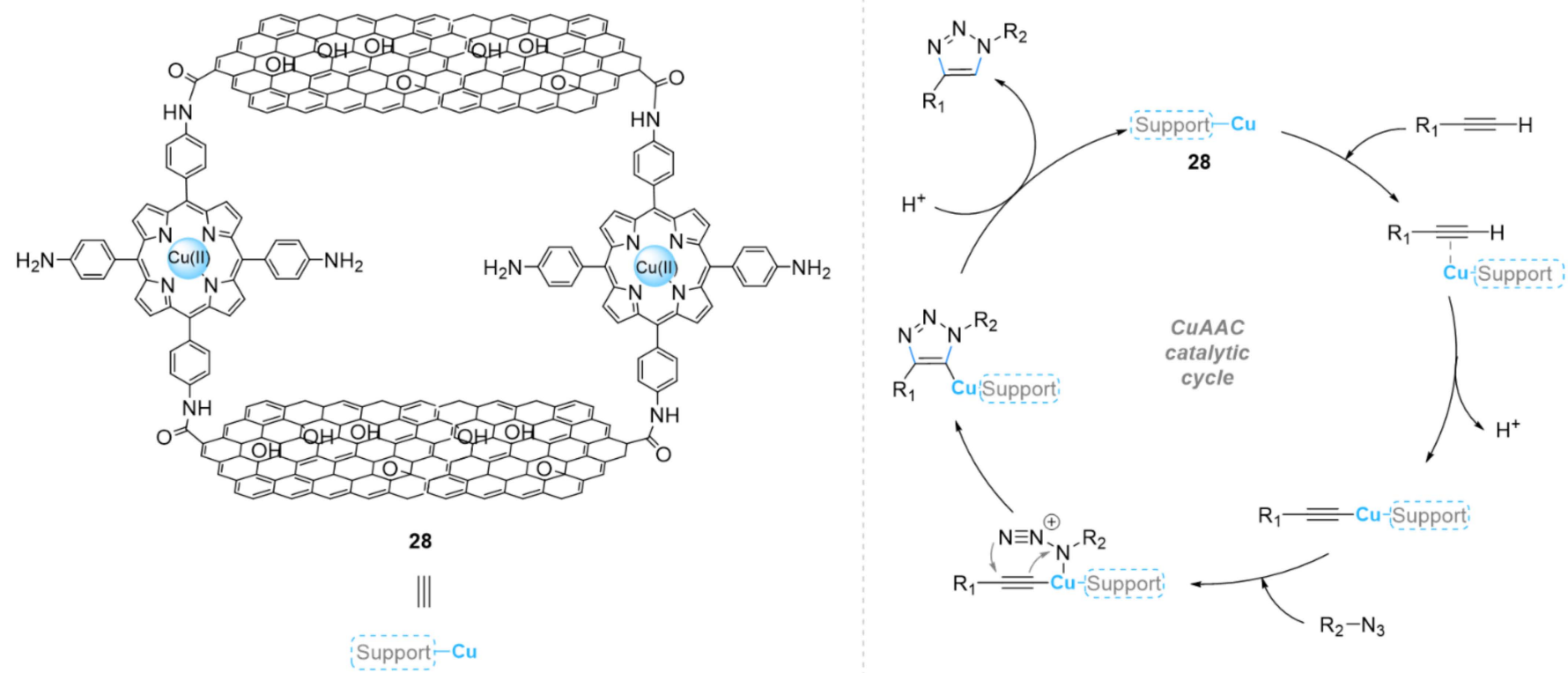

Scheme 11. Chemical structure of the catalyst 28 and its catalytic mechanism in the CuAAC reaction.

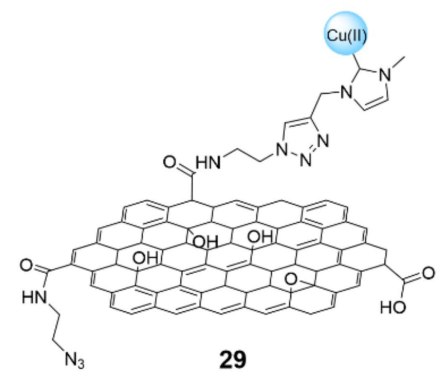

Figure 8. Chemical structure of the catalyst 29.

In 2018, Ma'mani et al. [114] reported the $\beta$-cyclodextrin functionalized polyethyleneglycol (PEG)ylated mesoporous silica nanoparticle-graphene oxide hybrid as a support for copper salt ( $\mathrm{Cu} @ \beta C D-P E G-m e s o G O)$. The as-prepared nanoparticles were then evaluated for a three-component click reaction of alkynes, benzyl bromides, and sodium azide in water at room temperature. Excellent yields for the synthesis of the corresponding 1,4-triazoles (82-91\% in 1-2 h) using $5 \mathrm{~mol} \%$ of catalyst were achieved. Moreover, $\mathrm{Cu} @ \beta C D$-PEG-mesoGO was recovered and recycled up to ten times without any significant decrease in its activity. More recently, Bhagavathsingh et al. [115] reported on the bis(2,2'-bipyridine)copper(II) complex supported on GO (GO@Cu(II)-(bpy) $\left.)_{2}\right)$ for the synthesis of 1,4-disubstituted 1,2,3-triazole derivatives. This catalyst was characterized by an XPS analysis that revealed the presence of copper(I) and copper(II) species in GO@Cu(II)- 
(bpy) $)_{2}$ with $3.4 \%$ of copper loading, as detected by inductively coupled plasma optical emission spectroscopy (ICP-OES). Next, the nanocomposites were employed for CuAAC reactions using the substrates of azides and acetylene in tert- $\mathrm{ButOH} / \mathrm{H}_{2} \mathrm{O}(2: 3 \mathrm{v} / \mathrm{v})$ at room temperature using sodium ascorbate as a reducing agent. The five click reactions showed excellent yields (80-91\%) within 60-80 min.

Reduced graphene oxide (r-GO) has also been used to support copper salts in the construction of click products. Navid Soltani Rad et al. reported the $\mathrm{Cu} /$ aminoclay $(\mathrm{AC}) /$ reduced graphene oxide nanohybrid $(\mathrm{Cu} / \mathrm{AC} / \mathrm{r}-\mathrm{GO}$ nanohybrid) (30) for the synthesis of $1 \mathrm{H}-1,2,3$-triazolyl carbocyclic nucleoside derivatives through $\mathrm{CuAAC}$ reactions between the synthesized $\mathrm{N}$-propargyl nucleobases and azido alcohols in a THF $/ \mathrm{H}_{2} \mathrm{O}$ (1:1 $\mathrm{v} / \mathrm{v}$ ) solvent mixture at room temperature using $\mathrm{K}_{2} \mathrm{CO}_{3}$ as a base (Figure 9) [116]. The catalyst 30 exhibited good to excellent results ( $80-94 \%$ yields in 3-12 h), and was also able to be reused for up to five consecutive runs without any significant loss of activity.

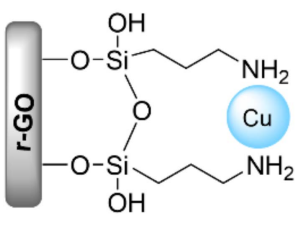

30

Figure 9. Chemical structure of the nanohybrid catalyst $\mathrm{Cu} / \mathrm{AC} / \mathrm{r}-\mathrm{GO}$ (30).

Recently, graphitic carbon nitride $\left(\mathrm{g}-\mathrm{C}_{3} \mathrm{~N}_{4}\right)$ has also attracted attention as an excellent support catalyst. This is due to abundant nitrogen functionalities on the surface sites that can act as strong Lewis base sites, while the $\mathrm{N}$-bonded planar layered configurations are utilized to anchor the desired metal, allowing its direct use as a heterogeneous catalyst in various reactions [117-124]. Therefore, Payra et al. [125] developed the g- $\mathrm{C}_{3} \mathrm{~N}_{4}$ supported copper chloride $\left(\mathrm{Cu} @ g-\mathrm{C}_{3} \mathrm{~N}_{4}\right)(31)$ material as a new heterogeneous catalyst for the one-pot $[3+2]$ cycloaddition (Scheme 12). The $\mathrm{Cu} @ g-\mathrm{C}_{3} \mathrm{~N}_{4}$ catalyst exhibited excellent activity in the regioselective preparation of 4-aryl-NH-1,2,3-triazole derivatives via 1,3-dipolar cycloaddition reactions of nitroolefins and sodium azide in water at ambient temperature (yield about $90-99 \%$ ) in a short reaction time ( $0.5 \mathrm{~h})$. Furthermore, the synthesized copper catalyst was reused for ten consecutive cycles, and only a minimal leaching $(0.08 \%)$ was observed.
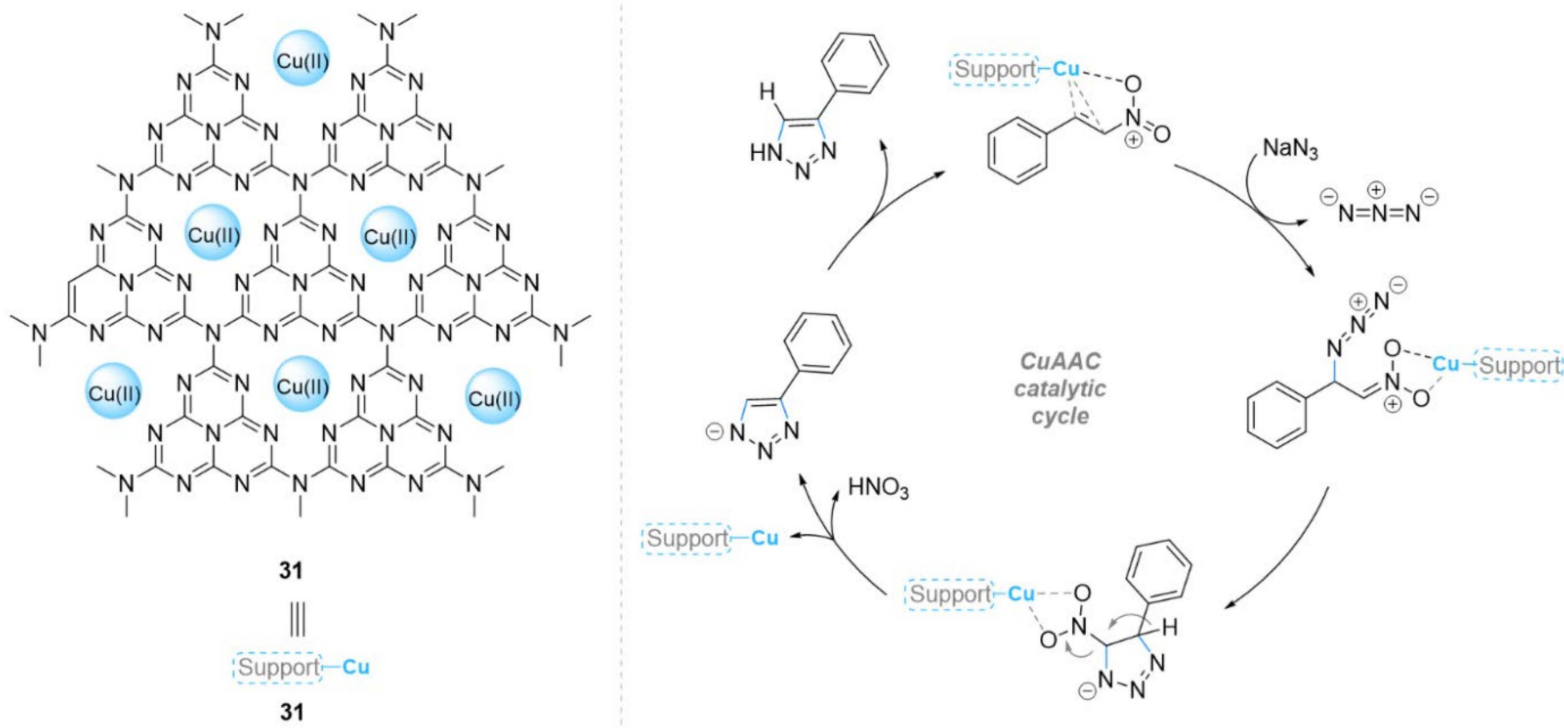

Scheme 12. Chemical structure of the catalyst 31 and its catalytic mechanism in the CuAAC reaction. 


\section{Magnetic Solid-Supported Catalysts for CuAAC}

The use of paramagnetic supports offers the opportunity for catalyst recovery by using a permanent external magnet. Indeed, this technique can be more advantageous than filtration or centrifugation, justifying the great interest in this approach over the last decade [126,127]. In this context, Hajipour et al. [128] used the $\mathrm{CuFeO}_{2}$ nanocatalyst with tetra- $n$-butylammonium bromide for a catalyzed azide-alkyne cycloaddition of phenylacetylene with aryl halides using water as a solvent at room temperature. Excellent yields were obtained (45-92\%) within 4 to $24 \mathrm{~h}$, and the catalyst was able to be recycled up to the fourth cycle. Saha et al. synthesized $\mathrm{CuFe}_{2} \mathrm{O}_{4}$ nanoparticles by both sonochemical and mechanochemical processes, and demonstrated that the sonochemical process was better for the uniformity of the sizes of the magnetic nanoparticles (MNPs) [129]. This magnetic $\mathrm{CuFe}_{2} \mathrm{O}_{4} \mathrm{NPs}$ species was used as a heterogeneous catalyst for three-component click reactions of alkyl halides, epoxides or boronic acids with sodium azide, and alkynes in water at $80^{\circ} \mathrm{C}$ to produce 1,4-disubstituted 1,2,3-triazole derivatives in moderate to excellent yields (55-95\%) from 2 to $4 \mathrm{~h}$. In addition, the reported catalyst was able to be reused for five runs without any significant yield decrease. More recently, Gupta et al. [130] reported on 1-butyl-4-methylpyridinium tetrafluoroborate-coated $\mathrm{CuFe}_{2} \mathrm{O}_{4}$ over L-tyrosine ( $L$-Tyr) functionalized titania nanospheres (IL@CuFe $\mathrm{O}_{4}-\mathrm{L}-\mathrm{Tyr}-\mathrm{TiO}_{2} / \mathrm{TiTCIL}$ ) (32) to reduce the aggregation of the nanoparticles in the solution and increase their activity (Figure 10). This magnetically separable nanocatalyst was utilized in a one-pot click reaction of organic bromides, sodium azide, and terminal alkynes. The corresponding products were obtained in good yields (52-95\% in 4-10 $\mathrm{min}$ ) in water at $40^{\circ} \mathrm{C}$. Further, the catalyst showed recyclability for up to seven runs. Eisavi et al. coated $\mathrm{CoFe}_{2} \mathrm{O}_{4}$ with the $\mathrm{Cu}(\mathrm{OH})_{2}$ catalyst to reduce the self-aggregation [131]. The resulting $\mathrm{CoFe}_{2} \mathrm{O}_{4} / \mathrm{Cu}(\mathrm{OH})_{2}$ magnetic nanocatalyst was used in a one-pot synthesis of $\beta$-hydroxy-1,4-disubstituted 1,2,3-triazole derivatives from aryl or alkyl epoxides, sodium azide, and terminal alkynes in water at $60^{\circ} \mathrm{C}$, with all the reactions being carried out efficiently within 3-6.5 $\mathrm{h}$ to give the resulting 1,2,3-triazoles in good yields (75-95\%). Furthermore, the catalyst was able to be reused seven times.

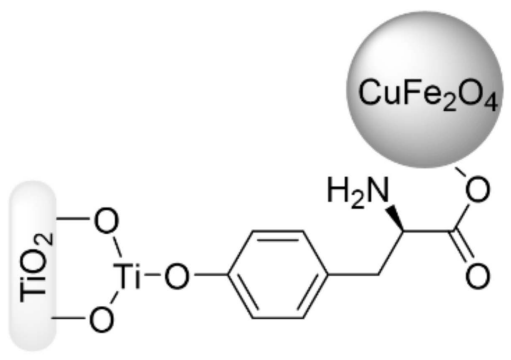

32

Figure 10. Chemical structure of the catalyst IL@CuFe $\mathrm{O}_{4}$-L-Tyr-TiO $2 / \mathrm{TiTCIL}$ (32).

In a related approach, many investigations explored the coating of nano-ferrites with a functionalized shell to reduce the aggregation of the nanoparticles in the solution and improve the catalyst's efficiency by increasing the number of functional groups on the surface. Among these, Moghaddam et al. [132] reported the immobilization of glucose (GLU) onto MNPs of $\mathrm{Fe}_{3} \mathrm{O}_{4}$-silica to stabilize copper(II), and studied their catalytic activity under greener conditions for the one-pot [3+2] cycloaddition reaction of alkyl halides, sodium azide, and alkynes using water as solvent (Figure 11). The use of $5 \mathrm{~mol} \%$ of (MNPs@GLU)Cl (33) catalyst produced excellent yields (76-99\% in 1-8 h) in the synthesis of various 1,4-triazole derivatives at $50^{\circ} \mathrm{C}$, due to the high dispersity of the catalyst in water by creating hydrogen bonds with the glucose. Furthermore, the catalyst 33 was able to be recycled and reused for up to seven runs. Jafari et al. reported on the copper(II) acetate/2aminobenthiol complex $\left(\mathrm{Cu}(\mathrm{OAc})_{2}-\mathrm{ABT}\right)$ immobilized on nanoparticles of magnetite-silica $\left(\mathrm{Fe}_{3} \mathrm{O}_{4} @ \mathrm{SiO}_{2} / \mathrm{ABT}-\mathrm{Cu}(\mathrm{OAc})_{2}\right)(34)$. It catalyzed the synthesis of 1,2,3-triazoles via a three- 
component click reaction of terminal alkynes, alkyl or benzyl halides, and sodium azide in a $\mathrm{PEG}_{400} / \mathrm{H}_{2} \mathrm{O}(9: 1 \mathrm{v} / \mathrm{v})$ solvent mixture at room temperature (Figure 11) [133]. The related products were obtained in excellent yields (85-95\%) within 10 to $30 \mathrm{~min}$. In addition, $\mathrm{Fe}_{3} \mathrm{O}_{4} @ \mathrm{SiO}_{2} / \mathrm{ABT}-\mathrm{Cu}(\mathrm{OAc})_{2}$ (34) was able to be reused for five cycles. Pore et al. described a novel magnetic silica functionalized by 3-aminopropyltriethoxysilane (am), then by acetyl pyridine (ACP), followed by copper coating $\left(\mathrm{CuACP}-\mathrm{Am}-\mathrm{Fe}_{3} \mathrm{O}_{4} @ \mathrm{SiO}_{2}\right)$ (35) as a catalyst for the one-pot three-component cycloaddition reactions of alkyl or aryl halides, sodium azide, and terminal alkynes in ethanol at $80{ }^{\circ} \mathrm{C}$ (Figure 11) [134]. The products were synthesized with excellent yields (82-95\% in 15-24 min) using sodium ascorbate as a reducing agent, and the catalyst 35 was able to be recycled six times. Khodabakhshi et al. [135] prepared an immobilized 2-(aminomethyl)benzimidazole-copper(II) complex on $\mathrm{Fe}_{3} \mathrm{O}_{4} @ \mathrm{SiO}_{2}$ nanoparticles to catalyze two different click reactions (Scheme 13). This $\mathrm{Fe}_{3} \mathrm{O}_{4} @ \mathrm{SiO}_{2} @ \mathrm{AMBI} / \mathrm{Cu}(36)$ nanocatalyst effectively catalyzed the click reactions of terminal alkynes and sodium azide with aryl iodide or benzyl halide for the formation of 1,4-disubstituted 1,2,3-triazole derivatives in DMSO) $/ \mathrm{H}_{2} \mathrm{O}$ at $100{ }^{\circ} \mathrm{C}$ with good to high yields. Zirak et al. [136] prepared a copper(II) complex supported on $\mathrm{Fe}_{3} \mathrm{O}_{4} @ \mathrm{SiO}_{2}$ coreshell MNPs by refluxing a dispersion of $\mathrm{Fe}_{3} \mathrm{O}_{4} @ \mathrm{SiO}_{2}$ and 3-aminopropyltriethoxysilane (APTES) in hexane under $\mathrm{N}_{2}$, followed by the treatment of $\mathrm{Fe}_{3} \mathrm{O}_{4} @ \mathrm{SiO}_{2}$-APTES MNPs with 2-cyanopyridine using sodium methoxide in methanol under reflux to give $\mathrm{Fe}_{3} \mathrm{O}_{4} @ \mathrm{SiO}_{2}$ MNPs functionalized with picolinimidoamide $\left(\mathrm{Fe}_{3} \mathrm{O}_{4} @ \mathrm{SiO}_{2}-\mathrm{PIA}\right)$. This last species transformed into the desired picolinimidoamide-copper(II) complex anchored on $\mathrm{Fe}_{3} \mathrm{O}_{4} @ \mathrm{SiO}_{2}$ core-shell MNPs $\left(\mathrm{Fe}_{3} \mathrm{O}_{4} @ \mathrm{SiO}_{2}-\mathrm{PIA}-\mathrm{Cu}\right)$ (37) via complexation with $\mathrm{CuCl}_{2} \cdot 2 \mathrm{H}_{2} \mathrm{O}$ (Figure 12). The catalyst showed moderate to high yields (53-97\%) for the synthesis of 1,2,3-triazole compounds via a one-pot cycloaddition reaction of organic halides, sodium azide, and various alkynes at $70^{\circ} \mathrm{C}$ in water for $12 \mathrm{~h}$. Moreover, the recoverability of the catalyst was also investigated, and it showed good stability and reactivity for four runs. Mogaddam et al. reported a magnetic heterogeneous catalyst synthesized via the immobilization of copper ion onto the triazole-functionalized $\mathrm{Fe}_{3} \mathrm{O}_{4}$ nanoparticles (Figure 12) [137]. The resulting magnetic catalyst (38) was used with sodium ascorbate in the synthesis of 1,2,3-triazoles via a one-pot multicomponent reaction of terminal alkynes, alkyl halides, and sodium azides in a $\mathrm{H}_{2} \mathrm{O} /$ tert- $\mathrm{BuOH}(3: 1 \mathrm{v} / \mathrm{v})$ solvent mixture at $55^{\circ} \mathrm{C}$. The catalyst was able to catalyze the desired reactions with excellent yields (85-99\%) in 2-7 h, and it was able to be reused ten times. In 2016, the same team reported another MNP catalyst functionalized with $\alpha$-amidotriazole as a ligand for the immobilization of copper ions on MNPs (MNPs@APTA) $\mathrm{Cl}_{2}$ (39) (Figure 12) [138]. The prepared catalyst was investigated in a one-pot clicking reaction of alkyl halides, sodium azides, and terminal alkynes in water at $55^{\circ} \mathrm{C}$ using sodium ascorbate. The results showed that the corresponding 1,4-triazoles were achieved in excellent yields (82-98\% in 2-8 h). In addition, the catalyst 39 was able to be reused for ten reaction cycles. In 2017, the novel magnetic heterogeneous copper catalyst MNPs@8-AQ.CuCl 2 (40) was synthesized via the immobilization of copper(II) chloride onto 8-aminoquinoline (8-AQ)-functionalized magnetic MNPs@8-AQ (Figure 12) [139]. This prepared material showed high catalytic performance for the one-pot three-component synthesis of 1,4-disubstituted 1,2,3-triazole derivatives in the presence of sodium ascorbate and micellar medium at room temperature. The reaction proceeded well for various benzyl/alkyl halides and benzyl/alkyl acetylene, and the corresponding products were obtained in high yields (87-98\% in 90-150 min). Furthermore, the catalyst was able to be recycled and reused for up to five runs. Zahmatkesh et al. reported another magnetic catalyst, 1,4-dihydroxyanthraquinone- $\mathrm{Cu}(\mathrm{II})$ supported on magnetic $\mathrm{Fe}_{3} \mathrm{O}_{4} @ \mathrm{SiO}_{2}$, for the synthesis of 1-aryl-1,2,3-triazoles [140]. The 1,4-triazoles were isolated in excellent yields (85-97\%) through a clicking reaction of the corresponding alkyne, aryl boronic acid derivatives, and $\mathrm{NaN}_{3}$ using $0.5 \mathrm{~mol} \%$ of the catalyst in an $\mathrm{H}_{2} \mathrm{O} / \mathrm{MeCN}(1: 1 \mathrm{v} / \mathrm{v})$ solvent mixture at room temperature within $2.5-6 \mathrm{~h}$. In addition, this heterogeneous catalyst was able to be reused for six consecutive reaction cycles. 


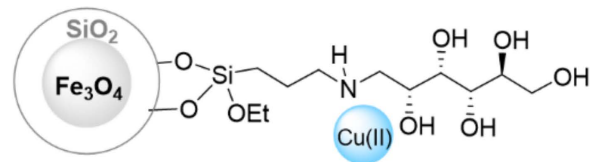

33

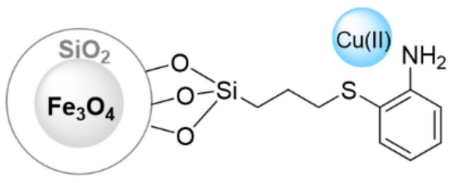

34

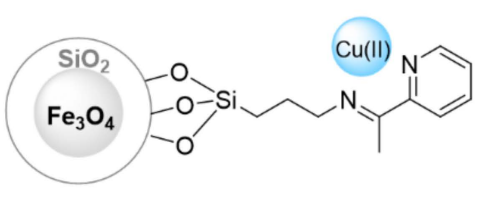

35

Figure 11. Chemical structure of the catalysts 33-35.

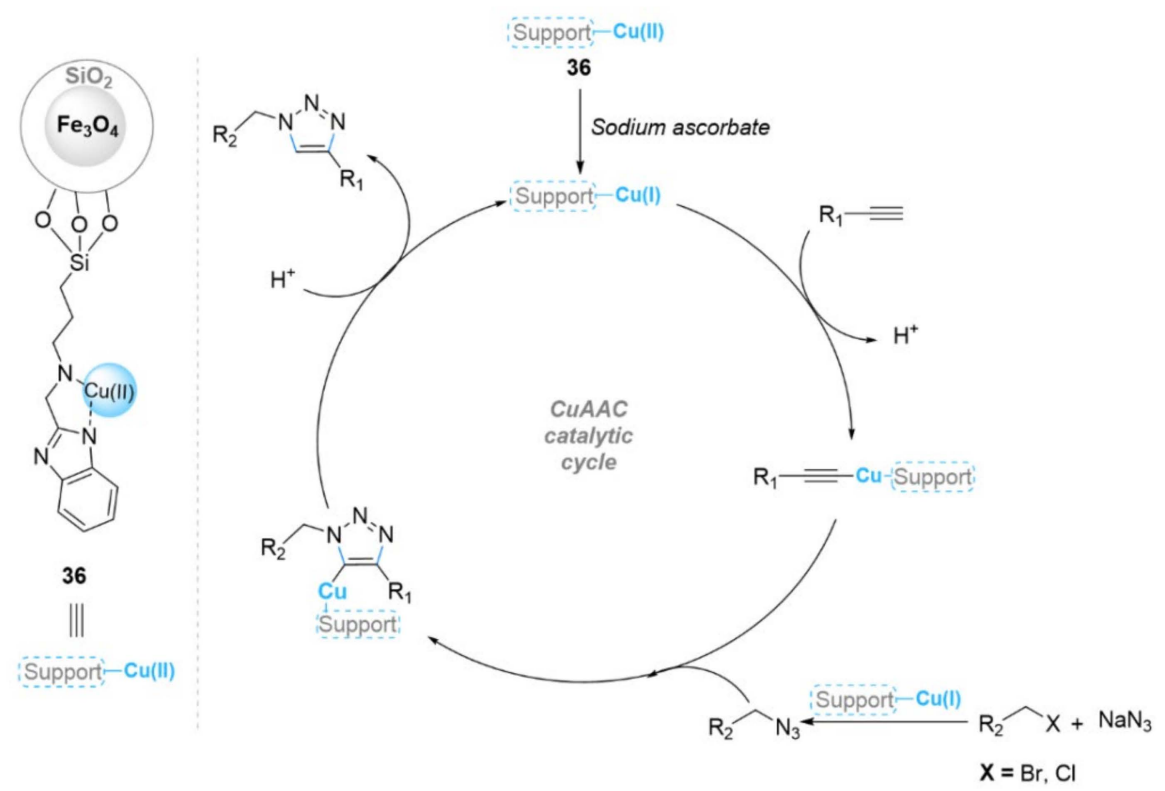

Scheme 13. Chemical structure of the catalyst 36 and its catalytic mechanism in the CuAAC reaction.

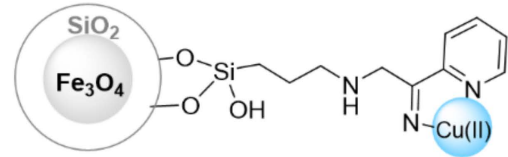

37

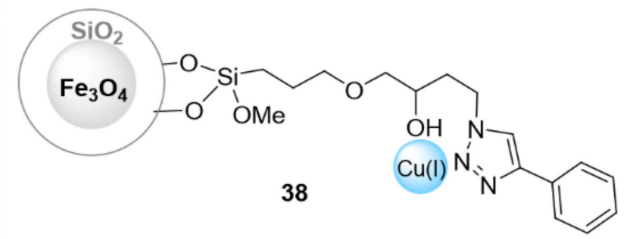

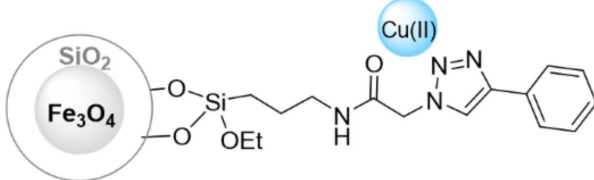

39

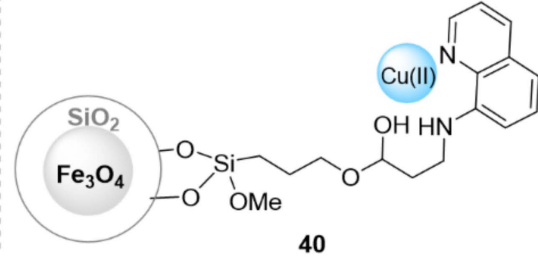

40

Figure 12. Chemical structure of the catalysts $\mathbf{3 7 - 4 0 .}$

In a similar approach, Esmaeilpour et al. synthesized a complex of copper(II) supported on superparamagnetic $\mathrm{Fe}_{3} \mathrm{O}_{4} @ \mathrm{SiO}_{4}$ nanoparticles for the synthesis of 1-aryl-1,2,3triazole derivatives via the clicking reaction of aryl boronic acid derivatives, alkyne, and sodium azide (Figure 13) [141]. The desired triazoles were obtained in excellent yields (86- 
$97 \%$ in $60-120 \mathrm{~min}$ ) in the presence of $2 \mathrm{~mol} \%$ of catalyst, and in water as a solvent at $60{ }^{\circ} \mathrm{C}$. The catalyst $\mathrm{Fe}_{3} \mathrm{O}_{4} @ \mathrm{SiO}_{4} /$ ligand/Cu(II) (41) was also able to be reused for subsequent reactions at least eight times. Zohreh et al. [142] reported a NNN-pincer-copper complex immobilized onto MNPs as a heterogeneous catalyst for click reactions (Figure 13). This magnetic catalyst was synthesized through functionalized MNPs via the covalent bonding of 2-aminopyridine to cyanuric chloride followed by complexation with $\mathrm{CuI}$. The finely synthesized catalyst MNP@NNN-pincer(Cu) (42) was employed in a one-pot click reaction in water, leading to excellent catalytic activity for the corresponding 1,4-triazoles at $80{ }^{\circ} \mathrm{C}$, and also at room temperature. Moreover, the nanocatalyst was able to be recycled at least eight times.

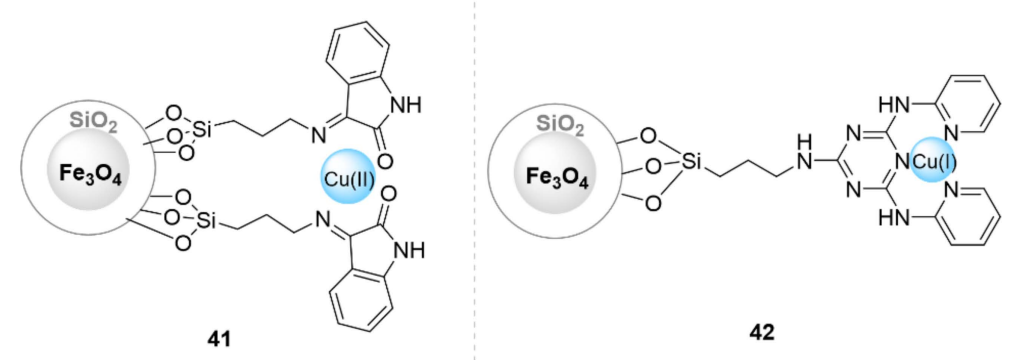

Figure 13. Chemical structure of the catalysts $\mathrm{Fe}_{3} \mathrm{O}_{4} @ \mathrm{SiO}_{4} /$ ligand/Cu(II) (41) and MNP@NNNpincer(Cu) (42).

Mohammadi et al. [143] reported two efficient $\mathrm{Cu}(\mathrm{I})$-nanomagnetic catalysts, namely $\mathrm{Fe}_{3} \mathrm{O}_{4} @ \mathrm{SiO}_{2} @ S c h i f f$ base- $\mathrm{Cu}(\mathrm{I})$ (43) and $\mathrm{Fe}_{3} \mathrm{O}_{4} @$ thiourea-Cu(I) (44), for the synthesis of 1,2,3-triazoles (Scheme 14). Both catalysts were tested in a one-pot three-compound reaction between $\mathrm{NaN}_{3}$, alkynes, and boronic acids or alkyl halides in a $\mathrm{H}_{2} \mathrm{O} / \mathrm{EtOH}$ solvent mixture at room temperature, and they showed excellent catalytic activity and recyclability up to five runs.

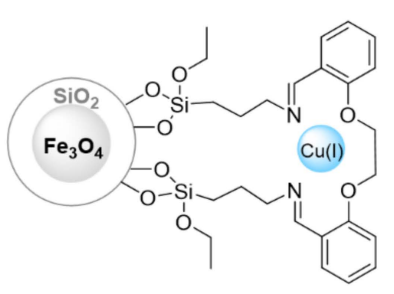

43

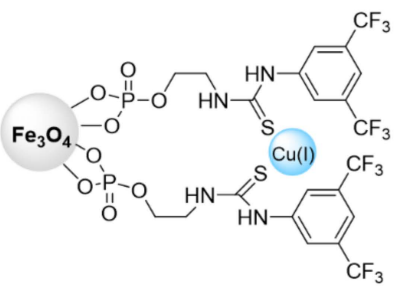

44

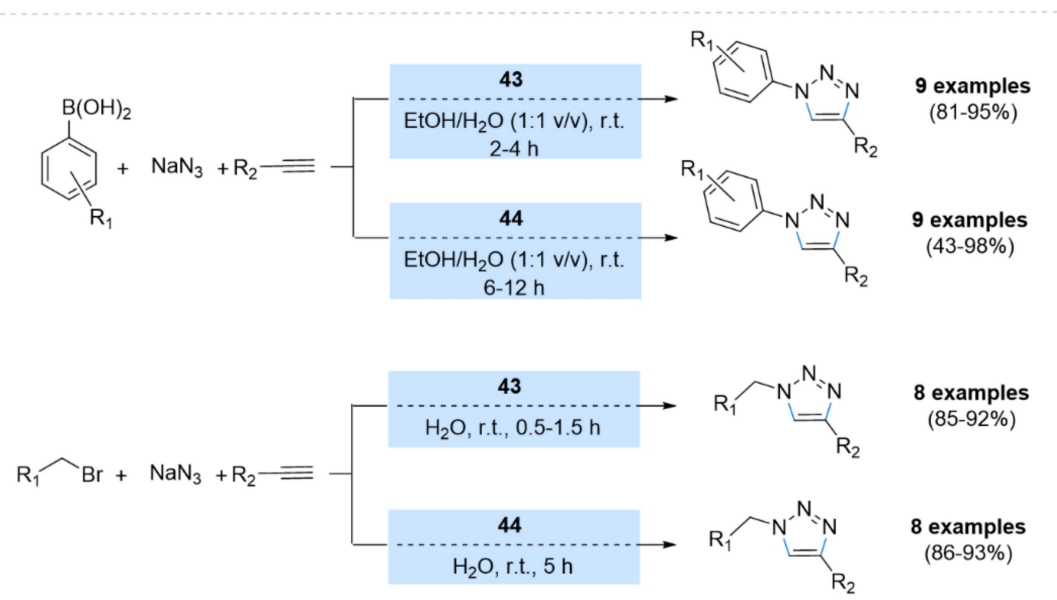

Scheme 14. Chemical structure and catalytic applications of the catalysts $\mathrm{Fe}_{3} \mathrm{O}_{4} @ \mathrm{SiO}_{2} @ S$ chiff base$\mathrm{Cu}(\mathrm{I})$ (43) and $\mathrm{Fe}_{3} \mathrm{O}_{4} @$ thiourea- $\mathrm{Cu}(\mathrm{I})(44)$ in multicomponent $\mathrm{CuAAC}$ reactions. 
Khodaei et al. reported a novel nanocatalyst that was synthesized via the immobilization of the $4^{\prime}$-(4-hydroxyphenyl)-2,2' $: 6^{\prime}, 2^{\prime \prime}$-terpyridine/CuI complex on MNPs through a surface modification (FMNPs@SiO $2-\mathrm{TPy}-\mathrm{Cu}$ ) (45) (Figure 14) [144]. The obtained nanocatalyst was employed for three-component syntheses of 1,4-disubstituted 1,2,3-triazoles from organic halides, sodium azide, and terminal alkynes in $\mathrm{a}_{2} \mathrm{O} / \mathrm{EtOH}(1: 1 \mathrm{v} / \mathrm{v})$ solvent mixture at room temperature. The resulting products were produced in excellent yields (83-97\% in 8-16 h), and the catalyst was able to be recycled for at least five runs. Tabakhsh et al. [145] functionalized nano-magnetite via 2,2'-biimidazole-containing $\mathrm{Cu}(\mathrm{I})$ and $\mathrm{Cu}(\mathrm{II})$ complexes for a catalyzed click reaction. The prepared nanocatalysts were then investigated for a one-pot synthesis of 1,4-disubstituted 1,2,3-triazoles through the click reaction of halides or tosylates, sodium azide, and terminal acetylenes in water as a solvent at room temperature. The obtained products were obtained in moderate to high yields (65-99\%) within 0.5 to $3.5 \mathrm{~h}$. Moreover, the catalyst was able to be easily recovered and reused for up to five consecutive runs.

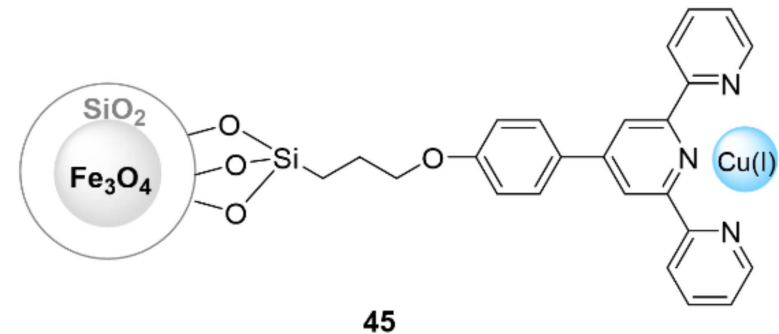

Figure 14. Chemical structure of the catalyst 45 .

Recently, N-heterocyclic carbenes (NHCs) as linking ligands between magnetic silica and a copper catalyst were also investigated. Misztalewska-Turkowiez et al. prepared a series of NHC-copper complexes immobilized on the surface of MNPs for catalyzed azide-alkyne cycloaddition reactions (46-49) (Scheme 15) [146]. Both supported complexes exhibited good activity in click reactions between the in situ-generated azides with terminal alkynes, but the copper(II) complexes exhibited better activity than those of copper(I). In addition, the catalysts were able to be reused three times.

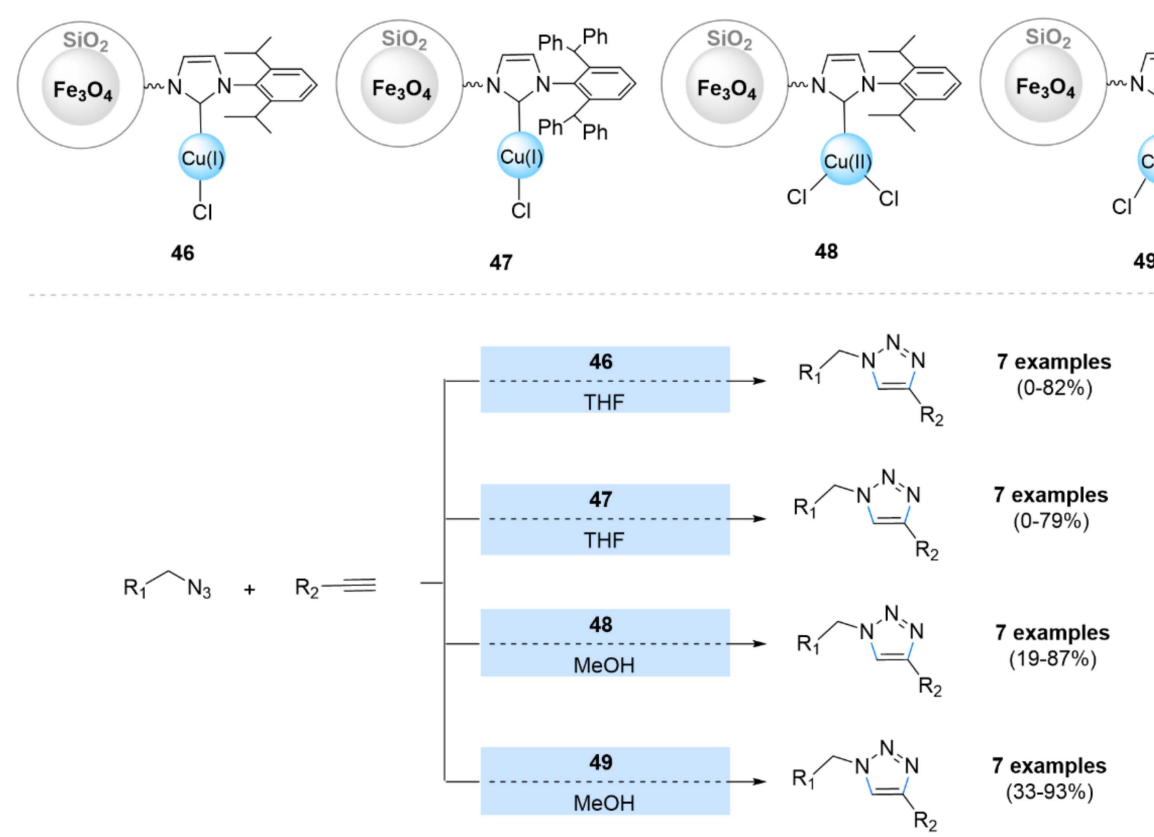

Scheme 15. Chemical structure and catalytic applications of the catalysts $46-49$ in multicomponent CuAAC reactions. 
In a similar approach, the use of $\beta$-cyclodextrin as a ligand in the anchoring of the copper catalyst to the magnetic silica was also investigated. Shafiee et al. [147] supported copper(I) chloride into $\beta$-cyclodextrin grafted superparamagnetic iron oxide nanoparticles (Cu@ $\beta$-CD@SPIONs]) (50) (Figure 15). This catalyst was reported to exhibit excellent catalytic activity (71-87\%) for obtaining 1-benzyl-1H-1,2,3- triazoldibenzodiazepinone derivatives via one-pot click reactions in a $\mathrm{EtOH} / \mathrm{H}_{2} \mathrm{O}(1: 1 \mathrm{v} / \mathrm{v})$ solvent mixture at room temperature within $24 \mathrm{~h}$, with the advantage of being able to be reused up to five times. Mahdavi et al. [148] also used the catalyst $\mathbf{5 0}$ for a one-pot synthesis of 1,2,3-triazolylquinazolinone derivatives from the reaction of 4-(prop-2-yn-1-yloxy)-benzaldehyde, benzyl azide, and 2-aminobenzamide (Figure 15). In this case, the catalyst $\mathbf{5 0}$ also exhibited excellent catalytic activity in constructing related products $(79-88 \%)$ in water as a solvent at room temperature within $24 \mathrm{~h}$. It was also able to be reused several times for at least ten cycles.

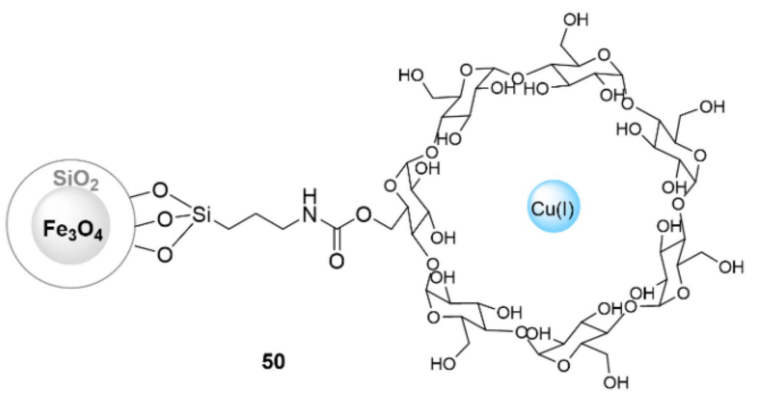

Figure 15. Chemical structure of $\mathrm{Cu} @ \beta-\mathrm{CD} @ S P I O N s$ (50).

More recently, Khoshneviszadeh et al. [149] reported copper(I) iodide supported on functionalized magnetic-silica core-shell [CuI $/ \mathrm{Fe}_{3} \mathrm{O}_{4} @ \mathrm{SiO}_{2}$ (TMS-EDTA)] (51) nanoparticles for a catalyzed azides-alkynes cycloaddition reaction (Scheme 16). This engineered nanocatalyst produced the corresponding triazole products in good to excellent yields that were also able to be reused up to five times.
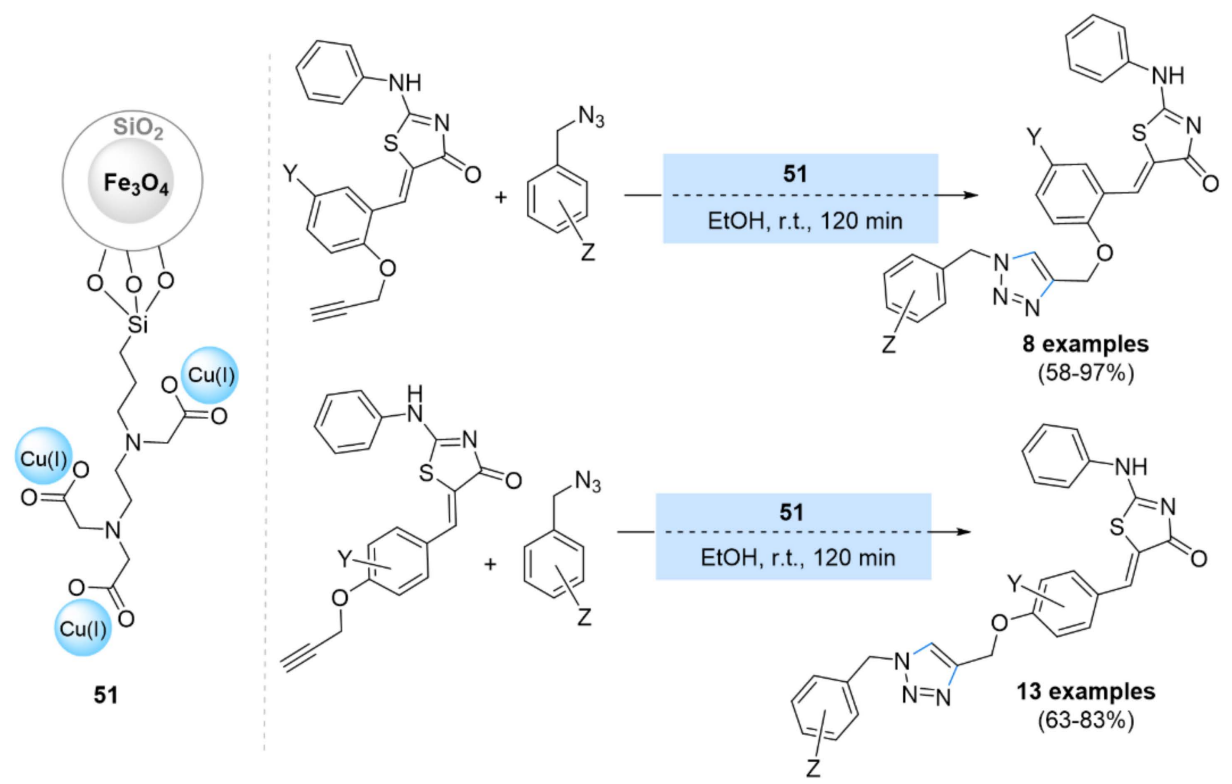

Scheme 16. Chemical structure and catalytic application of $\mathrm{CuI} / \mathrm{Fe}_{3} \mathrm{O}_{4} @ \mathrm{SiO}_{2}(\mathrm{TMS}-\mathrm{EDTA})$ (51) in $\mathrm{CuAAC}$ reactions. 
The immobilization of copper salts onto polymer-coated MNPs is one of the best ways to construct heterogeneous magnetic catalysts with high stability, high loading, and high activity. Several polymer-coated MNPs have been designed and used to support the immobilization of copper salts over the last few decades. Valizadeh et al. reported that MNPs functionalized with poly(4-vinylpyridine) immobilized copper(II) salts [150]. This material was used as a recoverable heterogeneous catalyst for a one-pot synthesis of 1,4-triazoles from terminal alkynes, alkyl halides, and sodium azide. An amount of $2 \mathrm{~mol} \%$ of this catalyst using sodium ascorbate revealed high yields $(73-98 \%)$ at $55^{\circ} \mathrm{C}$ in a $\mathrm{H}_{2} \mathrm{O} /$ tert$\mathrm{BuOH}(4: 1 \mathrm{v} / \mathrm{v})$ solvent mixture. In addition, this catalytic system was able to be separated and reused for at least nine cycles keeping its main activity. Bahrami et al. [151] immobilized copper(II) salts onto a ferromagnetic nanoparticle triazine dendrimer [FMNP@TD-Cu(II)] (52) (Figure 16). The nanoparticles of catalyst $\mathbf{5 2}$ were tested as heterogeneous catalysts in a one-pot reaction to prepare 1,4-disubstituted 1,2,3-triazole derivatives from terminal alkynes, organic halides, and sodium azide in the presence of $\mathrm{Na}_{2} \mathrm{CO}_{3}$ as a base and a EtOH$\mathrm{H}_{2} \mathrm{O}(1: 1 \mathrm{v} / \mathrm{v})$ solvent mixture at an ambient temperature. This catalytic system produced high yields of the corresponding products (90-99\%) within a short time (15-40 min), and it was also able to be reused several times up to six cycles keeping its main activity (99-93\%). Sardarian et al. [152] immobilized dendrimer-encapsulated copper(II) salts on $\mathrm{Fe}_{3} \mathrm{O}_{4} @ \mathrm{SiO}_{2}$ NPs (Scheme 17). This material (53) was used for the synthesis of regioselective 1,4disubstituted 1,2,3-triazole derivatives via a one-pot three-component reaction of alky halides, sodium azide, and terminal alkynes in excellent yields (70-95\% in 2-6 h) at room temperature in water as solvent. Furthermore, the catalyst 53 was able to be reused after eight consecutive recycles. More recently, Taheikal-Koshvandi et al. proposed a novel route to produce magnetic silica by synthesizing silicalite- 1 via a sol-gel process followed by a $\mathrm{Fe}_{3} \mathrm{O}_{4} /$ silicalite-1 nanocomposite, and finally $\mathrm{Fe}_{3} \mathrm{O}_{4} /$ silicalite-1/PVA/Cu(I) produced via an in situ process [153]. The obtained $\mathrm{Fe}_{3} \mathrm{O}_{4} /$ silicalite-1/PVA/Cu(I) composite was used in a three-component reaction. It showed excellent catalytic activity to yield the corresponding 1,2,3-triazoles from organic halides, sodium azide, and terminal alkynes in boiling water within 10 min (yield: 87-97\%). Moreover, the $\mathrm{Fe}_{3} \mathrm{O}_{4}$ / silicalite-1/PVA/Cu(I) catalyst was able to be recovered and directly reused for five runs with excellent activity up to $86 \%$.

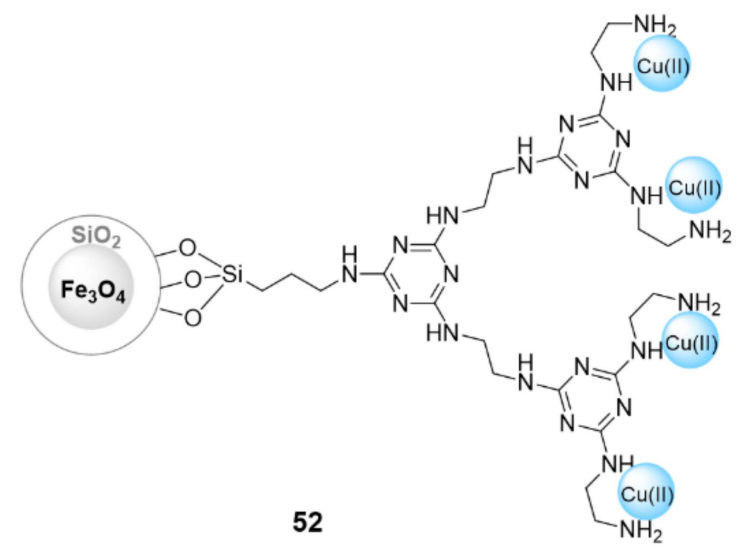

Figure 16. Chemical structure of the catalyst 52.

Magnetite nanoparticles coated by layered double hydroxides (LDH) instead of silica were also reported. Pazoki et al. [154] synthesized a copper(I)-cysteine complex immobilized on the surface of LDH-coated magnetite nanoparticles, $\mathrm{Fe}_{3} \mathrm{O}_{4} @ \mathrm{LDH} @$ cysteine-Cu(I) (54), as a novel recoverable nanocatalyst for the synthesis of 1,4-disubstituted 1,2,3-triazoles (Scheme 18). This LDH-based heterogeneous catalyst was able to effectively promote a one-pot reaction between organic halide derivatives, alkynes, and choline azide, both as a solvent and a reagent instead of using sodium azide to achieve the corresponding triazoles in excellent yields (80-97\%) at $75^{\circ} \mathrm{C}$. The magnetic catalyst 54 was able to be reused for up to five successive runs without any significant loss of high catalytic performance (90-86\%). 


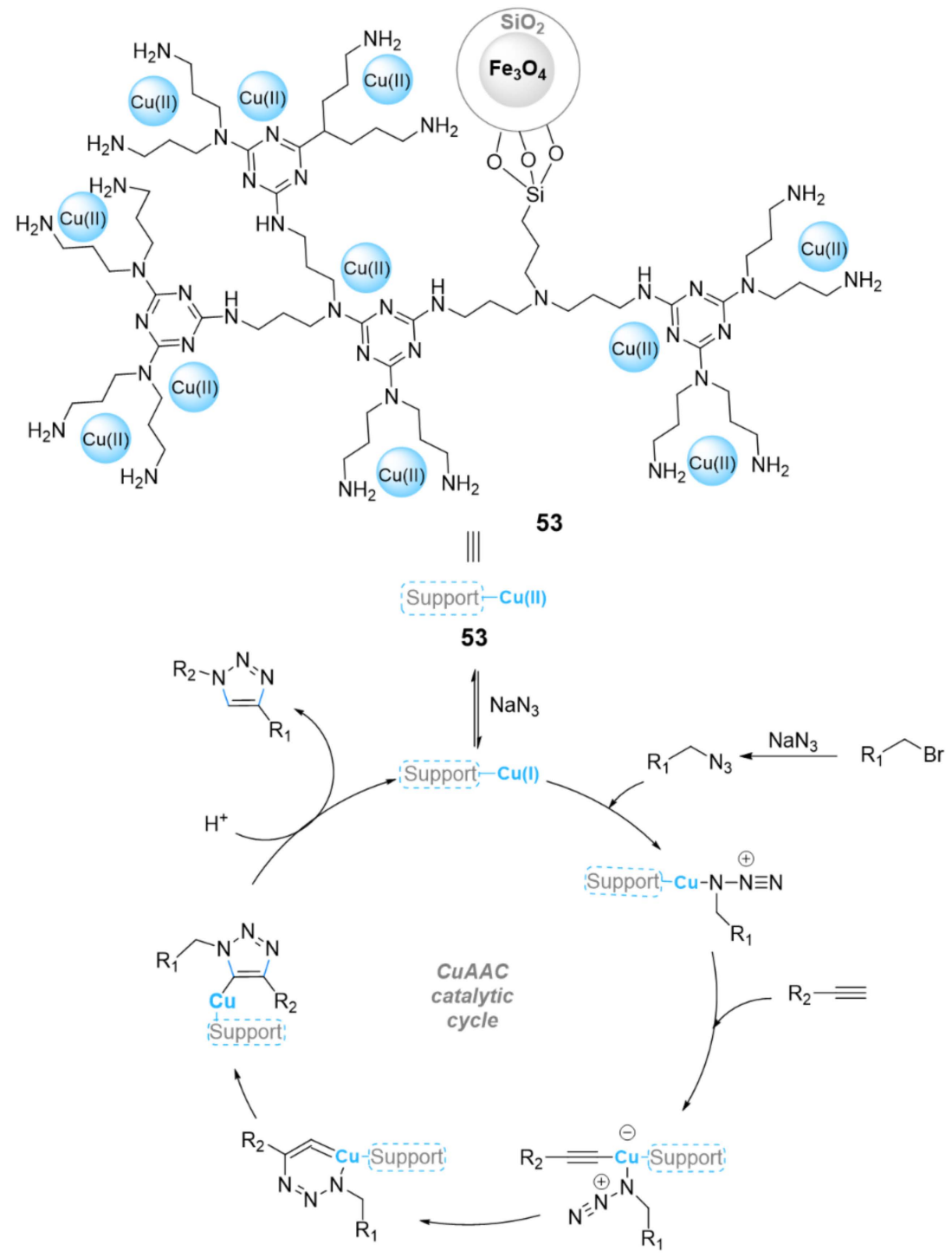

Scheme 17. Chemical structure of the catalyst 53 and its catalytic mechanism in the CuAAC reaction.

In recent years, the immobilization of MNPs on carbon materials, such as activated carbon and carbon nanotubes, has attracted great interest because it is a cheap and easily achieved process. In this context, catalysts based on magnetic carbon materials have also been studied as CuAAC catalyst supports. In this respect, Khalili et al. impregnated magnetic copper ferrite on mesoporous graphitic carbon nitride for the synthesis of the corresponding $\mathrm{CuFe} 2 \mathrm{O}_{4} / \mathrm{g}-\mathrm{C}_{3} \mathrm{~N}_{4}$ hybrids [155]. The magnetic nanocomposites showed excellent performance as heterogeneous catalysts in the one-pot azide-alkyne cycloaddition reaction between terminal alkynes and alkyl halides or epoxides azide precursors in water as a solvent at $80{ }^{\circ} \mathrm{C}$. Moreover, the $\mathrm{CuFe}_{2} \mathrm{O}_{4} / \mathrm{g}-\mathrm{C}_{3} \mathrm{~N}_{4}$ catalyst was able to be recovered and reused several times up to six catalytic cycles, with its main activity being retained (95-91\%). Moeinpour et al. [156] prepared graphene quantum dots (GQDs) modified $\mathrm{NiFe}_{2} \mathrm{O}_{4}$ and used them to stabilize copper(II) (Figure 17). The resulting $\mathrm{Cu}(\mathrm{II}) / \mathrm{GQDs} / \mathrm{NiFe}_{2} \mathrm{O}_{4}$ (55) nanomagnetic particles were used for the formation of 1,4-triazole derivatives via [3+2] azide-alkyne cycloaddition reactions in water as a solvent at $60{ }^{\circ} \mathrm{C}$, affording high yields (88-98\%) of the corresponding products in short reaction times (7-25 min). In addition, this catalyst was able to be reused in up to five consecutive cycles. In a similar approach, Rafiee et al. supported a mixed $\mathrm{Cu}(\mathrm{I}) / \mathrm{Cu}$ (II) catalyst on a magnetic cysteine functionalized graphene oxide [Cu $\left.\mathrm{Cu}^{\mathrm{I} / \mathrm{II}} / \mathrm{Cys}-\mathrm{MGO}\right]$ and used it for a one-pot synthesis of 1,4-diaryl-1,2,3triazoles [157]. The desired products were achieved in good to excellent yields (85-95\% 
in 110-300 $\mathrm{min})$ using $\mathrm{H}_{2} \mathrm{O} / \mathrm{EtOH}(1: 1 \mathrm{v} / \mathrm{v})$ as solvent mixture at $60{ }^{\circ} \mathrm{C}$. Furthermore, the $\mathrm{Cu}^{\mathrm{I} / \mathrm{II}} / \mathrm{Cys}-\mathrm{MGO}$ catalyst was able to be reused up to eight times. Shaabani et al. [158] reported a magnetic guanidine acetic acid (GAA)-functionalized multi-wall carbon nanotube (MWCNT) as a heterogeneous catalyst for click reactions (Figure 17). The catalytic activity of $\mathrm{Cu} / \mathrm{MWCNT}-\mathrm{GAA} @ \mathrm{Fe}_{3} \mathrm{O}_{4}(56)$ was investigated in azide-alkyne cycloaddition reactions in water as solvent at $50{ }^{\circ} \mathrm{C}$. The results showed a wide range of corresponding 1,2,3-triazoles, which were isolated in good to high yields (82-100\% in 1-10 h), and the catalyst 56 was able to be reused four times. Gravel et al. used a functionalized carbon nanotube-copper ferrite as a magnetic catalyst in a one-pot condensation reaction of organic halides, sodium azide, and terminal alkynes at room temperature, and in a $\mathrm{H}_{2} \mathrm{O} / \mathrm{EtOH}$ $(1: 1 \mathrm{v} / \mathrm{v})$ solvent mixture [159]. The triazole products were obtained in moderate to excellent yields (57-92\%) within $24 \mathrm{~h}$, and the catalyst was able to be reused for four catalytic cycles without any significant loss of its activity (90-87\%). Hamzehloueian et al. [160] reported the synthesis of a magnetic hybrid chitosan/graphene oxide composite as well as its complexation by copper(II) salts. This material was used as a heterogeneous catalyst for a one-pot synthesis of 1,2,3-triazoles from primary halides, sodium azide, and terminal alkynes using sodium ascorbate and $\mathrm{a}_{2} \mathrm{O} / \mathrm{EtOH}(1: 1 \mathrm{v} / \mathrm{v})$ solvent mixture at $50{ }^{\circ} \mathrm{C}$. The resulting products of the reactions were obtained in high yields (91-98\% in $0.25-2 \mathrm{~h}$ ) and the catalyst was able to be recovered and recycled for nine runs without any significant loss of its activity (98-95\%).

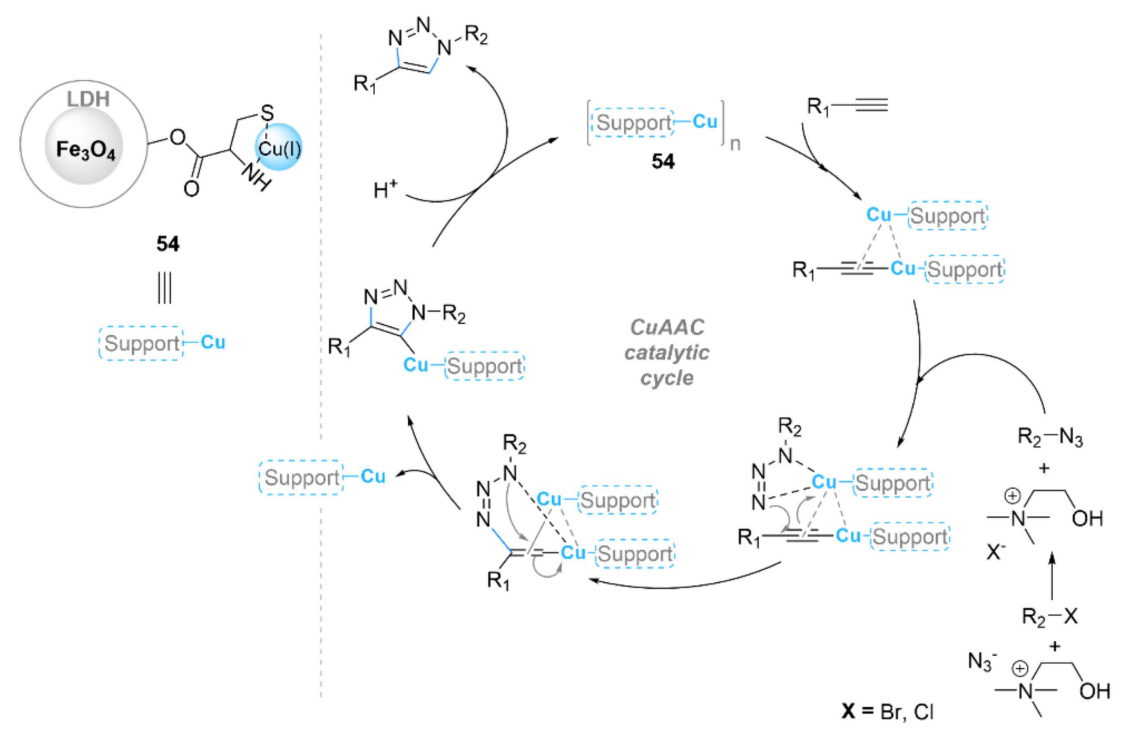

Scheme 18. Chemical structure of $\mathrm{Fe}_{3} \mathrm{O}_{4} @ \mathrm{LDH} @$ cysteine- $\mathrm{Cu}(\mathrm{I})(\mathbf{5 4})$ and its catalytic mechanism in the $\mathrm{CuAAC}$ reaction.
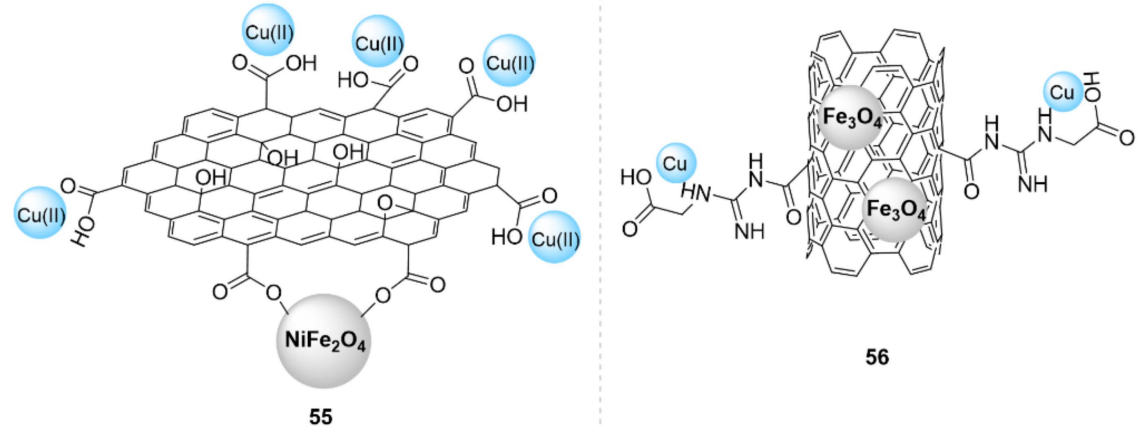

Figure 17. Chemical structure of the catalysts $\mathrm{Cu}(\mathrm{II}) / \mathrm{GQDs} / \mathrm{NiFe}_{2} \mathrm{O}_{4}$ (55) and $\mathrm{Cu} / \mathrm{MWCNT}$ GAA@ $\mathrm{Fe}_{3} \mathrm{O}_{4}$ (56). 


\section{Conclusions}

$\mathrm{CuAAC}$ is generally considered to be the most creative and successful click reaction leading to 1,4-disubstituted 1,2,3-triazoles in very high yields under mild conditions and with a dramatic rate acceleration. This strategy of making triazole linkers (which are considered more than just passive linkers) through carbon-nitrogen bond formation has also led to many interesting applications in drug discovery, bioconjugation applications, polymer chemistry, and synthesis of natural products. The heterogenization of CuAAC is an excellent strategy to take CuAAC into industrial processes. This tutorial review, as well as other recently published reviews [161], has discussed the prolific methods used to achieve such heterogenization of CuAAC by using the support of catalytically active copper(I) or its copper(II) or copper(0) precursors, which herein includes their immobilization on solid supports, including silica and related structures, carbon materials, and magnetic solids. These approaches have led to the production of efficient heterogeneous catalysts for the click reactions of a variety of functionalized triazoles, as summarized in the present review, under very mild conditions and easy recovery. Therefore, the development of new, cheap, and easily made heterogeneous catalytic systems that allow the performance of $\mathrm{CuAAC}$ reactions should take into consideration their use in water at room temperature and in the open air. This would make this excellent ligation process an easily accessible method for non-experts, such as biologists, and a more attractive strategy for the chemical industry manufacturing of pharmaceuticals and fine chemicals on a process scale, with respect to environmental regulations.

Author Contributions: Conceptualization, S.-E.S.; literature compilation, analysis and interpretation of data, N.A., H.B.E.A., L.B., M.J. and S.-E.S.; writing-original draft preparation, N.A., H.B.E.A., L.B., M.J. and S.-E.S.; writing-review and editing, N.A., H.B.E.A., L.B., H.A., M.J. and S.-E.S.; supervision, S.-E.S.; funding acquisition, M.J. and S.-E.S. All authors have read and agreed to the published version of the manuscript.

Funding: This research received no external funding support.

Institutional Review Board Statement: Not applicable.

Informed Consent Statement: Not applicable.

Data Availability Statement: Not applicable.

Conflicts of Interest: The authors declare no conflict of interest.

\section{References}

1. Kolb, H.C.; Finn, M.G.; Sharpless, K.B. Click chemistry: Diverse chemical function from a few good reactions. Angew. Chem. Int. Ed. 2001, 40, 2004-2021. [CrossRef]

2. Huisgen, R. 1,3-dipolar cycloadditions. Past and future. Angew. Chem. Int. Ed. Engl. 1963, 2, 565-598. [CrossRef]

3. Rostovtsev, V.V.; Green, L.G.; Fokin, V.V.; Sharpless, K.B. A Stepwise Huisgen Cycloaddition Process: Copper(I)-Catalyzed Regioselective "Ligation" of Azides and Terminal Alkynes. Angew. Chem. Int. Ed. 2002, 41, 2596-2599. [CrossRef]

4. Tornøe, C.W.; Christensen, C.; Meldal, M. Peptidotriazoles on solid phase: [1,2,3]-triazoles by regiospecific copper (I)-catalyzed 1,3-dipolar cycloadditions of terminal alkynes to azides. J. Org. Chem. 2002, 67, 3057-3064. [CrossRef]

5. Castro, V.; Rodríguez, H.; Albericio, F. CuAAC: An efficient click chemistry reaction on solid phase. ACS Comb. Sci. 2016, 18, 1-14. [CrossRef]

6. Delaittre, G.; Guimard, N.K.; Barner-Kowollik, C. Cycloadditions in modern polymer chemistry. Acc. Chem. Res. 2015, 48, 1296-1307. [CrossRef]

7. McNulty, J.; Keskar, K.; Vemula, R. The First Well-Defined Silver (I)-Complex-Catalyzed Cycloaddition of Azides onto Terminal Alkynes at Room Temperature. Chem. Eur. J. 2011, 17, 14727-14730. [CrossRef]

8. McNulty, J.; Keskar, K. Discovery of a robust and efficient homogeneous silver (I) catalyst for the cycloaddition of azides onto terminal alkynes. Eur. J. Org. Chem. 2012, 2012, 5462-5470. [CrossRef]

9. Zhang, L.; Chen, X.; Xue, P.; Sun, H.H.; Williams, I.D.; Sharpless, K.B.; Fokin, V.V.; Jia, G. Ruthenium-catalyzed cycloaddition of alkynes and organic azides. J. Am. Chem. Soc. 2005, 127, 15998-15999. [CrossRef]

10. Rasolofonjatovo, E.; Theeramunkong, S.; Bouriaud, A.; Kolodych, S.; Chaumontet, M.; Taran, F. Iridium-catalyzed cycloaddition of azides and 1-bromoalkynes at room temperature. Org. Lett. 2013, 15, 4698-4701. [CrossRef] 
11. Meng, X.; Xu, X.; Gao, T.; Chen, B. Zn/C-Catalyzed Cycloaddition of Azides and Aryl Alkynes. Eur. J. Org. Chem. 2010, 28, 5409-5414. [CrossRef]

12. Aher, N.G.; Pore, V.S.; Mishra, N.N.; Kumar, A.; Shukla, P.K.; Sharma, A.; Bhat, M.K. Synthesis and antifungal activity of 1,2,3-triazole containing fluconazole analogues. Bioorg. Med. Chem. Lett. 2009, 19, 759-763. [CrossRef] [PubMed]

13. Aly, M.R.E.S.; Saad, H.A.; Mohamed, M.A.M. Click reaction based synthesis, antimicrobial, and cytotoxic activities of new 1,2,3-triazoles. Bioorg. Med. Chem. Lett. 2015, 25, 2824-2830. [CrossRef] [PubMed]

14. Kharb, R.; Shahar Yar, M.; Sharma, P.C. New insights into chemistry and anti-infective potential of triazole scaffold. Curr. Med. Chem. 2011, 18, 3265-3297. [CrossRef] [PubMed]

15. Deng, Q.; Ding, N.N.; Wei, X.L.; Cai, L.; He, X.P.; Long, Y.T.; Chen, G.-R.; Chen, K. Identification of diverse 1 2,3-triazole-connected benzyl glycoside-serine/threonine conjugates as potent corrosion inhibitors for mild steel in HCl. Corr. Sci. 2012, 64, 64-73. [CrossRef]

16. Smith, N.W.; Alonso, A.; Brown, C.M.; Dzyuba, S.V. Triazole-containing BODIPY dyes as novel fluorescent probes for soluble oligomers of amyloid A $\beta 1-42$ peptide. Biochem. Biophys. Res. Commun. 2010, 391, 1455-1458. [CrossRef]

17. Lau, Y.H.; Rutledge, P.J.; Watkinson, M.; Todd, M.H. Chemical sensors that incorporate click-derived triazoles. Chem. Soc. Rev. 2011, 40, 2848-2866. [CrossRef]

18. Ye, C.; Gard, G.L.; Winter, R.W.; Syvret, R.G.; Twamley, B.; Shreeve, J.N.M. Synthesis of pentafluorosulfanylpyrazole and pentafluorosulfanyl-1,2,3-triazole and their derivatives as energetic materials by click chemistry. Org. Lett. 2007, 9, 3841-3844 [CrossRef]

19. Xiong, H.; Seela, F. Stepwise "click" chemistry for the template independent construction of a broad variety of cross-linked oligonucleotides: Influence of linker length, position, and linking number on DNA duplex stability. J. Org. Chem. 2011, 76, 5584-5597. [CrossRef]

20. Holla, B.S.; Mahalinga, M.; Karthikeyan, M.S.; Poojary, B.; Akberali, P.M.; Kumari, N.S. Synthesis, characterization and antimicrobial activity of some substituted 1,2,3-triazoles. Eur. J. Med. Chem. 2005, 40, 1173-1178. [CrossRef]

21. Lazrek, H.B.; Taourirte, M.; Oulih, T.; Barascut, J.L.; Imbach, J.L.; Pannecouque, C.; Witrouw, M.; De Clercq, E. Synthesis and anti-HIV activity of new modified 1,2,3-triazole acyclonucleosides. Nucleos. Nucleot. Nucleic Acids 2001, 20, 1949-1960. [CrossRef] [PubMed]

22. Hay, A.S. Oxidative coupling of acetylenes. J. Org. Chem. 1962, 27, 3320-3321. [CrossRef]

23. Meldal, M.; Tornøe, C.W. Cu-catalyzed azide-alkyne cycloaddition. Chem. Rev. 2008, 108, 2952-3015. [CrossRef]

24. Bhunia, S.; Pawar, G.G.; Kumar, S.V.; Jiang, Y.; Ma, D. Selected Copper-Based Reactions for C-N, C-O, C-S, and C-C Bond Formation. Angew. Chem. Int. Ed. 2017, 56, 16136-16179. [CrossRef]

25. Chassaing, S.; Bénéteau, V.; Pale, P. When CuAAC 'click chemistry' goes heterogeneous. Catal. Sci. Tech. 2016, 6, 923-957. [CrossRef]

26. Neto, J.S.; Zeni, G. A decade of advances in the reaction of nitrogen sources and alkynes for the synthesis of triazoles. Coor. Chem. Rev. 2020, 409, 213217. [CrossRef]

27. Tăbăcaru, A.; Furdui, B.; Ghinea, I.O.; Carac, G.; Dinică, R.M. Recent advances in click chemistry reactions mediated by transition metal based systems. Inor. Chim. Acta 2017, 455, 329-349. [CrossRef]

28. Haldón, E.; Nicasio, M.C.; Pérez, P.J. Copper-catalysed azide-alkyne cycloadditions (CuAAC): An update. Org. Biomol. Chem. 2015, 13, 9528-9550. [CrossRef]

29. Shiri, P.; Aboonajmi, J. A systematic review on silica-, carbon-, and magnetic materials-supported copper species as efficient heterogeneous nanocatalysts in "click" reactions. Beilstein J. Org. Chem. 2020, 16, 551-586. [CrossRef]

30. Singh, M.S.; Chowdhury, S.; Koley, S. Progress in 1,3-dipolar cycloadditions in the recent decade: An update to strategic development towards the arsenal of organic synthesis. Tetrahedron 2016, 13, 1603-1644. [CrossRef]

31. Buckley, B.R.; Heaney, H. Mechanistic investigations of copper (I)-catalyzed alkyne-azide cycloaddition reactions. In Click Triazoles; Springer: Berlin/Heidelberg, Germany, 2012; pp. 1-29.

32. Dervaux, B.; Du Prez, F.E. Heterogeneous azide-alkyne click chemistry: Towards metal-free end products. Chem. Sci. 2012, 3 , 959-966. [CrossRef]

33. Mandoli, A. Recent advances in recoverable systems for the copper-catalyzed azide-alkyne cycloaddition reaction (CuAAC). Molecules 2016, 21, 1174. [CrossRef] [PubMed]

34. Megia-Fernandez, A.; Ortega-Munoz, M.; Lopez-Jaramillo, J.; Hernandez-Mateo, F.; Santoyo-Gonzalez, F. Non-Magnetic and Magnetic Supported Copper (I) Chelating Adsorbents as Efficient Heterogeneous Catalysts and Copper Scavengers for Click Chemistry. Adv. Syn. Cat. 2010, 352, 3306-3320. [CrossRef]

35. Wang, C.; Ikhlef, D.; Kahlal, S.; Saillard, J.Y.; Astruc, D. Metal-catalyzed azide-alkyne "click" reactions: Mechanistic overview and recent trends. Coor. Chem. Rev. 2016, 316, 1-20. [CrossRef]

36. Alonso, F.; Moglie, Y.; Radivoy, G.; Yus, M. Copper nanoparticles in click chemistry: An alternative catalytic system for the cycloaddition of terminal alkynes and azides. Tetrahedron Lett. 2009, 50, 2358-2362. [CrossRef]

37. Jin, T.; Yan, M.; Yamamoto, Y. Click chemistry of alkyne-azide cycloaddition using nanostructured copper catalysts. ChemCatChem 2012, 4, 1217-1229. [CrossRef]

38. Alonso, F.; Moglie, Y.; Radivoy, G. Copper nanoparticles in click chemistry. Acc. Chem. Res. 2015, 48, 2516-2528. [CrossRef] 
39. Ramazani, A.; Asiabi, P.A.; Aghahosseini, H.; Gouranlou, F. Review on the synthesis and functionalization of $\mathrm{SiO}_{2}$ nanoparticles as solid supported catalysts. Curr. Org. Chem. 2017, 21, 908-922. [CrossRef]

40. Aflak, N.; Ben El Ayouchia, H.; Bahsis, L.; Anane, H.; Laamari, R.; Pascual-Alvarez, A.; Armentano, D.; Stiriba, S.E. Facile immobilization of copper(I) acetate on silica: A recyclable and reusable heterogeneous catalyst for azide-alkyne clickable cycloaddition reactions. Polyhedron 2019, 170, 630-638. [CrossRef]

41. Diz, P.; Pernas, P.; El Maatougui, A.; Tubio, C.R.; Azuaje, J.; Sotelo, E.; Guitián, F.; Gil, A.; Coelho, A. Sol-gel entrapped Cu in a silica matrix: An efficient heterogeneous nanocatalyst for Huisgen and Ullmann intramolecular coupling reactions. App. Cata. A Gen. 2015, 502, 86-95. [CrossRef]

42. Cook, A.W.; Jones, Z.R.; Wu, G.; Scott, S.L.; Hayton, T.W. An organometallic $\mathrm{Cu}_{20}$ nanocluster: Synthesis, characterization, immobilization on silica, and "Click" chemistry. J. Am. Chem. Soc. 2018, 140, 394-400. [CrossRef] [PubMed]

43. Zarenezhad, E.; Rad, M.N.S.; Behrouz, S.; Esmaielzadeh, S.; Farjam, M. Immobilized [Cu (cdsalMeen)] on silica gel: A highly efficient heterogeneous catalyst for 'Click'[3+2] Huisgen cycloaddition. J. Iran. Chem. Soc. 2017, 14, 509-519. [CrossRef]

44. Lim, M.; Lee, H.; Kang, M.; Yoo, W.; Rhee, H. Azide-alkyne cycloaddition reactions in water via recyclable heterogeneous Cu catalysts: Reverse phase silica gel and thermoresponsive hydrogels. RSC Adv. 2018, 8, 6152-6159. [CrossRef]

45. Bakherad, M.; Keivanloo, A.; Amin, A.H.; Ghmari, P. Silica-anchored Cu(I) aminothiophenol complex: An efficient heterogeneous catalyst for synthesis of 1,4-disubstituted 1,2,3-triazoles in water. Iran. J. Cat. 2018, 8, 179-187.

46. Emami, M.; Bikas, R.; Noshiranzadeh, N.; Kozakiewicz, A.; Lis, T. Cu(II)-Hydrazide Coordination Compound Supported on Silica Gel as an Efficient and Recyclable Heterogeneous Catalyst for Green Click Synthesis of $\beta$-Hydroxy-1,2,3-triazoles in water. ACS Omega 2020, 5, 13344-13357. [CrossRef]

47. Dehbanipour, Z.; Moghadam, M.; Tangestaninejad, S.; Mirkhani, V.; Mohammadpoor-Baltork, I. Copper(II) bis-thiazole complex immobilized on silica nanoparticles: Preparation, characterization and its application as a highly efficient catalyst for click synthesis of 1,2,3-triazoles. Polyhedron 2017, 138, 21-30. [CrossRef]

48. Soltani Rad, M.N.; Behrouz, S.; Mohammadtaghi-Nezhad, J.; Zarenezhad, E.; Agholi, M. Silica-tethered cuprous acetophenone thiosemicarbazone (STCATSC) as a novel hybrid nanocatalyst for highly efficient synthesis of new 1,2,3-triazolyl-based metronidazole hybrid analogues having potent antigiardial activity. Appl. Organometal. Chem. 2019, 33, e4799. [CrossRef]

49. Lai, B.; Huang, Z.; Jia, Z.; Bai, R.; Gu, Y. Silica-supported metal acetylacetonate catalysts with a robust and flexible linker constructed by using 2-butoxy-3,4-dihydropyrans as dual anchoring reagents and ligand donors. Cat. Sci. Tech. 2016, 6, 1810-1820. [CrossRef]

50. Díaz-Marta, A.S.; Tubío, C.R.; Carbajales, C.; Fernández, C.; Escalante, L.; Sotelo, E.; Guitián, F.; Barrio, V.L.; Gil, A.; Coelho, A. Three-dimensional printing in catalysis: Combining 3D heterogeneous copper and palladium catalysts for multicatalytic multicomponent reactions. ACS Catal. 2018, 8, 392-404. [CrossRef]

51. Hajipour, A.R.; Rafiee, F. Recent progress in ionic liquids and their applications in organic synthesis. Org. Prep. Proced. Interna. 2015, 47, 249-308. [CrossRef]

52. Yavir, K.; Marcinkowski, Ł.; Marcinkowska, R.; Namieśnik, J.; Kloskowski, A. Analytical applications and physicochemical properties of ionic liquid-based hybrid materials: A review. Anal. Chim. Acta 2019, 1054, 1-16. [CrossRef] [PubMed]

53. Zhang, X.; Geng, W.; Yue, C.; Wu, W.; Xiao, L. Multilayered supported ionic liquids bearing a carboxyl group: Highly efficient catalysts for chemical fixation of carbon dioxide. J. Environ. Chem. Eng. 2016, 4, 2565-2572. [CrossRef]

54. Buaki-Sogo, M.; Garcia, H.; Aprile, C. Imidazolium-based silica microreactors for the efficient conversion of carbon dioxide. Catal. Sci. Technol. 2015, 5, 1222-1230. [CrossRef]

55. Tavassoli, M.; Landarani-Isfahani, A.; Moghadam, M.; Tangestaninejad, S.; Mirkhani, V.; Mohammadpoor-Baltork, I. Copper dithiol complex supported on silica nanoparticles: A sustainable, efficient, and eco-friendly catalyst for multicomponent click reaction. ACS Sustain. Chem. Eng. 2016, 4, 1454-1462. [CrossRef]

56. Fehér, K.; Nagy, E.; Szabó, P.; Juzsakov, T.; Srankó, D.; Gömöry, Á.; Kollár, L.; Skoda-Földes, R. Heterogeneous azide-alkyne cycloaddition in the presence of a copper catalyst supported on an ionic liquid polymer/silica hybrid material. Appl. Organometal. Chem. 2018, 32, e4343. [CrossRef]

57. Khajehzadeh, M.; Moghadam, M.; Jamehbozorgi, S. Synthesis and characterization of a new poly (N-heterocyclic carbene Cu complex) immobilized on nano-silica,(CuII-NHCS) $\mathrm{N} @ \mathrm{NSIO}_{2}$, and its application as an efficient and reusable catalyst in the synthesis of benzimidazoles, benzothiazoles, 1,2,3-triazoles, bis-triazoles and sonogashira-hagihara reactions. Inorg. Chim. Acta 2019, 485, 173-189.

58. Calsolaro, F.; Martina, K.; Borfecchia, E.; Chávez-Rivas, F.; Cravotto, G.; Berlier, G. $\beta$-Cyclodextrin-Silica Hybrid: A Spatially Controllable Anchoring Strategy for $\mathrm{Cu}(\mathrm{II}) / \mathrm{Cu}(\mathrm{I})$ Complex Immobilization. Catalysts 2020, 10, 1118. [CrossRef]

59. Wang, Y.M.; Wu, Z.Y.; Zhu, J.H. Surface functionalization of SBA-15 by the solvent-free method. J. Solid State Chem. 2004, 177, 3815-3823. [CrossRef]

60. Jiao, L.; Regalbuto, J.R. The synthesis of highly dispersed noble and base metals on silica via strong electrostatic adsorption: II. Mesoporous silica SBA-15. J. Catal. 2008, 260, 342-350. [CrossRef]

61. Chmielarz, L.; Kuśtrowski, P.; Dziembaj, R.; Cool, P.; Vansant, E.F. Catalytic performance of various mesoporous silicas modified with copper or iron oxides introduced by different ways in the selective reduction of NO by ammonia. Appl. Catal. B 2006, 62, 369-380. [CrossRef] 
62. Pourhassan, F.; Eshghi, H. Novel hybrid thioamide ligand supported copper nanoparticles on SBA-15: A copper rich robust nanoreactor for green synthesis of triazoles and tetrazoles in water medium. Catal. Lett. 2019, 150, 1-14. [CrossRef]

63. Banan, A.; Nikbakht, F.; Ataie, S. SBA-15-supported Cu(II)/Schiff-base complex as an efficient and recyclable catalyst for one-pot azide-alkyne cycloaddition reaction. J. Porous Mater. 2019, 26, 1427-1433. [CrossRef]

64. Kakavand Ghalenoei, A.; Bakherad, M.; Keivanloo, A. SBA-15-supported-dithizone-copper (I): An efficient heterogeneous catalyst for synthesis of 1,4-disubstituted 1,2,3-triazoles in water. Iran. J. Catal. 2019, 9, 293-303.

65. Sun, N.; Yu, Z.; Yi, H.; Zhu, X.; Jin, L.; Hu, B.; Shen, Z.; Hu, X. Synthesis of a heterogeneous Cu(OAc) 2 -anchored SBA-15 catalyst and its application in the CuAAC reaction. New. J. Chem. 2018, 42, 1612-1616. [CrossRef]

66. Hosseini, H.G.; Doustkhah, E.; Kirillova, M.V.; Rostamnia, S.; Mahmoudi, G.; Kirillov, A.M. Combining ethylenediamine and ionic liquid functionalities within SBA-15: A promising catalytic pair for tandem Cu-AAC reaction. Appl. Catal. A 2017, 548, 96-102. [CrossRef]

67. Ojaghi Aghbash, K.; Noroozi Pesyan, N.; Batmani, H. Cu-Kojic Acid Complex Anchored to Functionalized Silica-MCM-41: A Promising Regioselective and Reusable Nanocatalyst for Click Reaction. ACS Omega 2020, 5, 22099-22108. [CrossRef]

68. Naeimi, H.; Nejadshafiee, V.; Masoum, S. Highly efficient copper-imprinted functionalized mesoporous organosilica nanocomposites as a recyclable catalyst for click synthesis of 1,2,3-triazole derivatives under ultrasound irradiation: Multivariate study by factorial design of experiments. RSC Adv. 2015, 5, 15006-15016. [CrossRef]

69. Naeimi, H.; Nejadshafiee, V.; Masoum, S. Copper@PMO nanocomposites as a novel reusable heterogeneous catalyst for microwave-assisted green synthesis of $\beta$-hydroxy-1,2,3-triazoles through experimental design protocol. Appl. Organometal. Chem. 2015, 29, 314-321. [CrossRef]

70. Mirsafaei, R.; Heravi, M.M.; Ahmadi, S.; Moslemin, M.H.; Hosseinnejad, T. In situ prepared copper nanoparticles on modified KIT-5 as an efficient recyclable catalyst and its applications in click reactions in water. J. Mol. Catal. A 2015, 402, 100-108. [CrossRef]

71. Yang, R.; Gao, Y.; Wang, J.; Wang, Q. Layered double hydroxide (LDH) derived catalysts for simultaneous catalytic removal of soot and NOx. Dalton Trans. 2014, 43, 10317-10327. [CrossRef]

72. Ötvös, S.B.; Georgiádes, Á.; Ádok-Sipiczki, M.; Mészáros, R.; Pálinkó, I.; Sipos, P.; Fülöp, F. A layered double hydroxide, a synthetically useful heterogeneous catalyst for azide-alkyne cycloadditions in a continuous-flow reactor. Appl. Catal. A 2015, 501, 63-73. [CrossRef]

73. González-Olvera, R.; Urquiza-Castro, C.I.; Negrón-Silva, G.E.; Ángeles-Beltrán, D.; Lomas-Romero, L.; Gutiérrez-Carrillo, A.; Lara, V.H.; Santillanc, R.; Morales-Serna, J.A. Cu-Al mixed oxide catalysts for azide-alkyne 1,3-cycloaddition in ethanol-water. RSC Adv. 2016, 6, 63660-63666. [CrossRef]

74. Corona-Sánchez, R.; Sánchez-Eleuterio, A.; Negrón-Lomas, C.; Ruiz Almazan, Y.; Lomas-Romero, L.; Negrón-Silva, G.E.; Rodríguez-Sánchez, Á.C. Cu-Al mixed oxide-catalysed multi-component synthesis of gluco- and allofuranose-linked 1,2,3triazole derivatives. R. Soc. Open Sci. 2020, 7, 200290. [CrossRef] [PubMed]

75. Amini, M.; Nikkhoo, M.; Farnia, S.M.F. Synthesis, characterization and catalytic properties of tetrachlorocuprate (II) immobilized on layered double hydroxide. Appl. Organometal. Chem. 2017, 31, e3710. [CrossRef]

76. Rezaeimanesh, F.; Bakherad, M.; Nasr-Isfahani, H.; Bahramian, B.; Naderi, S. Synthesis of 1,2,3 triazole-linked pyrimidines catalyzed by mg-Al-LDH-immobilized-CuI as a heterogeneous catalyst. J. Heter. Chem. 2020, 57, 565-574. [CrossRef]

77. Mekhzoum, M.E.M.; Benzeid, H.; Essassi, E.M.; Bouhfid, R. Copper(I) confined in interlayer space of montmorillonite: A highly efficient and recyclable catalyst for click reaction. Catal. Lett. 2016, 146, 136-143. [CrossRef]

78. Elnagdy, H.M.; Gogoi, K.; Ali, A.A.; Sarma, D. Claycop/hydrazine: A new and highly efficient recyclable/reusable catalytic system for 1,4-disubstituted-1,2,3-triazole synthesis under solvent-free conditions. Appl. Organometal. Chem. 2018, 32 , e3931. [CrossRef]

79. Dubey, N.; Sharma, P.; Kumar, A. Clay-supported Cu(II) catalyst: An efficient, heterogeneous, and recyclable catalyst for synthesis of 1,4-disubstituted 1,2,3-triazoles from alloxan-derived terminal alkyne and substituted azides using click chemistry. Synth. Commun. 2015, 45, 2608-2626. [CrossRef]

80. Agalave, S.G.; Pharande, S.G.; Gade, S.M.; Pore, V.S. Alumina-Supported Copper Iodide: An Efficient and Recyclable Catalyst for Microwave-Assisted Synthesis of 1, 4-Disubstituted 1,2,3-Triazoles via Three-Component Reaction in Water. Asian J. Org. Chem. 2015, 4, 943-951. [CrossRef]

81. Safa, K.D.; Mousazadeh, H. A simple and efficient synthesis of organosilicon compounds containing 1,2,3-triazole moieties catalyzed by ZSM-5 zeolite-supported Cu-Co bimetallic oxides. Monatsh. Chem. 2016, 147, 1951-1961. [CrossRef]

82. Mitrofanov, A.; Brandès, S.; Herbst, F.; Rigolet, S.; Bessmertnykh-Lemeune, A.; Beletskaya, I. Immobilization of copper complexes with (1,10-phenanthrolinyl) phosphonates on titania supports for sustainable catalysis. J. Mater. Chem. A 2017, 5, 12216-12235. [CrossRef]

83. Amini, A.; Fallah, A.; Cheng, C.; Tajbakhsh, M. Natural phosphate-supported Cu(II), an efficient and recyclable catalyst for the synthesis of xanthene and 1,4-disubstituted-1,2,3-triazole derivatives. RSC Adv. 2018, 8, 41536-41547. [CrossRef]

84. Xiong, X.; Tang, Z.; Sun, Z.; Meng, X.; Song, S.; Quan, Z. Supported copper(I) catalyst from fish bone waste: An efficient, green and reusable catalyst for the click reaction toward N-substituted 1,2,3-TRIAZOLES. Appl. Organometal. Chem. 2018, 32 , e3946. [CrossRef] 
85. Ting, J.M.; Lin, W.C. Unprecedented re-growth of carbon nanotubes on in situ re-activated catalyst. Nanotechnology 2008, 20, 025608. [CrossRef] [PubMed]

86. Geim, A.K.; Novoselov, K.S. The rise of graphene. Nat. Mater. 2007, 6, 183-191.

87. Tsakadze, Z.L.; Levchenko, I.; Ostrikov, K.; Xu, S. Plasma-assisted self-organized growth of uniform carbon nanocone arrays. Carbon 2007, 45, 2022-2030. [CrossRef]

88. Fejes, D.; Hernádi, K. A review of the properties and CVD synthesis of coiled carbon nanotubes. Materials 2010, 3, $2618-2642$. [CrossRef]

89. Aflak, N.; Ben El Ayouchia, H.; Bahsis, L.; El Mouchtari, E.M.; Julve, M.; Rafqah, S.; Anane, H.; Stiriba, S.-E. Sustainable Construction of Heterocyclic 1,2,3-Triazoles by Strict Click [3+2] Cycloaddition Reactions Between Azides and Alkynes on Copper/Carbon in Water. Front. Chem. 2019, 7, 81. [CrossRef]

90. Rani, G.S.; Vijay, M.; Prabhavathi Devi, B.L. $\mathrm{SO}_{3} \mathrm{Cu}$-Carbon: A Novel Heterogeneous Catalyst for the Synthesis of $\beta$-Hydroxy 1,2,3-Triazoles by One Pot Cycloaddition Reaction. ChemistrySelect 2019, 4, 10133-10142. [CrossRef]

91. Liu, Z.X.; Chen, B.B.; Liu, M.L.; Zou, H.Y.; Huang, C.Z. Cu(I)-Doped carbon quantum dots with zigzag edge structures for highly efficient catalysis of azide-alkyne cycloadditions. Green Chem. 2017, 19, 1494-1498. [CrossRef]

92. Dreyer, D.R.; Park, S.; Bielawski, C.W.; Ruoff, R.S. The chemistry of graphene oxide. Chem. Soc. Rev. 2010, 39, 228-240. [CrossRef] [PubMed]

93. Xu, C.; Wang, X.; Zhu, J. Graphene-metal particle nanocomposites. J. Phys. Chem. C 2008, 112, 19841-19845. [CrossRef]

94. Dong, L.; Gari, R.R.S.; Li, Z.; Craig, M.M.; Hou, S. Graphene-supported platinum and platinum-ruthenium nanoparticles with high electrocatalytic activity for methanol and ethanol oxidation. Carbon 2010, 48, 781-787. [CrossRef]

95. Scheuermann, G.M.; Rumi, L.; Steurer, P.; Bannwarth, W.; Mülhaupt, R. Palladium nanoparticles on graphite oxide and its functionalized graphene derivatives as highly active catalysts for the Suzuki-Miyaura coupling reaction. J. Am. Chem. Soc. 2009, 131, 8262-8270. [CrossRef] [PubMed]

96. Pyun, J. Graphene oxide as catalyst: Application of carbon materials beyond nanotechnology. Angew. Chem. Int. Ed. 2011, 50, 46-48. [CrossRef] [PubMed]

97. Caliman, C.C.; Mesquita, A.F.; Cipriano, D.F.; Freitas, J.C.C.; Cotta, A.A.C.; Macedo, W.A.A.; Porto, A.O. One-pot synthesis of amine-functionalized graphene oxide by microwave-assisted reactions: An outstanding alternative for supporting materials in supercapacitors. RSC Adv. 2018, 8, 6136-6145. [CrossRef]

98. Singh, R.K.; Kumar, R.; Singh, D.P. Graphene oxide: Strategies for synthesis, reduction and frontier applications. RSC Adv. 2016, 6, 64993-65011. [CrossRef]

99. Shanmugharaj, A.M.; Yoon, J.H.; Yang, W.J.; Ryu, S.H. Synthesis, characterization, and surface wettability properties of amine functionalized graphene oxide films with varying amine chain lengths. J. Colloid Interface Sci. 2013, 401, 148-154. [CrossRef]

100. Pumera, M.; Wong, C.H.A. Graphane and hydrogenated graphene. Chem. Soc. Rev. 2013, 42, 5987-5995. [CrossRef]

101. Bendi, R.; Imae, T. Renewable catalyst with $\mathrm{Cu}$ nanoparticles embedded into cellulose nano-fiber film. RSC Adv. 2013, 3 , 16279-16282. [CrossRef]

102. Zhang, H.; Kuila, T.; Kim, N.H.; Yu, D.S.; Lee, J.H. Simultaneous reduction, exfoliation, and nitrogen doping of graphene oxide via a hydrothermal reaction for energy storage electrode materials. Carbon 2014, 69, 66-78. [CrossRef]

103. Khanra, P.; Kuila, T.; Bae, S.H.; Kim, N.H.; Lee, J.H. Electrochemically exfoliated graphene using 9-anthracene carboxylic acid for supercapacitor application. J. Mater. Chem. 2012, 22, 24403-24410. [CrossRef]

104. Parviz, D.; Das, S.; Ahmed, H.T.; Irin, F.; Bhattacharia, S.; Green, M.J. Dispersions of non-covalently functionalized graphene with minimal stabilizer. ACS Nano 2012, 6, 8857-8867. [CrossRef] [PubMed]

105. Pourjavadi, A.; Safaie, N.; Hosseini, S.H.; Bennett, C. Graphene oxide/poly (vinyl imidazole) nanocomposite: An effective support for preparation of highly loaded heterogeneous copper catalyst. Appl. Organometal. Chem. 2015, 29, 601-607. [CrossRef]

106. Naeimi, H.; Shaabani, R. Ultrasound promoted facile one pot synthesis of triazole derivatives catalyzed by functionalized graphene oxide $\mathrm{Cu}(\mathrm{I})$ complex under mild conditions. Ultrason. Sonochem. 2017, 34, 246-254. [CrossRef]

107. Naeimi, H.; Shaabani, R.; Moradian, M. Functionalized graphene oxide supported copper(I) complex as effective and recyclable nanocatalyst for one-pot three component synthesis of 1,2,3-triazoles. Appl. Organometal. Chem. 2017, 31, e3626. [CrossRef]

108. Naeimi, H.; Shaabani, R. Preparation and characterization of functionalized graphene oxide $\mathrm{Cu}(\mathrm{I}) \mathrm{complex}$ : A facile and reusable nanocatalyst for microwave assisted heterocyclization of alkyl halides with alkynes and sodium azide. Catal. Commun. 2016, 87, 6-9. [CrossRef]

109. Naeimi, H.; Ansarian, Z. Functionalized polytriazoles on graphene oxide-supported copper(I) complex as an effective reusable catalyst for sonochemical click synthesis of triazoles in aqueous media. Inorg. Chim. Acta 2017, 466, 417-425. [CrossRef]

110. Naeimi, H.; Ansarian, Z. Immobilized polytriazole complexes of copper (I) onto graphene oxide as a recyclable nanocatalyst for synthesis of triazoles. Appl. Organometal. Chem. 2017, 31, e3796. [CrossRef]

111. Khojastehnezhad, A.; Bakavoli, M.; Javid, A.; Siuki, M.M.K.; Shahidzadeh, M. Synthesis, characterization, and investigation of catalytic activity of copper (II) porphyrin graphene oxide for azide-alkyne cycloaddition. Res. Chem. Intermed. 2019, 45, 4473-4485. [CrossRef]

112. Dabiri, M.; Alavioon, S.I.; Movahed, S.K. N-Heterocyclic carbine-copper complex supported on ionic liquid-modified graphene oxide: Versatile catalyst for synthesis of (i) 1,2,3-triazole and (ii) propargylamine derivatives. J. Iran. Chem. Soc. 2018, 15, 2463-2474. [CrossRef] 
113. Shaygan Nia, A.; Rana, S.; Döhler, D.; Jirsa, F.; Meister, A.; Guadagno, L.; Koslowski, E.; Bron, M.; Binder, W.H. Carbon-supported copper nanomaterials: Recyclable catalysts for Huisgen [3+2] cycloaddition reactions. Chem. A Eur. J. 2015, 21, 10763-10770. [CrossRef] [PubMed]

114. Bahadorikhalili, S.; Ma'mani, L.; Mahdavi, H.; Shafiee, A. Copper supported $\beta$-cyclodextrin functionalized PEGylated mesoporous silica nanoparticle-graphene oxide hybrid: An efficient and recyclable nanocatalyst for straightforward synthesis of 2-arylbenzimidazoles and 1,2,3-triazoles. Microporous Mesoporous Mater. 2018, 262, 207-216. [CrossRef]

115. Samuel, A.G.; Nagarajan, K.; Cidhuraj, K.; Gopal, B.; Chakravarty, S.; Selvaraj, V.; Lourdusamy, E.; Bhagavathsingh, J. Copper(II) complex intercalated graphene oxide nanocomposites as versatile, reusable catalysts for click reaction. Appl. Organometal. Chem. 2020, 34, e6017. [CrossRef]

116. Navid Soltani Rad, M.; Behrouz, S.; Jafar Hoseini, S.; Nasrabadi, H.; Saberi Zare, M. Copper/Graphene/Clay Nanohybrid: A Highly Efficient Heterogeneous Nanocatalyst for the Synthesis of Novel 1,2,3-Triazolyl Carboacyclic Nucleosides via 'Click'Huisgen 1,3-Dipolar Cycloaddition. Helv. Chim. Acta 2015, 98, 1210-1224. [CrossRef]

117. Elavarasan, S.; Baskar, B.; Senthil, C.; Bhanja, P.; Bhaumik, A.; Selvam, P.; Sasidharan, M. An efficient mesoporous carbon nitride $\left(\mathrm{gC}_{3} \mathrm{~N}_{4}\right)$ functionalized Pd catalyst for carbon-carbon bond formation reactions. RSC Adv. 2016, 6, 49376-49386. [CrossRef]

118. Goettmann, F.; Fischer, A.; Antonietti, M.; Thomas, A. Chemical synthesis of mesoporous carbon nitrides using hard templates and their use as a metal-free catalyst for Friedel-Crafts reaction of benzene. Angew. Chem. Int. Ed. 2006, 45, 4467-4471. [CrossRef]

119. Notestein, J.M.; Katz, A. Enhancing heterogeneous catalysis through cooperative hybrid organic-inorganic interfaces. Chem. Eur. J. 2006, 12, 3954-3965. [CrossRef]

120. Dadashi-Silab, S.; Kiskan, B.; Antonietti, M.; Yagci, Y. Mesoporous graphitic carbon nitride as a heterogeneous catalyst for photoinduced copper (I)-catalyzed azide-alkyne cycloaddition. RSC Adv. 2014, 4, 52170-52173. [CrossRef]

121. Xu, J.; Shang, J.K.; Jiang, Q.; Wang, Y.; Li, Y.X. Facile alkali-assisted synthesis of $\mathrm{gC}_{3} \mathrm{~N}_{4}$ materials and their high-performance catalytic application in solvent-free cycloaddition of $\mathrm{CO}_{2}$ to epoxides. RSC Adv. 2016, 6, 55382-55392. [CrossRef]

122. Goettmann, F.; Fischer, A.; Antonietti, M.; Thomas, A. Metal-free catalysis of sustainable Friedel-Crafts reactions: Direct activation of benzene by carbon nitrides to avoid the use of metal chlorides and halogenated compounds. Chem. Commun. 2006, 4530-4532. [CrossRef] [PubMed]

123. Verma, S.; Baig, R.N.; Han, C.; Nadagouda, M.N.; Varma, R.S. Oxidative esterification via photocatalytic C-H activation. Green Chem. 2016, 18, 251-254. [CrossRef]

124. Ansari, M.B.; Min, B.H.; Mo, Y.H.; Park, S.E. $\mathrm{CO}_{2}$ activation and promotional effect in the oxidation of cyclic olefins over mesoporous carbon nitrides. Green Chem. 2011, 13, 1416-1421. [CrossRef]

125. Payra, S.; Saha, A.; Banerjee, S. On Water Cu@g-C3N4 Catalyzed Synthesis of NH-1,2,3-Triazoles via [2+3] Cycloadditions of Nitroolefins/Alkynes and Sodium Azide. ChemCatChem 2018, 10, 5468-5474. [CrossRef]

126. Goettmann, F.; Boissière, C.; Grosso, D.; Mercier, F.; Le Floch, P.; Sanchez, C. New hybrid bidentate ligands as precursors for smart catalysts. Chem. Eur. J. 2005, 11, 7416-7426. [CrossRef]

127. Goettmann, F.; Le Floch, P.; Sanchez, C. Hybrid bidentate ligand for functional recognition: An application to regioselective C [double bond, length as m-dash] C double bond hydrogenation. Chem. Commun. 2006, 2036-2038. [CrossRef]

128. Hajipour, A.R.; Karimzadeh, M.; Fakhari, F.; Karimi, H. $\mathrm{CuFeO}_{2}$ /tetrabutylammonium bromide catalyzes selective synthesis of 1,4-disubstituted 1,2,3-triazoles in neat water at room temperature. Appl. Organometal. Chem. 2016, 30, 946-948. [CrossRef]

129. Mondal, B.; Kundu, M.; Mandal, S.P.; Saha, R.; Roy, U.K.; Roychowdhury, A.; Das, D. Sonochemically synthesized spin-canted $\mathrm{CuFe}_{2} \mathrm{O}_{4}$ nanoparticles for heterogeneous green catalytic click chemistry. ACS Omega 2019, 4, 13845-13852. [CrossRef]

130. Sharma, N.; Gupta, M.; Chowhan, B.; Frontera, A. Magnetically separable nanocatalyst (IL@CuFe $\left.{ }_{2} \mathrm{O}_{4}-\mathrm{L}_{-}-\mathrm{Tyr}_{\mathrm{r}} \mathrm{TiO}{ }_{2} / \mathrm{TiTCIL}\right)$ Preparation, characterization and its applications in 1,2,3-triazole synthesis and in photodegradation of MB. J. Mol. Struct. 2021, 1224, 129029. [CrossRef]

131. Eisavi, R.; Karimi, A. $\mathrm{CoFe}_{2} \mathrm{O}_{4} / \mathrm{Cu}(\mathrm{OH})_{2}$ magnetic nanocomposite: An efficient and reusable heterogeneous catalyst for one-pot synthesis of $\beta$-hydroxy-1,4-disubstituted-1,2,3-triazoles from epoxides. RSC Adv. 2019, 9, 29873-29887. [CrossRef]

132. Moghaddam, F.M.; Saberi, V.; Kalhor, S.; Ayati, S.E. A novel highly dispersive magnetic nanocatalyst in water: Glucose as an efficient and green ligand for the immobilization of copper (ii) for the cycloaddition of alkynes to azides. RSC Adv. 2016, 6, 80234-80243. [CrossRef]

133. Jafari, A.A.; Mahmoudi, H.; Firouzabadi, H. A copper acetate/2-aminobenzenthiol complex supported on magnetite/silica nanoparticles as a highly active and recyclable catalyst for 1,2,3-triazole synthesis. RSC Adv. 2015, 5, 107474-107481. [CrossRef]

134. Vibhute, S.P.; Mhaldar, P.M.; Korade, S.N.; Gaikwad, D.S.; Shejawal, R.V.; Pore, D.M. Synthesis of magnetically separable catalyst $\mathrm{Cu}-\mathrm{ACP}-\mathrm{Am}-\mathrm{Fe}_{3} \mathrm{O}_{4} @ \mathrm{SiO}_{2}$ for Huisgen 1,3-dipolar cycloaddition. Tetrahedron Lett. 2018, 59, 3643-3652. [CrossRef]

135. Mehdipour, M.; Khodabakhshi, M. 2-(Aminomethyl) benzimidazole $/ \mathrm{Cu}^{2+}$ immobilized on $\mathrm{Fe}_{3} \mathrm{O}_{4} @ \mathrm{SiO}_{2}$ : A convenient magnetic nanocatalyst for click reaction of aryl iodide/benzyl halide, sodium azide and terminal alkyne. Curr. Chem. Lett. 2020, 9, 9-18. [CrossRef]

136. Zirak, M.; Jamali Garegeshlagi, E. Picolinimidoamide-Cu(II) complex anchored on $\mathrm{Fe}_{3} \mathrm{O}_{4} @ \mathrm{SiO}_{2}$ core-shell magnetic nanoparticles: An efficient reusable catalyst for click reaction. J. Coord. Chem. 2018, 71, 1168-1179. [CrossRef]

137. Moghaddam, F.M.; Ayati, S.E. Copper immobilized onto a triazole functionalized magnetic nanoparticle: A robust magnetically recoverable catalyst for "click" reactions. RSC Adv. 2015, 5, 3894-3902. [CrossRef] 
138. Moghaddam, F.M.; Ayati, S.E.; Firouzi, H.R.; Ghorbani, F. Immobilization of copper ions onto $\alpha$-amidotriazole-functionalized magnetic nanoparticles and their application in the synthesis of triazole derivatives in water. Appl. Organometal. Chem. 2016, 30, 488-493. [CrossRef]

139. Mogaddam, F.M.; Eslami, M.; Ayati, S.E. Copper(II) Ions Immobilized onto Aminoquinoline-Functionalized Ferrite: A New Efficient and Recoverable Catalyst for "in Water" Synthesis of Triazole Derivatives. ChemistrySelect 2017, 2, 11942-11948. [CrossRef]

140. Zahmatkesh, S.; Esmaeilpour, M.; Javidi, J. 1,4-Dihydroxyanthraquinone-copper(ii) supported on superparamagnetic Fe $\mathrm{O}_{4} @$ $\mathrm{SiO}_{2}$ : An efficient catalyst for $\mathrm{N}$-arylation of nitrogen heterocycles and alkylamines with aryl halides and click synthesis of 1-aryl-1,2,3-triazole derivatives. RSC Adv. 2016, 6, 90154-90164. [CrossRef]

141. Esmaeilpour, M.; Javidi, J.; Davan, E.E. Click Synthesis of 1-Aryl-1,2,3-Triazole Derivatives Catalyzed by Recyclable Ligand Complex of Copper(II) Supported on Superparamagnetic $\mathrm{Fe}_{3} \mathrm{O}_{4} @ \mathrm{SiO}_{2}$ Nanoparticles. Iran. J. Sci. Technol. Trans. Sci. 2018, 42, 487-496. [CrossRef]

142. Zohreh, N.; Jahani, M. NNN-pincer-copper complex immobilized on magnetic nanoparticles as a powerful hybrid catalyst for aerobic oxidative coupling and cycloaddition reactions in water. J. Mol. Catal. A 2017, 426, 117-129. [CrossRef]

143. Mohammadi, L.; Zolifgol, M.A.; Yarie, M.; Ebrahiminia, M.; Roberts, K.P.; Hussaini, S.R. Application of two magnetic nanoparticlesupported copper (I) catalysts for the synthesis of triazole derivatives. Res. Chem. Intermed. 2019, 45, 4789-4799. [CrossRef]

144. Khodaei, M.M.; Bahrami, K.; Meibodi, F.S. Ferromagnetic nanoparticle-supported copper complex: A highly efficient and reusable catalyst for three-component syntheses of 1,4-disubstituted 1,2,3-triazoles and C-S coupling of aryl halides. Appl. Organometal. Chem. 2017, 31, e3714. [CrossRef]

145. Tajbakhsh, M.; Farhang, M.; Baghbanian, S.M.; Hosseinzadeh, R.; Tajbakhsh, M. Nano magnetite supported metal ions as robust, efficient and recyclable catalysts for green synthesis of propargylamines and 1,4-disubstituted 1,2,3-triazoles in water. New J Chem. 2015, 39, 1827-1839. [CrossRef]

146. Misztalewska-Turkowicz, I.; Markiewicz, K.H.; Michalak, M.; Wilczewska, A.Z. NHC-copper complexes immobilized on magnetic nanoparticles: Synthesis and catalytic activity in the CuAAC reactions. J. Catal. 2018, 362, 46-54. [CrossRef]

147. Mahdavi, M.; Lijan, H.; Bahadorikhalili, S.; Ma'mani, L.; Ranjbar, P.R.; Shafiee, A. Copper supported $\beta$-cyclodextrin grafted magnetic nanoparticles as an efficient recyclable catalyst for one-pot synthesis of 1-benzyl-1 H-1,2,3-triazoldibenzodiazepinone derivatives via click reaction. RSC Adv. 2016, 6, 28838-28843. [CrossRef]

148. Bahadorikhalili, S.; Ashtari, A.; Ma'mani, L.; Ranjbar, P.R.; Mahdavi, M. Copper-supported $\beta$-cyclodextrin-functionalized magnetic nanoparticles: Efficient multifunctional catalyst for one-pot 'green' synthesis of 1,2,3-triazolylquinazolinone derivatives. Appl. Organometal. Chem. 2018, 32, e4212. [CrossRef]

149. Darroudi, M.; Ranjbar, S.; Esfandiar, M.; Khoshneviszadeh, M.; Hamzehloueian, M.; Khoshneviszadeh, M.; Sarrafi, Y. Synthesis of Novel Triazole Incorporated Thiazolone Motifs Having Promising Antityrosinase Activity through Green Nanocatalyst $\mathrm{CuI}-\mathrm{Fe}_{3} \mathrm{O}_{4} @ \mathrm{SiO}_{2}$ (TMS-EDTA). Appl. Organometal. Chem. 2020, 34, e5962. [CrossRef]

150. Banan, A.; Bayat, A.; Valizadeh, H. Copper immobilized onto polymer-coated magnetic nanoparticles as recoverable catalyst for 'click' reaction. Appl. Organometal. Chem. 2017, 31, e3604. [CrossRef]

151. Bahrami, K.; Arabi, M.S. Copper immobilized ferromagnetic nanoparticle triazine dendrimer (FMNP@TD-Cu(II))-catalyzed regioselective synthesis of 1,4-disubstituted 1,2,3-triazoles. New. J. Chem. 2016, 40, 3447-3455. [CrossRef]

152. Sardarian, A.R.; Mohammadi, F.; Esmaeilpour, M. Dendrimer-encapsulated copper(II) immobilized on $\mathrm{Fe}_{3} \mathrm{O}_{4} @ S i \mathrm{~S}_{2} \mathrm{NPs} \mathrm{A}$ robust recoverable catalyst for click synthesis of 1,2,3-triazole derivatives in water under mild conditions. Res. Chem. Intermed. 2019, 45, 1437-1456. [CrossRef]

153. Kal-Koshvandi, A.T.; Ahghari, M.R.; Maleki, A. Design and antibacterial activity assessment of "green" synthesized 1,4disubstituted 1,2,3-triazoles via an $\mathrm{Fe}_{3} \mathrm{O}_{4}$ / silicalite-1/PVA/Cu(I) nanocomposite catalyzed three component reaction. New J. Chem. 2020, 44, 12619-12632. [CrossRef]

154. Pazoki, F.; Salamatmanesh, A.; Bagheri, S.; Heydari, A. Synthesis and Characterization of Copper (I)-Cysteine Complex Supported on Magnetic Layered Double Hydroxide as an Efficient and Recyclable Catalyst System for Click Chemistry Using Choline Azide as Reagent and Reaction Medium. Catal. Lett. 2020, 150, 1186-1195. [CrossRef]

155. Khalili, D.; Rezaee, M. Impregnated copper ferrite on mesoporous graphitic carbon nitride: An efficient and reusable catalyst for promoting ligand-free click synthesis of diverse 1,2,3-triazoles and tetrazoles. Appl. Organometal. Chem. 2019, 33 , e5219. [CrossRef]

156. Deilam, R.; Moeinpour, F.; Mohseni-Shahri, F.S. Catalytic performance of $\mathrm{Cu}(\mathrm{II})$-supported graphene quantum dots modified $\mathrm{NiFe}_{2} \mathrm{O}_{4}$ as a proficient nanocatalyst in the synthesis of 1,2,3-triazoles. Monatsh. Chem. 2020, 151, 1153-1162. [CrossRef]

157. Rafiee, F.; Khavari, P. Preparation of aryl azides of aryl boronic acids and one-pot synthesis of 1,4-diaryl-1,2,3-triazoles by a magnetic cysteine functionalized GO-Cu${ }^{\mathrm{I} / \mathrm{II}}$ nanocomposite. Appl. Organomet. Chem. 2020, 34, e5789. [CrossRef]

158. Shaabani, A.; Afshari, R.; Hooshmand, S.E.; Tabatabaei, A.T.; Hajishaabanha, F. Copper supported on MWCNT-guanidine acetic acid@ $\mathrm{Fe}_{3} \mathrm{O}_{4}$ : Synthesis, characterization and application as a novel multi-task nanocatalyst for preparation of triazoles and bis(indolyl) methanes in water. RSC Adv. 2016, 6, 18113-18125. [CrossRef]

159. Prakash, P.; Kumar, R.A.; Miserque, F.; Geertsen, V.; Gravel, E.; Doris, E. Carbon nanotube-copper ferrite-catalyzed aqueous 1,3-dipolar cycloaddition of in situ-generated organic azides with alkynes. Chem. Commun. 2018, 54, 3644-3647. [CrossRef] 
160. Mahdavinasab, M.; Hamzehloueian, M.; Sarrafi, Y. Preparation and application of magnetic chitosan/graphene oxide composite supported copper as a recyclable heterogeneous nanocatalyst in the synthesis of triazoles. Int. J. Biol. Macromol. 2019, 138, 764-772. [CrossRef]

161. Saini, P.; Sonika; Singh, G.; Kaur, G.; Singh, J.; Singh, H. Robust and versatile Cu(I) metal frameworks as potential catalysts for azide-alkyne cycloaddition reactions: Review. Mol. Catal. 2021, 504, 111432. [CrossRef] 